\title{
3 Karl Morgenstern und Aubin Louis Millin
}

Briefwechsel zwischen Karl Morgenstern und Groddeck 1805-1824

Aubin Louis Millin an Groddeck 1806-1816

\subsection{Briefwechsel zwischen Groddeck und Karl Morgenstern 1805-1824}

\section{Karl Morgenstern an Groddeck, am 16. 5.1805}

Hn. Professor Groddeck

Hochwohlgebn

in Wilna

Ew. Hochwohlgeb<oren>

Dorpat, 16. May 1805

sage ich so wohl im Namen der Universitätsbibliothek, der ich vorzustehen die Ehre habe, als auch im meinigen, den verbindlichsten Dank für gütige Übersendung Ihres sehr gelehrten Antrittsprogramms. Ich nehme mir die Freyheit, Ihnen dagegen eine Kleinigkeit (de arte vett. mnem. Comm. P. I. $)^{1}$ zu übersenden. Beyliegendes Ex. bitte ich \an die Univers.Bibl. und/ an Hn. Prof. Abicht ${ }^{2}$ abzugeben.

Es freut mich, daß Sie die Professur der Gr<iechischen> Litt<eratur $>$ und das Bibliothekariat in Wilna angenommen. ${ }^{3}$ Längst waren Sie mit der Nation I vertraut ${ }^{4}$, auf die Sie in Ihrem Berufe nun nützlich wirken. Als ich noch in Danzig lebte(n) ${ }^{5}$, wünschten Ihre Freunde Trendelenburg ${ }^{6}$, Ewerbeck ${ }^{7}$ etc., die auch die meinigen waren, Sie oft in unsre Mitte. Um so werther war mir, dem Ihnen persönlich Unbekannten, Ihre gütige Erinnerung.

Mit wahrer Hochachtung bin ich

Ew. Hochwohlgeboren gehors. Diener

Morgenstern

${ }^{1} \mathrm{Zu}$ Morgensterns Abhandlung De arte veterum mnemonica commentatio s. Süss 1928 S. 128 f. (K). - ${ }^{2}$ Abicht, s. Czartoryski Nr. 15 Anm. 16. $-{ }^{3}$ Groddeck war 1804 als Professor für Griechische Sprache und Literatur sowie als Bibliothekar der Universitätsbibliothek nach Wilna berufen worden. $-{ }^{4}$ Groddeck stammte aus Danzig, war wohl polnischer Herkunft; doch wurde in der Familie nur deutsch gesprochen.; s. die Briefe der Mutter und des Bruders an ihn. - ${ }^{5}$ Morgenstern war von 1798-1802 als Gymnasialprofessor in Danzig. - ${ }^{6}$ Johann Georg Trendelenburg (1757-1825) aus Lübeck, seit 1779, noch als Student, nach Danzig als Professor für Griechisch und orientalische Sprachen am Akademischen Gymnasium in Danzig berufen. Vgl. Altpreuß. Biographie II 6, 1965, 742 a. $-{ }^{7}$ Christian Gottfried Ewerbeck (1761-1838) aus Konitz, seit 1789 Professor für Mathematik am Danziger Gymnasium, 1790 auch Professor für Philosophie und Leiter der Stadtbibliothek. Vgl. Altpreuß. Biographie I 1941, $171 \mathrm{f}$. 
2. Karl Morgenstern an Groddeck, am 21. 5. /2. 6. 1808

Dorpat am 21 May / 2 Juny 1808

Hochwohlgeborner,

Hochzuehrender Herr Hofrath.

Ew. Hochwohlgeboren Aufträge zu unsere Doubletten-Auction, kamen wie Sie in Ihrem Schreiben vom 26. April ${ }^{1}$ vermuthen, wirklich zu spät indem die Auction schon am 9t April geendigt war. Dennoch kann ich Ihnen noch drey verlangte Werke, die ich für die Univers. Bibliothek des zu niedrigen Preises wegen der dafür geboten ward, zurückerstand, nämlich:

$$
\begin{aligned}
& \text { Nr. 4. Berengarius }{ }^{2} \text {, } \\
& \text { 5-28. Acta Eruditor }<\mathrm{um}>^{3} \text {; und } \\
& \text { 423-31. Eru<... }>\mathrm{ch}^{4}
\end{aligned}
$$

$\mathrm{zu}$ billigen Preisen überlassen. Zugleich werde ich Ihnen nächstens ein geschriebenes Verzeichnis unsrer neuen Doubletten übersenden, die sich nach dem Drucke des ersten Verzeichnisses gefunden haben. Vielleicht finden Sie manches Brauchbare darunter und bestimmen mir dann gefälligst was die Wilnaische Univers. Bibliothek dafür geben könne.

Dem Hn. Struwe ${ }^{5}$ habe ich wegen der aus dem Additament von Ihnen verlangten Bücher Nachricht gegeben. I Die Gymnasiums-Bücher wurden nur bis Nr. 84 versteigert. Auch hat er den Grotius, des zu geringen $<\mathrm{Ge}>$ bots wegen für die Gymnas. Bibliothek zurückerstanden.

Vielleicht sende ich Ew. Hochwohlgeboren schon nach acht Tagen das erwähnte Verzeichniß der neuen Doubletten und erwarte dann Ihre Antwort. Sobald diese erfolgt kann Ihnen alles in einer Kiste zugeschickt werden.

Mit der vollkommensten Hochachtung habe ich die Ehre zu seyn

Ew. Hochwohlgebohren gehorsamster Diener Morgenstern

Empfehlen Sie mich Hn. Hofrath Jos. Frank ${ }^{6}$, den ich persönl. kenne, und Hn. Prof. Abicht, mit dem ich sonst (seines Philos. Freundes ${ }^{7}$ halber) im Briefwechsel stand. Neulich bekam ich manche interessante Nachricht von unserm Danzig, als die Frau des Danziger Rathsherrn, Labes ${ }^{8}$, meine alte Bekannte, von Petersburg mit ihren Kindern zurückkommend, hier durchreiste. Wahrscheinlich werde ich die gute Stadt auf einer kurzen Reise in I mein Vaterland, für die ich schon um Urlaub unterlegt habe, bald, im Fluge wenigstens, wiedersehen, und unseren wackeren Trendelenburg.

\footnotetext{
${ }^{1}$ Nicht erhalten. - ${ }^{2}$ Wohl Berengar von Tours (nach 1000-1088), scholastischer Theologe, bedeutend vor allem durch seine Theologie des Abendmahls. - ${ }^{3}$ Die Acta Eruditorum, erste deutsche gelehrte Zeitschrift, begründet von Prof. Otto Mencke (1644-1707) zusammen u.a. mit Leibniz 1682, weiter geführt von Sohn, dann Enkel Menckes, eingestellt 1782. - ${ }^{4}$ Unklar. $-{ }^{5}$ Carl Ludwig Struwe (1785-1838)
} 
aus Hannover, 1804-1813 in Dorpat Gymnasiallehrer und Privatdozent für klassische Philologie. Dann in Königsberg als Nachfolger Hamanns Direktor des Altstädtischen Gymnasiums; s. Węclewski 1876, S. 98 f. und Süss S. 160. - ${ }^{6}$ Frank: Professor für Medizin in Wilna; zu ihm s. Węclewski 1876, S. 93 f. $-{ }^{7}$ Sein philosophischer Freund: nicht ermittelt. $-{ }^{8}$ Johann Labes (1754-1809), Kaufmann in Danzig, 1807 Senator.

3. Karl Morgenstern an Groddeck, am 6. 7.1808

Hochwohlgeborner Herr Hofrath,

Dorpat am 6. Jul. 1808.

Hochzuverehrender Herr Professor.

Ew. Hochwohlgeboren Vereichniß des aus unserm Doubletten-Katalog Ausgewählten habe ich mit dem Ihnen mitgetheilten Katalog erhalten. Mit den von Ihnen beygesetzten Preisen kann die Universitäts-Bibliothek zufrieden seyn und ich trage Ihnen daher die von Ew. Hochwohlgeb. getroffene Auswahl für die runde Summe von Einhundert $\underline{R}^{\mathrm{u}}$ Silber-Münze hiedurch an. -

Da ich in einigen Tagen eine Reise ins Ausland ${ }^{1}$ antrete so muß ich Sie ersuchen sich wegen des von Ihnen etwa vorzuschlagenden leichteren Transports dieser Bücher, oder auch zur Adresse des Geldes, an den Vice-Bibliothekar Herrn Hofrath und Professor Pöschmann² zu wenden.

Mit vollkommenster Hochachtung habe ich die Ehre zu seyn

Ew. Hochwohlgeboren

gehorsamster Diener

Morgenstern

${ }^{1}$ „Morgensterns große Reise“ von Juli 1808 bis Februar 1810, vgl. Süss S. 140, vgl. auch Nr. 9 Anm. 1. -

2 Pöschmann: Historiker in Dorpat, trat gelegentlich auch als Universitätsdichter auf; mit Morgenstern in gespannten Beziehungen; vgl. Süss S. 119, 146, 285.

4. Karl Morgenstern an Groddeck, am 17. 7.1811

Sr. Hochwohlgeb.

Hn. Hofrath und Professor Dr. Groddeck in Wilna

Dorpat, 17. Jul. 1811.

Indem ich einige Ex. des deutschen Lectionskatalog dieser Univers. nach Wilna sende (der lat. folgt später) nehme ich mir die Freyheit, eine Anzahl Exemplare der subscr. Anzeigen auf meine Ital. Reise ${ }^{1}$ beyzufügen.

Ew Hochwohlgeb. werden verzeihen, daß ich Ihren verehrten Namen, unter diejenigen Herren gesetzt habe, von deren Gefälligkeit ich die Mühe der Annahme der Subscription erwarte. Empfehlen Sie mich dem Hn. Hofr. Joh. Frank, Hn. Prof. Abicht 
u.s.w. In kurzem werden Sie einen 2.ten Doubletten Katalog der hiesigen Univers. Bibliothek erhalten.

Ich weiß jetzt oft nicht mehr, wie ich beym gegenwärtigen Cours der Russ. $<\ldots\rangle^{2}$ Assignation die nothwendigsten Bücherpreise der Un. Bibliothek an neuen Büchern, Journalen etc. beytreiben soll. -

Mit unveränderlicher Verehrung

Ew. Hochwohlgeb. gehors. Diener

${ }^{3}$ für H. Horn ${ }^{4} 1$

Morgenstern. I

$\begin{array}{ll}- & \text { Haustein } 5 \\ - & \text { Frank } 2 \\ \text { - } & \text { Heymann } 6 \\ \text { - } & \text { Bibliothek } 5 \\ \text { - } & \text { moi 6 } \\ \text { - } & \text { Tiefenbach } 57 \\ \text { - } & \text { Rosen }^{5} 8\end{array}$

\footnotetext{
${ }^{1}$ Reise in Italien: erschien seit 1811 in Einzelheften als Fortsetzungswerk; s. Węclewski S. 97 Anm. 1 und Süss S. 308-314; vgl. Nr. 7 Anm. 3. - ${ }^{2}$ Eine Abkürzung unlesbar; „blo.“? - ${ }^{3}$ Neues Blatt von anderer Hand; Groddeck? vgl. die folgende Position „moi“ und den folgenden Brief Groddecks. - ${ }^{4}$ Horn, war 1804-1810 in Dorpat Professor für Kirchengeschichte. Süss S. 180: „, boshafter Querulant“. - ${ }^{5}$ Nicht ermittelt. $-{ }^{6}$ Zu Heymann vgl. auch Nr. 20 Anm. 4.
}

5. Groddeck an Karl Morgenstern, am 16. 8.1811

Wilna den 16. August 1811

\section{Hochwohlgeborener \\ Hochzuverehrender Herr Hofrath,}

Mit dem größten Vergnügen hab ich mich des von Ew. Hochwohlgeb. unterm 17. Jul<y $>$ empfangenen Auftrags entledigt. Nicht ich sondern die Saumseligkeit meiner respectiven Committenten ist schuld daß es so spät geschieht. Vorläufig hab ich die Ehre Ihnen wenigstens die Liste von 8 Suscrib. auf die intereßante Reise, die ich vorzüglich mit vieler Ungeduld erwarte, zu übersenden. Daß es noch so wenige sind, kann Ew. Hochwohlgeb. als Maaßstab dienen für deutsche Litteratur in Wilna. Hier sind die Namen in alphabetischer Ordnung:

Hochw, Ritter Joh. Frank 1 Ex. Hochw. Baron von Rosen 1 Ex.

Groddeck 1 -

3 - Hofrath $\underline{\text { Horn }}$

2) - \Salomon/ Heymann 1 -

Ritter u. Coll.Rath. Tiefenbach 1 Ex.

1) - Adjunct Haustein. 1 Ex.

Wilnaer UBibliothek

1 Exemplar auf beßerm Papier

8 Exemplare I 
Von einigen erwarte ich noch Bestellungen, deren Namen, sobald sie eingehen, Ew. Hwohlgeb. ich nachtragen werde. Für die mir gütigst überschickten kleineren Gedichte eines Reisenden ${ }^{1}$ meinen wärmsten Dank.

Vielleicht besitzen Ew. Hochwohlgeb. noch eine Anzahl Exemplare von Quintilian's Censura auctorum LX. ${ }^{2}$ die, wo ich nicht irre, Sie haben abdrucken laßen. In diesem Falle würden Sie $<$ m>ich sehr verbinden wenn Sie mir ein zwanzig bis dreißig ohne große Transportkosten zukommen laßen könnten.

Mit wahrer Verehrung

$$
\begin{array}{r}
\text { Ew. Hochwohlgeboren } \\
\text { ergebenster Diener } \\
\text { Groddeck }
\end{array}
$$

${ }^{1}$ Von Morgenstern? - ${ }^{2}$ Censura auctorum, im Buch X der Institutio oratoria X 1,46 ff. Vgl. Süss S. 129 (K).

\section{Karl Morgenstern an Groddeck, am 27. 8.1811}

\Sr. Hochwohlgeb./ Hn. Hofrath Groddeck, Prof. u. Univers.Bibliothekar der K. Univers.Bibliothek zu Wilna

Dorpat 27 Aug 1811

Hochwohlgeborener,

Hochzuverehrender Herr Hofrath,

Ihrem ${ }^{1}$ mir sehr angenehmen Schreiben vom $16^{\underline{t}}$ Aug. zufolge, habe ich die Ehre Ihnen die verlangten 8 Suscriptions-Exemplare des ersten Heftes meiner Reise in Italien zu übersenden, nemlich 7 auf ord., u. 1 auf größeren Papier, der Bestellung gemäß. Für Ihre gütige Bemühung der Sammlung der Subscribenten bin ich Ihnen sehr verbunden.

Quintiliani Censura Anitt. <?> Gr. et Lat. habe ich beym hiesigen Buchdrucker Grenzius $^{2}$ auf dessen Rechnung abdrucken lassen. Exemplare sind noch genug vorhanden. Ich werde deshalb mit Hrn. Grenzius sprechen, und ihm auftragen mit für Sie nebst Bemerkung des (übrigens geringen, doch mir nicht genau bekannten) Preises, den ich Ihnen melden werde, die von Ihnen verlangten 30 Exemplare zu übersenden. Sie können dem nächstens von hier aus zu übersendenden lat. Auctionscatalog der hies. Universität beygelegt werden, so daß sie Ihnen gar keine Transportkosten I machen werden.

Der Druck des 2ten Hefts meiner Reise, Florenz betreffend ${ }^{3}$, wo ich 3 Wochen war, werde ich in wenigen Tagen anfangen lassen. Ich bin so eben damit beschäftigt, einiges in meinen Briefen und andern Büchern Enthaltene mit meinem an Ort und Stelle genau Aufgezeichneten zu vergleichen. Ich schmeichle mir, daß auch dieß 2te Heft manches dem Freunde der Kunst und Literatur interessante Detail mittheilen ${ }^{4}$ 
werde. Möge das erste Ihnen nicht mißfallen. Auch abweichende Ansichten würden mir willkommen seyn. So wären mir z.B. über das Herculan<ische> Fragment ${ }^{5} \underline{\text { Ihre }}$ Urtheile wichtig, und ohne Zweifel lehrreich. Mit wahrer Hochachtung

Ew. Hochwohlgeb. ergebenster Diener

Morgenstern

\footnotetext{
${ }^{1}$ Im Ms.: Ihren; danach gestrichen: z. - ${ }^{2} J o h a n n$ Michael Gerhard Grenzius (1759-1822) aus Stendhal, dann Buchdrucker und Buchhändler in Dorpat. Vgl. Süss S. 184. $-{ }^{3}$ Zweites Heft meiner Reise nach Florenz, s. auch Nr. 3 Anm. 1. $-{ }^{4} \mathrm{Im}$ Ms. über gestrichenem: enthalten. $-{ }^{5}$ Zum Bellum Actiacum vgl. Süss S. 245 (K).
}

7. Karl Morgenstern an Groddeck, am 27. 10.1811

Ew. Hochwohlgeb.

Dorpat, 27. Oct. a $<$ lten $>$ St $<$ ils $>1811$

werden mein letztes Schreiben vom 27. August erhalten haben, wobey ich Ihnen 8 Exemplare des 1ten Heftes meiner Reise in Italien auf Ihr gütiges Verlangen für die von Ihnen bemerkten Subskcribenten, zu senden die Ehre hatte. Jetzt erhalten Sie Exemplare des 2ten Doubletten Katalogs der Univers.-Bibliothek, der vielleicht auch dieß Mal manches Ihrer Univ.Bibl. Brauchbare enthalten wird.

Zugl<eich> habe ich das Vergnügen, Ihnen den lat. Lectionskatalog vom 1ten Aug. zu übersenden, dessen Programm durch Ihre Äußerung wegen \des Abdrucks der Stelle aus/ Quintilian ${ }^{1}$ veranlaßt ist. Ich sende Ihnen hiebey für Sie selbst I 1 Ex. dieses Abdrucks von den sehr wenigen Exemplaren auf besserem Papier, die ich noch bey mir fand. Die Exemplare auf ord. Druckpapier verkauft der Buchhändler ${ }^{2}$ Grenzius. Auf mein Verlangen, daß er für Ihre Rechnung 30 Ex. packen solle, die ich mit diesem Paquet fortschicken wollte, erwidert er mir, er habe neulich durch Buchh<ändler> Hartmann $^{3}$ in Riga eine ähnliche Anzahl, wie er vermutete, für Wilna, abgesendet. Um nicht doppelt zu senden, erwartet er also ausdrücklich neuen Befehl. Gelegenheit einer Sendung dieser Art ohne Kosten zu machen ist zugl<eich> nicht, als bey der Übersendung des lat. Katalogs. I

Ich weiß nicht, ob Sie schon meine Commentare de Plat. Aest. ${ }^{4}$ und die Schrift de fide Velleii ${ }^{5}$ besitzen. Sollte es nicht der Fall seyn, so bitte ich Sie dieselben von mir anzufordren. Haben Sie sie aber schon, so ersuche ich Sie, solche der Bibl. der Univers. zu geben. - Es würde mir angenehm seyn, wenn die Verhältnisse Ihnen vielleicht erlaubten, von beyden ehmals auf meine Rechnung gedruckten Sachen, wovon ich noch eine Anzahl Exemplare vorräthig habe, in Wilna bey Liebhabern der alten Litt. \künftig etwas/ anzubringen ${ }^{6}$ oder mir einen zuverlässigen Buchhändler nach- 
zuweisen, der dgl. in Commission nähme ${ }^{6}$. Die Commentt. de Plat. Aest. kosten $1 \mathrm{Slb}$. Rbl. Sä..sch <?>, die Schrift über Velleius 6 grosch. -

Mit vorzüglicher Hohachtung

Ew.Hochwohlgeb. gehorsamster Diener

Morgenstern

\footnotetext{
${ }^{1}$ Vgl. Nr. 5 Anm. 2. - ${ }^{2}$ Vgl. Nr. 6 Anm. 2. $-{ }^{3}$ Carl Johann Gottfried Hartmann (1770-1828) aus Gotha, später Buchhändler in Riga. - Danach gestrichen: in. $-{ }^{4}$ Kommentar zu Platos Aest.; vgl. Süss S. 129. $-{ }^{5}$ Dazu vgl. Süss S. 245 (K). $-{ }^{6-6}$ Am linken Rand quer geschrieben.
}

8. Groddeck an Karl Morgenstern, am 26.11. 1811

Wilna den 26. November 1811 Vor allen Entschuldigungen meinen wärmsten herzlichsten Dank für alle die schönen litterarischen Geschenke mit denen Ew. Hochwohlgeboren mich eben so sehr erfreut als Sich höchst verbindlich gemacht haben, so wie die höchst ehrenvolle Erwähnung, mit der Ihre zuvorkommende und nur zu nachsichtsvolle Freundschaft mich überrascht hat. In Ihren geistvollen Erinnerungen an unser Vaterland, um deßen Anblick und leider! nur viel zu kurzen Genuß ${ }^{1}$ ich Sie dennoch beneiden könnte, zog mich, wie Sie's selbst ahndeten, vor allem Pompeii u. Hercul. und gli Studi zu Neapel an, ${ }^{2}$ Beschreibungen die ich mit Heißhunger verschlang, wiewohl das viele intereßante und wißenswürdige, was ich fand, meine Sehnsucht nach mehrerem nicht stillen konnte, so daß ich beinahe mit Ruhnkens ${ }^{3}$ bei einer andern Gelegenheit gegen Heyne ${ }^{4}$ geäußerten Worten Ihnen hätte zurufen mögen: Atque hic irascor academicis tuis occupationibus que tibi iustum in fortunatis his sedibus commorandi tempus eripuerunt. - Auch ein sehr werthes Andenken war mir das I von Ihrer eigenen Hand verbeßerte schöne Quintilianische Fragment, zu deßen nochmaliger Revision ich mich freue, Ihnen Veranlaßung gegeben zu haben. Und die längst von mir gewünschte mit eben so behutsamer und unpartheiischer Critik und eindringender Beobachtung entworfene, als durch den schönsten Vortrag und eine klaßische Diktion sich auszeichnende Ehrenrettung des Velleius, war mir ein recht unerwarteter und darum desto angenehmerer Fund. Ihre Schrift über Plato's Republik ${ }^{5}$ verdankte ich schon ehemals Ihrer zuvorkommenden Güte, und habe daher das mir aufs neue zugekommene Exemplar der hies. UBibl. Ihrer Verfügung gemäß, überliefert. Da mit dem $d<u r c h>$ die Großmuth unsres Curators ${ }^{6}$ seit vorigem Jahre unter meiner Leitung errichteten philolog. Seminarium I auch eine kleine Bibliothek verbunden ist, aus der ich den auf die Schulen u. Gymnasien als Lehrer abgehenden Mitgliedern eine Anzahl nöthiger Bücher zum weitern Fortstudirn u. philolog. Bildung und zugleich zum Andenken an diese wohlthätige Anstalt verschenke, so würde I \mir/ eine kleine Anzahl von Exemplaren (etwa 5) sowohl von der Schrift über Plato als der strengeren über Velleius zu 
der Sie mir Hoffnung machen, recht willkommen seyn. Nur haben Sie die Güte die Preise auf Silber Rubel zu reduciren oder darnach zu berechnen.

Beigeschloßen erhalten Ew. Hochwohlgeboren die Hälfte der Suscription für 8 Exemplare der Reise in Italien, mit 82 Rubel BA ${ }^{7}$ oder vielmehr $80 \mathrm{BA}$ u. Einen halben R. in Silber ${ }^{8}$ worunter 7 Ex. zu 10 R. u. Eins zu 12 berechnet ist. Daß ich diese Schuld so spät abtrage, würde unverzeihlich seyn, wenn diese beinah dreimonatliche Zögerung Imeiner Antwort/ blos mir zuzuschreiben wäre. Aber so gehört mir nur ein Theil derselben zu, und zwar ein solcher, für den ich am ersten von Ihnen Verzeihung hoffen darf. Ich wollte diese Gelegenheit nutzen, Ew. Hochwohlgebor. mit meinem erst vor ungefähr Einem Monat völlig fertig gewordenen Handbuch der Griech. Lit.gesch. zu huldigen, um wenigstens die unter Gastfreunden geheiligte alterthümliche Sitte der Erwiederung - wären's auch nur $\chi \rho v \sigma \varepsilon \omega v \chi \alpha \lambda \kappa \varepsilon เ \alpha^{9}$ - in Ehren zu halten. Dazu kam die Abwesenheit zweier Subskribenten \zu Ihrer Reise/ von I Wilna, von denen selbst der eine noch bis itzt in Petersburg ist. - Von dem Quintilian. Fragment hat mir H. Hartmann in Riga wirklich 30 Ex. geschikt; ich würde aber doch noch ein zehn Exemplare brauchen können, wenn H. Grentz<ius > sie mir gelegentl. und ohne Transport Kosten zuschicken könnte. - Bestellung auf einige in dem Doublett-Catalog d. Dorp. UBibl. erhalten Ew. Hochwohlgebor. am Ende dieses oder zu Anfang d. künftigen Jahres.

Was mich zu der undankbaen Ausarbeitung eines Handbuchs für die gr. Literaturgesch. ${ }^{10}$ bewog, war einzig Bedürfniß für dieses Land und meine Vorlesungen. Nur aus diesem Gesichtspunkte wünschte ich's beurtheilt zu sehen. Sonst hätte ich mich gewiß gehütet, Eulen nach Athen zu tragen. $\underline{\text { Harles }}^{11}$ ist viel zu weitläuftig für Anfänger $u$. giebt auch keine faßliche Übersicht, der Trockenheit $n<i c h t>$ zu erwähnen. Die übrigen Handbücher, unter denen Rienäcker ${ }^{12}$ mir noch am ersten zusagen möchte, sind in deutscher Sprache, deren Kentniß weder hier noch in den Bezirken bei den Schülern voraus zu setzen ist. - Der kleine Grundriß der röm. Alterth. ${ }^{13}$ ist auf Heyneschem Grund $\mathrm{u}$. Boden erwachsen, wiewohl in ganz veränderter Ordnung, die vielleicht ihre Mängel haben kann, aber mir doch mehr gefällt, als die ietzt in den meisten Handbüchern beliebten \statistischen/, wo der Artikel von den Sklaven die ganze Doctrin seltsam genug eröffnet!

Mit Versicherung der ausgezeichnetesten Hochachtung hab ich die Ehre zu seyn

Ew. Hochwohlgeboren

gehorsamster Diener

Groddeck

${ }^{14}$ N. S. Da ich ohne beträchtlichen Verlust die vorräthigen 20 1/2 SR. gegen Assignationen nicht auswechseln kann, so sehe ich mich genöthigt Ew. Hochwohlg. die obige Summe in Silber mit der Post, nach Abzug der Tr<ansport>kosten, zu übersenden, und die literarischen Beilagen, um das Porto nicht zu vergrößern, unter der Adreße der Universität besonders zu schicken. 


\begin{abstract}
${ }^{1}$ Reise Morgensterns nach Deutschland: vgl. Nr. 4 Anm. 1. - ${ }^{2}$ Danach gestrichen: die ich. $-{ }^{3}$ David Ruhnkens (1723-1798) aus Stolp, Professor für klassische Philologie in Leiden. $-{ }^{4}$ Christian Gottlieb Heyne (1729-1812) aus Chemnitz, klassischer Philologe in Göttingen. ${ }^{5}$ Vgl. auch Nr. 32 zu Anm. 7. $-{ }^{6}$ Fürst Adam Czartoryski (1770-1861), ehemals Freund des Kaisers Alexanders I. 1808 Kurator des Schulbezirks Litauen und der Universität Wilna. $-{ }^{7}$ BA: Assignaten. $-{ }^{8-8}$ Am linken Rand quer geschrieben. - ${ }^{9}$ Vgl. Homer, Ilias VI 236 (K). - ${ }^{10}$ Handbuch der Griechischen Literaturgeschichte: Historiae Graecorum litterariae elementa. In usum lectionum conscripsit Godofred. Ernestus Groddeck. Vilnae 1811. Die zweite Aufl. erschien in zwei Bänden: Initia historiae Graecorum litterariae, secundum edidit Godofr. Ernestus Groddeck, Vilnae 1821/1823 (K). - ${ }^{11}$ Gottlieb Christoph Harless (1738-1815), Introductio in historiam linguae graecae, Altenburg 1778, 2. Aufl. 1792-1795; Supplementa I, Jena 1804, II 1806. Eine Brevior notitia litteraturae graecae imprimis scriptorum graecorum ordini temporis adcomodata in usum studiosae iuventutis erschien in Leipzig erst 1812 (K). - ${ }^{12}$ Johann August Rienäcker (1779-1859); Philologe und Domprediger. Hier gemeint sein Handbuch der Geschichte der griechischen Litteratur, Berlin 1802. $-{ }^{13}$ Antiquitatum Romanarum doctrina in usum lectionum academicarum, 1811. - ${ }^{14}$ Rest am linken Rand quer geschrieben.
\end{abstract}

9. Karl Morgenstern an Groddeck, am 20. 3.1812

Dorpat, d. 20. März 1812

Hochwohlgeborner, hochzuverehrender Herr Hofrath,

Sie erhalten auf dem nächstfolgenden Blatte das Verzeichniß des für Sie durch mich, Ihres gütigen Auftrags zufolge, in der DoublettenAuction im Februar 1812 Erstandenen. Die Auction fand übrigens erst 14 Tage später Statt, als sie angekündigt war, wegen später einlaufender Commissionen, insonderheit aus $\underline{A b o}$, den<en> Sie es auch zuzuschreiben haben, daß Sie nicht alles Gewünschte, und manches zu höhern Preisen, erhalten, indem die Univers. Abo mir eine beträchtliche Anzahl bedeutender Commissionen anvertraut hatte. Doch hoffe ich, daß Sie zufrieden seyn werden, da Sie fast lauter wichtige Werke erhalten. Auch bin ich noch unter Ihrer Summe geblieben, indem Sie 50 Silb. Rbl., allenfalls auch 10 bis $15 \backslash$ Silb./Rbl. darüber, bestimmten.

Ich habe Ihnen noch meinen herzlichen Dank abzustatten, sowohl für Ihren Brief vom 26. Nov., als für \die/ demselben beygelegten, mir sehr willkommenen litterarischen Geschenke, nemlich Ihres Handbuchs der griech. Literaturgeschichte und Ihres Grundrisses der Röm. Antiquitäten. An einem Buche, wie Ihres ist, hat es in der That bisher gefehlt, da Harles allerdings ${ }^{1}$ viel zu weitläufig ${ }^{2}$, auch nicht bis zu den neuesten Zeiten durchgeführt ist, besonders auch zu wenig Übersichten der Litteratur nach ihren Hauptzeugen gewährt. Ich zweifle nicht, daß dieses <...>liche ${ }^{3}$ Werk auch in Deutschland und in anderen Ländern $<\ldots \mid . . .>^{4}$ und bekannt werden möchte, für seinen Zweck statt ${ }^{5}$ den bisherigen Compendien als vorzüglich brauchbar anerkannt werden wird. - Ich ersuche Ew. Hochwohlgeb. mir gelegentl. zu melden, ob und für welchen Preis es im Buchhandel zu haben seyn möchte, damit, wer es etwa einmal auch bey Vorlesungen über die Gesch. d. Gr. Litt. zum Grunde zu legen wünschte, es jungen Leuten leichter nachweisen könnte. Den Grundriß der Röm. Antiqu. behalte 
ich mir vor, wenn ich selbst wieder an den Vortrag dieser Wissenschaft komme, näher zu prüfen.

Die mir übersandten 20 Rbl. Silb., als Hälfte der Subscr. für 8 Ex. der Reise in Italien, worunter 1 auf größerem Papier, habe ich richtig empfangen, und bin Ihnen auch dafür sehr verbunden.

Ich erwarte jetzt, daß Ew. Hochwohlgeb. mir den Weg anzeigen, auf welchem Sie die erstandenen Bücher für die Univers. Bibl. zu erhalten wünschen.

Zugleich werde ich Ihnen alsdann auch die verlangten 10 Exemplare des Fragments aus Quintilian vom hiesigen Un.Buchdrucker Grenzius senden, so wie das 2te, so eben fertig gewordenen Heft meiner Reise, das ganz von Florenz handelt, und dessen ${ }^{6}$ Beendigung mir dadurch sich etwas länger als ich gedacht, verzögert hat, daß statt der versprochenen 12 Bogen eines Heftes es beynah 20 stark geworden ist. Ebenso werde ich dann auch die verlangten Ex. der Hefte de Plat. Rep. und de Vell. Quaten., von welchen Sie einen mir so angenehmen Gebrauch machen wollen, Ihrem Vorschuß gemäß beylegen. - Das 2te Heft der Reise erhalten Sie vielleicht auch noch $\langle\ldots\rangle^{7}$, zugleich mit dem lat. Lect.Katal. der Univers. Mit der wärmsten und auch höchsten Hochachtung unveränderlich Ew. Hochwohlgeb. gehorsamster Diener Morgenstern

${ }^{1}$ Danach gestrichen: zu. - ${ }^{2}$ Danach gestrichen: ist. $-{ }^{3}$ Das Wort am unteren Zeilenrand nicht lesbar. $-{ }^{4}$ Letztes Wort der Seite und erstes der nächsten nicht lesbar. $-{ }^{5}$ Über gestrichenem: von. $-{ }^{6}$ Danach gestrichen: schnell. $-{ }^{7}$ Ein Wort unleserlich.

(beigelegtes Blatt von anderer Hand:)

Die Kaiserliche Universitäts-Bibliothek in Wilna hat in der Doubletten=Auction der Dörptschen Universitäts=Bibliothek in Auftrag des Herrn Hofr. u. Prof. Groddeck erstanden:

No.

1-3 Thesauri Epistolici Lacroziani

28 I. S. Assemanns Oriental. Bibliothek

$41 \quad$ Vita Reuchlini Phorcensis

62 Commentatio de Quinti Smyrnaei

67 C. Jul. Caesar. Cura Oudendorpii

83 G.J.Vossii Etymolog. LL.

87 L.Schefferi de Re vehicul. veter. lib. II

127 D' Herbelot Biblioth. orient.

135.36 Zend-Avesta

168 Leben des Grafen von Brühl

188

240

264

753

$$
\text { Histoire de la Papesse Leanne }
$$

A. M. Schroeckhii Hist. Relig. Chr. M. Pfaffii de orig. jur. Ecclesiast. Galilaei Galilaei, Syst. Cosm.
Rbl. Cop.

8. - -

1. -

3. 50

1. 50

3950

$18-$

$5-$

$27 \quad-$

$28-$

150

- 50

275

170

17 - 
Dorpat, d. 20. März

1812
A. Euler Theoria motuum Lun. Apoll. Pergaei de Spect. etc. Dissertatt. Acad. Upsal. Steph. Blancardi Lexic. nov. Med. etc.

${ }^{1}$ Angestellter der Universitätsverwaltung in Dorpat.

10. Karl Morgenstern an Groddeck', am 14. 3.1813

\section{Hochwohlgeborener Herr}

Hochzuverehrender Herr Hofrath und

Professor.

Schon im März vorigen Jahres übersandte ich Ew. Hochwohlgeb. auf officiellem Wege das Verzeichniß der zufolge Ihres Auftrages, auf der hiesigen, im Februar 1812 gehaltenen Universitäts-Doubletten Auction, für die Kaiserliche Wilnaische UniversitätsBibliothek erstandenen Bücher. Später habe ich auch, in einem Privatschreiben, diese Anzeige wiederholt. Wahrscheinlich sind die bald nachher eingetretenen KriegsUnruhen ${ }^{2}$ Schuld, daß wir bis jetzt vergeblich auf eine Antwort gewartet haben. Vielleicht ist auch \der/ das Verzeichniß begleitende Brief aus dem nämlichen Grunde gar nicht in Ew. Hochwohlgeb. Hände gekommen. Da nun aber die Kommunikation zwischen Livland und Litthauen wieder eröffnet ist, so wende ich mich, bey Übersendung einer Abschrift des erwähnten Verzeichnisses, von Neuem an Ew. Hochwohlgeb. mit der Bitte, mir bald, bey Übersendung I der Auctions-Summe <...>>197 Rbl 30 Kop. B. Aß<ignaten>, <an> die Adresse und Mittelspersonen, an welche die BibliotheksKanzelley jene Bücher (die uns seither im Wege stehen) spediren soll, gefälligst aufzugeben. -

Mit vorzüglicher Hochachtung habe ich die Ehre zu seyn

Ew Hochwohlgeb.

${ }^{4}$ gehorsamster

Diener

Morgenstern

Ich habe von der Wilnaischen Un.Bibl. zusage, lin Abo/ auf die meisten der obigen zum Theil schon an sich theuren $\mathrm{u}$ in der That nicht theurer erstandenen ${ }^{5}$ Bücher die gleich unbestimmten, worin Discretion erbeten gütig, als von Ihnen überlassenen Commissionen der Aboischen Univ.Bibliothek, die Hr. Prof. und Bibliothekar Palander ${ }^{6}$ mir I anvertraut hatte, ${ }^{7}$ unerfüllt gelassen, und mich darauf beschränkt, andere, (wo nicht die gleich Collision Statt fand) der Aboist Univers. Bibl. (S²10 Rbl) 
zu erstehn, wofür die Aboisch<e> Univers., sehr zufrieden mit dem Erstandenen und den Preisen, <.>frdl<.. $>^{8}$ aufs verbindlichste gedankt hat.

Ich zweifle im geringsten nicht, daß nur die Zeitumstände vonseiten der Wiln. Un.Bibl. den Aufenthalt verursacht haben. Doch ist's meine Amtspflicht, in dieser Sache das mir Obliegende nicht zu versäumen, wie ich hiemit thue. Ich behalte übrigens mir vor Ihnen, verehrtester Freund, gelegentl. noch besonders zu schreiben, sobald ich wieder eine Nachricht von Ihnen erhalte.

Mein ${ }^{9}$ Programm in dem $<. . .>^{10}$ Lectt. Katalog vom Febr. 1812: Symbb. criticae in Platonis Critonem, werden Sie erhalten haben. das 3ㄹ Heft meiner Reise (16 Bogen stark) wird Ihnen mit Ihren Büchern gesendet werden. ${ }^{11}$

${ }^{12}$ In Monatsfrist werde ich herausgeben: Dörptsche Beyträge, Zeitschrift für Freunde der Philosophie, Litteratur und Kunst. $1^{\text {tes }}$ Stück. Etwa 8 Bogen (3 sind eben gedruckt.)

${ }^{1}$ Diktat von anderer Hand. $-{ }^{2}$ Gemeint ist die schnelle Besetzung Wilnas durch Napoléon nach dessen Angriff auf Rußland im Juni 1812. - ${ }^{3}$ Ein Wort unleserlich: gr<..> $3 .{ }^{4}$ Das Folgende von eigener Hand. $-{ }^{5}$ Nach bzw. über gestrichenem: be|zahlten. $-{ }^{6}$ Gabriel Palander (1776-1821), Professor der Literaturgeschichte und Bibliothekar in Abo. - ${ }^{7}$ Danach gestrichen: Ab<er>? $-{ }^{8}$ Anfang und Ende des Wortes nicht lesbar. $-{ }^{9}$ Danach gestrichen: lat<einisches>. $-{ }^{10}$ Danach ein Wort durch einen Fleck unleserlich. $-{ }^{11}$ Rest der Zeile unleserlich. ${ }^{-12}$ Rest am linken Rand quer geschrieben.

\section{Groddeck an Karl Morgenstern, am 6. 4.1813}

Hochwohlgeborner,

Hochzuverehrender Herr Collegien Rath

Nicht Saumseligkeit, oder Vergeßen, oder Unerkenntlichkeit gegen die gütigst und zu unsrer größten Zufriedenheit übernommene Mühe bei der Bücherversteigerung der in der Dorpatischen Ubibliothek vorräthigen Doubletten haben die fast beispiellose Verspätung dieses Briefes - für die ich Sie tausendmal um Verzeihung bitte - verursacht. In Ihrem Briefe vom 20 März vor<igen> Jahres ${ }^{1}$ (nur diesen habe ich erhalten; keine andre Sendung auf officiellem Wege, deren Ihr gegenwärtiger Brief vom 14 März erwähnt, ist mir zu Händen gekommen) machten Sie mir Hoffnung die Fortsetzung Ihrer Reise in Italien nebst einigen anderen gewünschten Schriften zukommen zu laßen, in deren Erwartung ich anfänglich die Beantwortung Ihres gütigen Briefes verschob. Leider die bald darauf eingetretenen \erst/ häuslichen (denn ich mußte meine Wohnung dem ietzt verstorbenen trefflichen Prinzen Oldenburg K. H. ${ }^{2}$ I abtreten) und dann öffentl. Unruhen, die alle Communication zwischen uns und unserm Musensitze unterbrachen, endlich, nach der eben so unerwarteten als glücklichen Rückkehr der alten Ordnung, in der der Finger der ernsten alten Nemesis so fühlbar ist, der Mangel au fond, da 2 Tertiale der hiesigen Universität, 70000 R. in Silber, noch in Rückstand sind, sind die wahren Ursachen dieser Verzögerung. Doch hoffe ich in Zeit von 4 Wochen im Stande zu seyn Ew. Hochwohlgeboren die Auctions-Summe laut des 
erhaltenen Verzeichnißes von hier mit der Post nach Dorpat zu übersenden. Übrigens haben Sie nur die Güte, die Bücher geradezu an mich und unter meiner Adreße mit einem Fuhrmann nach Wilna zu schicken, dem ich die Transport u. Embalage Kosten ersetzen werde. Andre Mittelspersonen weiß ich Ihnen nicht anzugeben. Von Riga aus wird es gewiß nicht schwer seyn zu wohlfeilem Preise eine Gelegenheit nach Wilna zu finden, aber ob auch von Dorpat nach Riga, das ist mir unbekannt. Ich erinnre mich nicht mehr, auf welchem Wege ich bei der ersten Auction die erstandenen Bücher aus Dorpat erhielt: sonst I würde ich Sie bitten, denselben Weg auch jetzt einzuschlagen. Weder das $\underline{2}^{\text {te }}$ Stück Ihrer Reise in Italien, noch den Dorpater Auctions catalog mit den Symbolis crit. in Plat. ist noch bis itzt mir zu Händen gekommen; ich begreife die Ursache dieses Verlustes nicht. Unser Frank, der noch im April $<1>812$ Wilna verließ, ist noch immer in Wien und hat eine Verlängerung seines Urlaubs bis zu Ende August angesucht. In literarischer Hinsicht hat die unglückliche vorjährige Catastrophe uns wieder auf Jahre lang zurückgeworfen. Ich beneide Ihre gelehrte Muße, der wir, wie ich aus Ihrer letzten Zuschrift sehe, wieder eine neue schöne Frucht verdanken auf die Sie mich sehr begierig gemacht haben. Ich schicke diesen Brief mit der wiederholten Bitte um Ihre gütige Nachsicht und noch 4wöchentliche Geduld und bleibe unveränderlich mit der ausgezeichnetesten Hochachtung u. freundschaftlichen Ergebenheit der Ihrige Groddeck

<Beigefügt:>

Bibliothekar Leibnitz, 21. 4. 1813

Am 7 ten Junius 1812 wurde aus der Kanzelley dieser Kaiserlichen Universitäts-Bibliothek ein Brief des Herrn Direktors derselben, KollegienRaths Professors Dr. Morgenstern, vom nämlichen dato, (dem <...>buche ${ }^{4}$ einverleibt sub Nr. 21) nebst Paquet, an den Herrn Hofrath und Professor Grodeck in Wilna expedirt. Das Paquet enthielt, wie das bey der Akte vorschriftsmäßig asservirte officielle AuftragsSchreiben des Herrn Bibliotheksdirektors an den Sekretär (ebenfalls vom 7. Junij 1812 Nr. 47) beweist: einige Exemplare des hiesigen Lektionskatalogs mit dem Programm des Hn. KollegienRaths Morgenstern (Symbolae criticae in Platonis Critonem) und acht Exemplare von dessen Reise in Italien, ersten Bandes zweyten Heftes. - Auf Verlangen des Herrn KollegienRaths Morgenstern wird hierüber von der Kanzelley dieser UniversitätsBibliothek das aktenmäßige officielle Zeugniß deswillen ausgefertigt.

Dorpat am 21. April 1813

Bibliothekssekretär Karl <... $>^{4}$

Gouv.Secr. Leibnitz, Bibl.Kanzl.

\footnotetext{
${ }^{1}$ S. Nr. 9. - ${ }^{2}$ Gemeint Peter Friedrich Georg (1784-1812), zweiter Sohn des Herzogs Peter von Oldenburg und der Prinzessin von Württemberg, Schwester der Kaiserin Maria Fjodorovna. Peter, in Rußland Georg, heiratete 1809 die Großfürstin Katharina Pavlovna, war danach Generalgouverneur von Tver', Novgorod und Jaroslavl'. - ${ }^{3}$ Anfang des Wortes nicht lesbar. - ${ }^{4}$ Unterschrift unleserlich: Pol<...> ? - Auf gesondertem Blatt die Anschrift: Sr. Hochwohlgebornen I Herrn CollegienRth und Professor I Carl Morgenstern I auf der Kaiserl. Universität I Морген<..> I 1 $18^{\text {te }}$ I Dorpat
} 
12. Karl Morgenstern an Groddeck, am 21.4.1813

Dorpat, d. 21 April 1813

Hochwohlgeborner,

Hochzuverehrender Herr Hofrath,

Ihr gütiges Schreiben vom $6^{\text {ten }}$ April eile ich mit der nächsten Post ${ }^{1}$ mit welcher es mir zu beantworten möglich ist, da Ihr Schreiben ankam, als ich \auf/ ein paar Tage aufs Land gefahren war, zu beantworten.

Die in der Doubletten-Auction vor Jahr und Tag in Ihrem Auftrag für Ihre Univers. Bibliothek erstandenen Bücher stehen noch für Sie bereit. Mit 4wöchentl. Aufschub der Zahlung, dessen Sie erwähnen, sind wir gern zufrieden, und sehe ich in dieser Hinsicht, der Erfüllung der von Ihnen gefälligst gemachten Hoffnung entgegen. Die Kiste wird von hier, sobald Gelegenheit seyn wird, mit \einem/ Fuhrmann nach Riga gesandt, und von da durch einen Spediteur (und I zwar vermuthl. durch den dortigen Preußisch. Consul, Hn. Ellinger ${ }^{2}$ ) nach Wilna spedirt werden. Der Kiste beylegen werde ich die Ihnen zukommenden 8 Exemplare des $3^{\text {ten }}$ Hefts meiner Reise in Italien, womit der $1^{\text {te }}$ Band schließt. - Bey Empfang des $3{ }^{\text {ten }}$ Hefts darf ich (so waren die gedruckten Subscr. Bedingungen) wohl auf die $2^{\text {te }}$ Hälfte des Betrages rechnen. Auf jeden Fall erhalten Sie von mir $\backslash$ auch die weitere $/{ }^{3}$ Fortsetzung, sobald sie erscheint.

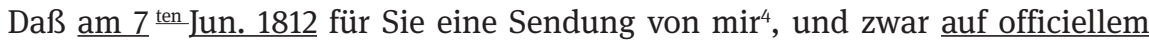
Wege mit der Post, gemacht ist beweist einliegender officieller Schein der hiesigen Un.Bibliotheks-Kanzelley von welchem ich Ew. Hochwohlgeb. bey allen Interessenten meiner Reise in Italien Gebrauch zu machen, sehr bitte. In dieser Sendung waren sowohl die für Ihre Universität von der unsrigen bestimmten Exemplare I des lat. Lectt. Katalogs vom 1. Febr. 1812 (der aber erst im $\mathrm{May}^{5}$ mit dem Programm fertig gedruckt war), als auch die 8 Exemplare des $2^{\text {ten }}$ Hefts der Reise für Sie und Ihre Committenten, wie solches ausdrückl. zu seiner Zeit in $\mathrm{de}<\mathrm{n}>^{6}$ in unserm Bibliotheks Archiv aufbewahrten officiellen Büchern der Geschäftsführung verschrieben ist. Der Feind rückte

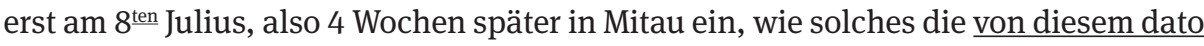
herrührende in den öffentl. Blättern stehende Publication des Kurländ. Civilgouvernements, des (damal.) Geh. Rths (nunmehrigen Gen.Lieut.) Fr. Sivers ${ }^{7}$ beweist, der an denselben Tagen Mitau verließ. Am 7. Junius dachte in unsrer Gegend kein Mensch an Feindesnähe von hier bis Wilna. Ich sandte mit der Post, auf officiellem Wege. Die Aufschrift war: „An die K. Univers. zu Wilna - Abz. an Hn. Hofrath pp. Groddeck. Einliegend die lat. Lectt. Kataloge der Univers. Dorpat und akademische Schriften desselben“. - Ich weiß nicht, wie ich damals besser hätte verfahren können.

Vielleicht liegt das Paquet noch irgendwo, wofern Sie es I nicht nun schon haben. Was ich thun kann in Hinsicht der Post, soll geschehen. Ich requirire neml. so eben den Herrn Rector magnif. der Univers. Dorpat, durch das hiesige Postamt Laufzettel zu veranlassen, die auf den Postämtern von hier nach Wilna anfragen. Ein Gleiches rathe ich auch Ew. Hochwohlgeb. Ihrerseits zu thun. 
Leider besitze ich nicht ein einziges einzelnes Heft, sondern nur complette Exemplare, die theils an die Subscribenten etc. verabfolgt, theils zum Verkauf anderwärts nach Leipzig etc. versandt sind. - Mir ist dieser Verlust in jeder Hinsicht äußerst verdrüßlich. Jedoch habe ich noch einige Hoffnung, da in der damal. Zeit auf den Postämtern manches Paquet soll auf die Lucht geworfen seyn, ${ }^{8}$ oder wohl ${ }^{9}$ mir immer noch die Absendung am 7 Jun. in eine $<. . .>^{10}$ zu gehören scheint, und zwischen Dorpat oder $^{11}$ Wilna der $<. . .>^{12}$, auch in Ihrer Nähe, wohl noch nicht gefr $<. .>t^{13}$ war; was ich indeß nicht genau wissen kann.

Die nächsten verlangten Schriften (Ex. v. d. Fragm. Quintilians, v<on $>$ m<einen $>$ Commentt. de Plat. Republ. etc.) sollen \in/ die Kiste beygelegt werden nebst der kleinen Note derselben. - Einstweilen sende ich Ihnen und Ihrer Un.Bibl. nächstens von dem lat. Lectt. Katal. mit d. Progr. de Plat. Criton. hiebey \von Gymnprogram/14 2 Exemplare. Ihr Urtheil über letzteres wird mir nicht gleichgültig seyn. Doch werden Sie mir zustimmen <?>, daß ich auf Complimente weder wie schon vorher erwarte noch $<\ldots . .>^{15}$

Mit der vollkommensten Hochachtung und freundschaftlichen Ergebenheit der Ihrige Morgenstern

\footnotetext{
${ }^{1}$ Danach gestrichen: da. $-{ }^{2} J o s e p h$ v. Ellinger (†1827), Hofrat; s. Neuer Nekrolog I 277, 404. $-{ }^{3}$ Am linken Rand nachgetragen. Danach gestrichen: die. $-{ }^{4}$ Danach gestrichen: gem<acht>. $-{ }^{5}$ Danach gestrichen: ganz. $-{ }^{6}$ Im Ms.: dem. $-{ }^{7}$ Entweder Georg Joachim Johann Sievers (1775-1843), der Generalleutnant, aber nicht Geheimrat war; doch wahrscheinlich Fjodor Fjodorovič Sievers (1746-1823), Generalmajor und Geheimrat, Senator und Zivilgouverneur von Kurland. $-{ }^{8}$ Danach gestrichen: vielleicht. $-{ }^{9}$ Danach gestrichen: mir. $-{ }^{10}$ Wort nicht lesbar. $-{ }^{11}$ Danach gestrichen: Livland. $-{ }^{12}$ Ein Wort nicht lesbar. $-{ }^{13}$ Wort nicht lesbar. - ${ }^{14}$ Über der Zeile, kaum lesbar. $-{ }^{15}$ Rest der Zeile und Anfang nächster Zeile, 6 Worte, nicht lesbar.
}

13. Karl Morgenstern an Groddeck, am 27. 6.1813

${ }^{1}$ Hochwohlgeborner,

Hochzuverehrender Herr Hofrath und Professor.

die durch Ew. Hochwohlgeb. auf unserer letzten Doubletten-Auction erstandenen Bücher für die Wilnaische Universitäts-Bibliothek sind bereits in eine Kiste gepackt und werden in diesen Tagen durch Fuhrmanns Gelegenheit an den Preußischen Consul Herrn Klinger ${ }^{2}$ in Riga, zu weiterer Spedition nach Wilna, abgesendet werden. Ew. Hochwohlgeb. werden jedoch denselben, mit der Anweisung auf Ersatz seiner Auslagen, ungesäumt beauftragen die Fracht von hier bis Riga dem Fuhrmann zu entrichten und den weiteren Transport der Kiste zu besorgen.

Mit besonderer Hochachtung habe ich die Ehre zu seyn

Ew. Hochwohlgeb.

gehorsamster Diener 
${ }^{3}$ Dorpat, 27 Junij 1813 I

Morgenstern

${ }^{4}$ In der Kiste befinden sich noch die 5 Ex. meiner Comentt. de Platon. Republ., welche Sie verlangt haben und an die Sie noch einmal zu erinnern die Güte hatten. Sie verlangen die Angabe des Preises in Silbergeld. In Deutschl. ist der Ladenpreis 1 Thaler 8 Groschen Cour.Geld. Ich muß die Exemplare selbst aus Halle kommen lassen. Der Landtransport beträgt im Ganzen jetzt in Deutschland nahezu 1/3 des Preises der Bücher. Ich will also für den mir kostbaren Transport nur $4^{5}$ Groschen Cour.Geld das Ex. rechnen; so \rechne ich/ ${ }^{6}$ das Ex. 1 Thlr. 12 Groschen, oder 11/2 Silb. Rbl. Obige 5 Ex. kosten also 71/2 Silb. Rbl.

Von den Comment. crit. de Velleio Q. finde ich leider keine Exemplare mehr übrig. Auch hat sie der Rector Krause in Hannover ${ }^{6}$ seiner Edition des Velleius vorangesetzt, wo sie also leicht zu finden ist, \so daß ich dem etwanigen $/{ }^{7} \mathrm{Käufer}^{8}$ doppelt dasselbe zu kaufen erspare, wenn ich kein apartes Ex. ${ }^{9}$ verkaufen lasse.

Für Ihre Univ.Bibl. habe ich 1 Ex. meiner Rede am Sarge des F. Kutusow ${ }^{10}$ beygelegt. Ihnen hatte ich mehr Ex..$^{11}$ gratis gesandt, erlaube es der Zweck des I Drucks, der am Schluß erwähnt ist. Sollten andre in Wilna Exemplare verlangen, so bedarf es nur eines Winks. Dieselben sind ja schon von hier gesandt worden.

Ankündigung meiner $\mathrm{D}<$ ör $>$ pschen Beyträge ${ }^{12}$ liegen in den Exemplaren des $2^{\text {ten }}$ Hefts meiner Reise, die Sie in der Kiste gleichfalls finden, neml. 1 gratis Ex. für Ihre Univ.Bibl. u. 7 für die übrigen Subscribenten. Übrigens beziehe ich mich nicht $\langle\text {... }\rangle^{13}$ diesen Brief über den Gegenstand. Die hiesige Post hat wegen des Paquets, worin die Exemplare ${ }^{14}$ von dem $2^{\text {ten }}$ Hefte für die Subscribenten waren, wirkl. an die ${ }^{15}$ anderen Postbehörden geschrieben. Es sollen sich noch immer liegen gebliebene Paquete finden. Vielleicht erhalten Sie das Ihrige auch noch. Die Lectt. Kataloge von der UB für Ihre Univ.Bibl. liegen auch in der Kiste.

Der hiesige sehr genaue Univ.-Buchdrucker Grenzius ist wegen der 10 Ex. der Blätter für Runkelius noch ehrgestern wieder von mir an diese erinnert. Der unordentliche Mann kann aber I in seiner Officin (der Zeitungsdruckerey pp.) nichts finden. So muß ich die Kiste ohne jene 10 Ex. abgehn lassen.

Ich erwarte ein gefälliges Schreiben von Ihrer Güte über den Empfang dieser Sachen.

Dem Briefe der Berichtigung des ${ }^{16}$ sieht die hiesige Univ.-Bibl. entgegen.

Ihre Universität und die Bibliothek derselben bedauere ich herzlich wegen des im Kriege erlittenen Schadens. Verzeihung wegen dieser halb unleserlichen Zeilen, die ich an einer Stelle schreibe, wo bessere Schreibmaterialien fehlten und das Schreiben unbequem war.

Mit der größten Hochachtung und Ergebenheit unveränderlich

der Ihrige

Morgenstern 


\begin{abstract}
${ }^{1}$ Von anderer Hand, Diktat. - ${ }^{2}$ Friedrich Maximilian v. Klinger (1752-1831), Freund Goethes, seit 1780 in russischen Diensten, 1811 Generalleutnant, seit 1803 Kurator der Universität Dorpat. $-{ }^{3}$ Datum und Unterschrift von eigener Hand. $-{ }^{4}$ Weiter von eigener Hand. $-{ }^{5}$ Danach gestrichen: Slb. $-{ }^{6} \mathrm{Zu}$ ihm vgl. Süss S. 16 und 98. $-{ }^{7}$ Über gestrichenem: und die. ${ }^{8}$ Danach gestrichen: auf. ${ }^{9}$ Danach gestrichen: mehr. ${ }^{10}$ Fürst Michail Ilarionovič Goleniščev-Kutuzov ( $\left.{ }^{*} 1745\right)$ war im April 1813 gestorben. Zu der Rede vgl. Süss S. 141. - ${ }^{11}$ Danach gestrichen: geb<unden>. $-{ }^{12}$ Gemeint: Dörptische Beyträge für Freunde der Philosophie, Litteratur und Kunst, herausgekommen in Dorpat. Erschienen waren drei Doppelbände zwischen 1813 und 1821, und zwar I 1, hrg. zusammen mit Johann Michael Gerhard Grenzius, 1813; die weiteren Bände zusammen mit Johann Joachim Christian Schünmann, nämlich: | 2, 1814; II 1 und I| 2, 1815; III 1, 1817; III 2, 1821, Ich danke Herrn Dr. Peter Wörster, Marburg, für freundliche Ermittlung bibliographischer Einzelheiten. Mehr Information im estnischen Internet eeva unter Dörptische Beyträge. ${ }^{13}$ Zwei Worte unlesbar. $-{ }^{14}$ Danach gestrichen: der Subskribenten. $-{ }^{15}$ Danach gestrichen: weiteren. $-{ }^{16}$ Danach gestrichen: Doubletten Betrags; dann ein Wort nicht lesbar.
\end{abstract}

\title{
14. Groddeck an Karl Morgenstern, am 6. 7.1813
}

\section{Hochwohlgeborner}

Hochzuverehrender Herr CollegienRath, Ihrer gütigen Aufforderung und meinem mit vorletzter Post (bei Absendung der letzten Hälfte meiner Schuld) Ihnen gegebenen Versprechen gemäß, bin ich so frei Ihrer Beurtheilung einige bei aufmerksamer wiederholter Durchlesung Ihres, in Inhalt und Form, gleich intereßanten Progr. vom Febr. 1812 welches die Symb. crit. in Crit. Plat. ${ }^{1}$ enthält, mir beigefallnen Bemerkungen zu unterwerfen. Was gleich die erste Anmerk. zu c. 3. betrifft, so gestehe ich Ihnen freimüthig, daß ich selbst nach Erwägung Ihres mit Scharfsinn u. Gelehrsamkeit, besonders in der Note am Ende aufgestellten Gründe, doch $\coprod_{a c o b s}^{2}$ Meinung beitrete. So einen schönen Sinn oủ $\delta \varepsilon \mu$ í $\alpha$ giebt, so stört, wie Ew. Hochwohlgeb. selbst bemerken, das $\alpha \lambda \lambda \dot{\alpha}$ und folgende 3 . Selbst wenn man nach Ihrem Vorschlage $\alpha \lambda \lambda \dot{\alpha}$ wegwerfen wollte, so scheint das folgende doch nicht recht zu paßen zu dem Begriff des höchsten Unglücks, besonders da das, was gerade

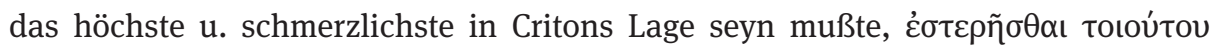

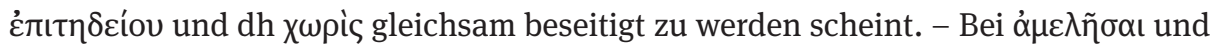
in der scharfsinnigen Erklärung von $\dot{\omega} \varsigma$ oíós $\tau \varepsilon \omega ̈ \nu$, so wie in $\pi \rho \circ \mu \eta \varepsilon \varepsilon \tilde{u}$ bin ich völlig Ihrer Meinung. Auch gestehe ich gern, Ihrer Erklärung von w் oĩos einen weit paßendern und, wie mir dünkt, den einzig wahren Sinn dieser Stelle zu verdanken. - C. s.p.

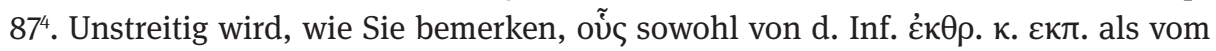
partic. $\kappa \alpha \tau \alpha \lambda$. regiert, und insofern sollte freilich das Comma nach $\varepsilon \dot{\kappa} \kappa \alpha \mathrm{I} \delta<\varepsilon \tilde{v} \sigma \alpha \mathrm{l}>$ wegbleiben. Doch, glaub' | ich, dürft' es, um den Anfänger durch die Länge des Satzes nicht zu verwirren, zu dulden seyn. Der Anfänger, werden Sie sagen, liest freilich den Plato nicht. Indeßen auch der Geübtere braucht zuweilen eine kleine Nachhülfe. Und wenn die Regel in der Interpunction gelten sollte, so steht unsere gedruckte Ausgabe, in der es (in beiden Sprachen) von solchen Fehlern wimmelt, eine große Revolution bevor. - Bei c. 6. p. 90. würde ich doch lieber mit Jacobs nach $\varphi \rho o v i ́ \mu \omega v$ ein Fragezei- 
chen setzen. - Eine CapitalAnmerkg ist die zu c. 5. p. 88. ${ }^{5}$ Sehr richtig bemerken Sie,

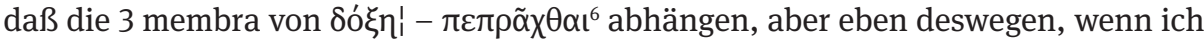
nicht der in unsern philologischen Tagen übelberüchtigten Schneidekritik fürchtete,

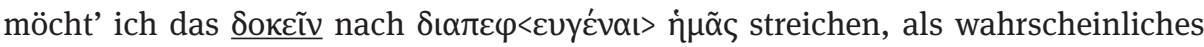

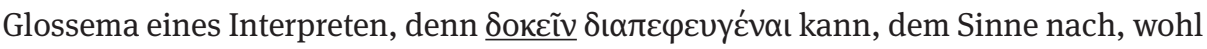
nicht mit $\pi \varepsilon \pi \rho \tilde{\alpha} \chi \theta \alpha \mathrm{I}$ verbunden werden oder davon abhängen. Jacobs Meinung aber,

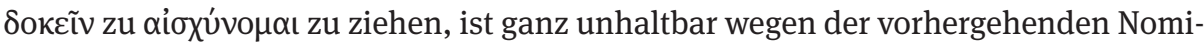

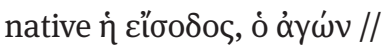

C. 8. p. 93. ${ }^{7}$ ich wünschte die von Ihnen so empfohlene Ursache der vorgezogenen

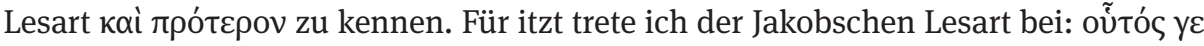

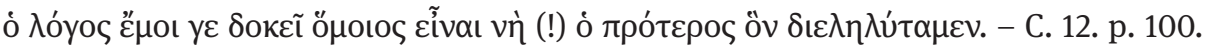
Nach Ihrer Erklärung, womit Sie die vulgata zu retten suchen, scheint mir doch das

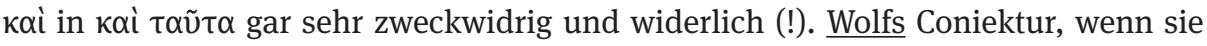
den Sprachgebrauch für sich hätte, hilft dem Sinne der Stelle unstreitig am besten auf. Aber woher hat \acobs sein $\mu \tilde{\omega} v$ zu Anfange des Satzes? -

C. 14. p. $106 .{ }^{8}$ Die Worte oi vó $\mu$ o $\delta \eta \lambda o v$ ótı <sic!> laß ich mir nicht nehmen; sie runden den Satz so schön, der ohne diesen (übrigens ganz, wie mir scheint, in Platons Manier gemachten) Zusatz etwas ${ }^{9}$ decustatum $u$. mutilem bekömmt, wod $<$ urc $>h$, mit Ciceros Worten, aures, tanquam debito fraudentur, offenduntur. Noch weniger kann ich daher $\underline{\text { Henicke }}^{10}$ beistimmen der auch das folgende tívı yà $\rho$ verdächtig machen will. Denn wenn auch wie I Sie bemerken, nicht de civitate ac de legibus universe quaeritur, so konnte doch der Satz allgemein ausgedrückt werden, obgleich in ganz spezieller Beziehung auf $\mathrm{Cr}<\mathrm{e}>$ tha. -

Den Sinn der Stelle c. 15. p. 108. haben Sie vortrefflich entwickelt und ich stimme Ihnen ganz, gegen Schleierm<acher $>^{11}$ bei. Ebenfalls zu c. 16. p. 109. gegen Wolfs Erklärung, die nur durch das unmerklich eingeschobene posse von dem der Text nichts weiß, einige Haltung bekömmt. Auf den Gegensatz von $\alpha \lambda \lambda \dot{\alpha}$ möchte ich gleichwohl nicht viel rechnen; dieß ließe sich auch wohl bei der Wolfischen Erkl<ärung> rechtfertigen. Auch \acobs versteht die Stelle wie Sie, das zeigt die Note zu ä $\mu \varepsilon ı v o v$ عiv ${ }^{12} \backslash$ tibi/ proderit. - Dies wären die Kleinigkeiten alle, bei denen ich mehr auf den guten Willen des Gebers als auf den Werth der Gabe zu sehen bitte. Malo enim, quem studio tuo sum obsecutus, desiderari a te prudentiam meam, quam si id non fecerim benevolentiam. - Bei dieser Gelegenheit darf ich Sie wohl auch, als Erwiederg Ihres freundschaftlichen Aufrufes um Ihr Urtheil über eine sehr leichte ${ }^{13}$, aber mir sehr nothwendig scheinende, Veränderung einer Stelle in Dem. or. pr. cor. ${ }^{14}$ ersuchen. Sie

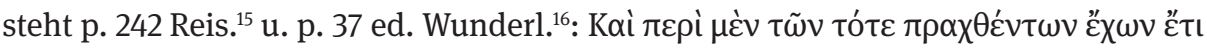

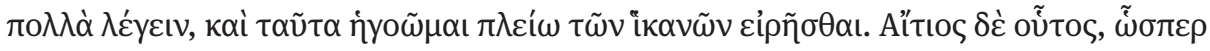

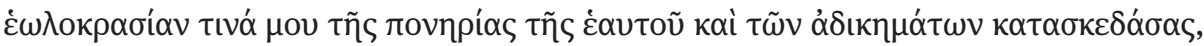

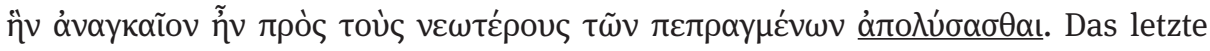
Wort giebt freilich einen recht guten angemeßenen Sinn, aber doch weniger zu dem

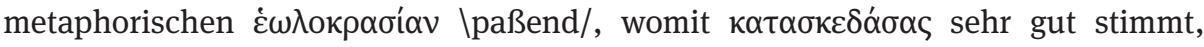

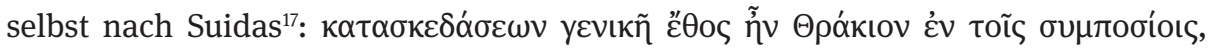




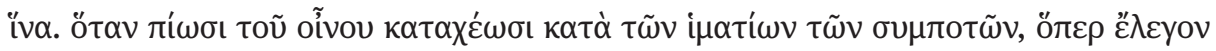

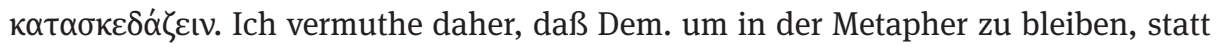

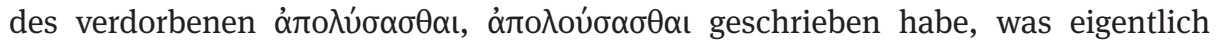
lavando se purgare a sordibus, hier aber in figural. Sinne, wie das lateinische purgare se, statt diluere, refutare, refellere criminationes gebraucht seyn würde. Der Sinn wäre freilich derselbe, aber der Ausdruck, wie mir scheint gewählter: Ad quod idem ille me provocavit, sua I ipsius nequitiae atque maleficiorum velut $\mathrm{f}(\mathrm{a})$ ecula me perfundens, de qua propter iuniores aetate purgare me necesse erat. Eine Authorität für

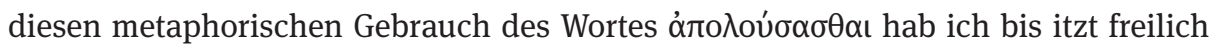
noch nicht auffinden können, aber er scheint so natürlich zu seyn, daß selbst der Mangel derselben an dieser Stelle der Gültigkeit der Vermuthung keinen Abbruch thun dürfte. Doch bescheide ich mich gern, wenn Sie anders denken sollten. -

Noch Eins hab ich seit lange hier auf dem Herzen. Das sind die Machtsprüche unsres sonst so trefflichen $\underline{\text { Hermanns }}^{18}$, denen es doch oft, genauer besehen, an gehöriger Haltung fehlt. So erinnere ich mich vor langer Zeit, ich weiß nicht mehr wo, die Bemerkung von ihm gelesen zu haben, daß kein ächter Lateiner iemals nec vor einem Vokal gebraucht habe - ein Ausspruch, der mich anfangs stutzig machte wegen des Ansehens seines Urhebers und des dictatorischen Tons mit dem er, wie gewöhnlich, vorgebracht wurde. Daß er aber ganz grundlos ist, kann fast iede Seite in Cic. u. Liv. beweisen, so daß ich's kaum begreife wie Hermann so etwas beifallen konnte. - Eine fast gleiche Bewandniß scheint es mir mit einer andern seiner lateinischen Sprachbemerkungen zu haben ad Viger. ${ }^{19}$ p. 795 (547) quum - tum usurpari (solommodo) ubi causa indicanda sit, qua fiat, ut id, de quo in altero membro tum dicitur, verum sit. Das Geschrobene des Ausdrucks, was man so häufig bei ihm wahrnimmt, abgerechnet, möchten, wie mir dünkt, viele Stellen bei den Alten der Allgemeinheit dieser Regel widersprechen. Mir sind, aliud agenti, nur folgende aufgestoßen, die ich Ihrer Beurtheilung vorlege: Liv. XXI ${ }^{20}$ 32. wo die neapolitanische Gesandte, dem Senat 40 goldene Pateren darbringend aequum censuisse aiunt, Neapolitanos, quod auri sibi quum ad templor<um > ornatum, tum ad subsidium fortunae a maioribus relictum foret, eo iuvare pop. Rom. Eben so an einer andern Stelle XXII. 60 nisi quis credere potest ... non invidere eos quum incolumitati tum gloriae illorum per virtutem partae. Ferner Cic. Philipp. 1. c. 2. talis animadversio fuit Dolabellae, quum in audaces sceleratosque servos, tum in impuros et nefarios liberos. Endlich, wenn Sueton auch als eine Auktorität gelten kann, in Jul. Caes. c. 3. Et Lepidi quidem societate ... abstinuit, quum ingenio eius diffisus, tum occasione, quam minorem opinione offenderet ; doch manum de tabula. - Mit Ungeduld erwarte ich die versprochene Fortsetzung Ihrer Reise nach Italien. Wie wird es mit dem zweiten Hefte werden? - Für die Dörptschen Beiträge bitte ${ }^{22}$ ich die hiesige Bibliothek als Subskribent einzuzeichnen $\mathrm{u}$. das erste Stück aus den in der Auction erstandenen Büchern gütigst beizulegen. Mit der ausgezeichnetesten Hochachtung Ihr ergebenster

Wilna den 6 Jul 1813.

Groddeck: 
${ }^{1} \mathrm{p} .44 \mathrm{~b}(\mathrm{~K}) .-{ }^{2}$ Friedrich Jacobs (1764-1847), Philologe aus Gotha, bedeutend durch seine kritischen Ausgaben vor allem griechischer Autoren. Zu seiner Bedeutung für Morgenstern s. Süss S. 72 und

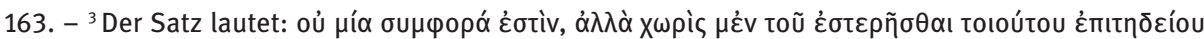

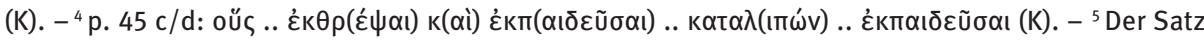

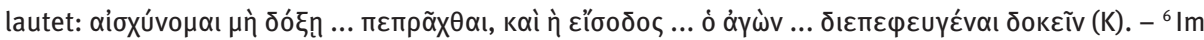

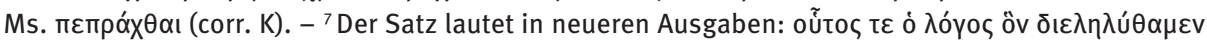

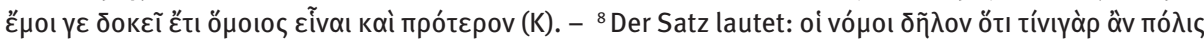

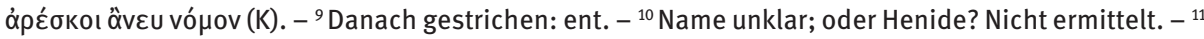
Friedrich Schleiermacher (1786-1834) hatte die Werke Platons übersetzt, Bd. I-V, Berlin 1804-1810.

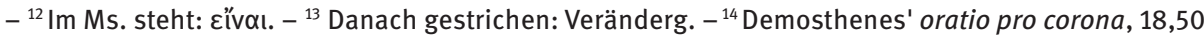
(K). - ${ }^{15}$ Johann Jakob Reiske (1716-1774), Gräzist in Leiden (1738) und Leipzig (1746). Die Edition des Demosthenes in seinen Die griechischen Redner, I-XII, Leipzig 1770-1775. - ${ }^{16}$ Ernst Karl Friedrich Wunderlich (1783-1816), Philologe, Lehrer. $-{ }^{17}$ Griechischer Grammatiker um 970 n. Chr. Verfasser eines Wort- und Sachlexikons, das viel kritisiert, aber durch Materialreichtum wertvoll war. ${ }^{18}$ Gottfried Hermann (1772-1848), nach F. A. Wolf bedeutendster Philologe und Philosoph (nach Kant und Reinhard) in Leipzig, Vertreter einer neuen Textkritik. Freund Goethes. ${ }^{19}$ Franciscus Vigerus, d.i. François Vigier, französischer Jesuit erste Hälfte 17. Jh. Von ihm erschien 1627 De praecipuis Graecae dictionis, das 1813 cum animadversionibus ... Godofredi Hermanni neu gedruckt wurde, zuletzt 1834. Groddeck hat jedoch eine frühere, fehlerfafte Auflage benutzt (K). - ${ }^{20}$ Muß heißen. XXII (K). - ${ }^{21} \mathrm{Im}$ Text zuerst unterstrichen, dann Unterstreichung getilgt. - ${ }^{22}$ Danach gestrichen: $d<i e>$.

15. Karl Morgenstern an Groddeck, am 14. 8.1813

an den Herren Hofrath und Professor Groddeck

in Wilna

Dorpat am 14. August 1813

${ }^{1}$ Hochwohlgeborner

Hochzuverehrender Herr Hofrath und

Professor.

Seit zwey Tagen von einer Ferienreise nach St. Petersburg zurückgekehrt, erhalte ich Ihren Brief vom 2. Jul. d. J. ${ }^{2}$ mit der zweiten Hälfte der AuctionsSchuld für die von unsrer Universitäts-Bibliothek erstandenen Doubletten. Ich habe also deren ganzen Betrag erhalten. Die überschießenden 2 Rl. 70. Kop. mag für die Kiste und Emballage, die ich gar nicht in Anschlag bringen wollte, gerechnet werden.

Messen Sie mir die Schuld der so lange verzögerten Übersendung der Bücherkiste ja nicht bey. Kurz vor meiner Abreise nach St. Petersburg schrieb ich an Herrn Ellinger $^{3}$ und fragte an: ob er die Besorgung derselben nach Wilna übernehmen wolle? Ich forderte ihn auf, seine Antwort an den Herrn Bibliothek-Kanzellisten, Gouv.Secr. Leibnitz zu adressiren, damit die Kiste I dann gleich abgesandt werde. Dieser Vorsicht ungeachtet ist aber Herrn Ellingers Antwort mit den übrigen in meiner Abwesenheit angekommenen Briefen auf der Post liegen geblieben und ich erhalte ihn erst jetzt. Herr Ellinger schreibt: 
„In ergebener Erwiederung Ew. Hochwohlgeb. geneigter Zuschrift vom 27ten Juny befaße ich mich gar nicht mehr mit Speditions Geschäften, und es thut mir daher leid, daß ich Ihnen nicht in Hinsicht der Beförderung der Kiste Bücher für den Herrn Hofrath Groddeck in Wilna nicht <!> gefällig werden kann. Hiesiger Herr Klein, welcher die Geldgeschäfte der Kaiserl. Universität betreibt, wird bey den Vortheilen welche er dabey hat, wohl auch gerne gegenseitig die Spedition für dieselbe übernehmen.“

Ich habe demnach mit heutiger Post an die Herren Zuckerbecker Klein \& Co. in dieser nämlichen Angelegenheit geschrieben und sobald ich deren bejahende Antwort erhalte melde ich sie Ihnen gleich und sende die Kiste ab. Es ist mir höchst unangenehm daß durch solche Weitläuftigkeiten der Transport Ihrer Bücher verzögert worden ist. Da unsre Universität in den I letzten Paar Jahren fast in gar keiner Verbindung mit den Rigischen Handelshäusern gestanden hat, wird es jetzt schwierig dieses wieder von Neuem anzuknüpfen, um so mehr da die Herren Kaufleute sich auf Besorgungen wie diese, die ihnen nur wenig Vortheil bringen, nicht gern einlaßen mögen.

${ }^{4}$ So weit aus der Bibl.Kanzelley, meinen officiellen Aufträgen zufolge. Für Ihren ausführlichen Brief vom 6. Jul. sage ich Ihnen, Verehrtester Hr. Hofrath, den verbindlichsten Dank. $\quad$ Erst seit ein paar Tagen von einer $\mathrm{B}<$... $>$ rätlichen ${ }^{5}$ Reise nach Reval und St. Petersburg zurück, bin ich noch von zu gehäuften Geschäften umlagert, und von ${ }^{6}$ alle Augenblick sich wiederholenden Unterbrechungen zu sehr gestört, um auf Ihren gehaltvollen Brief ordentl. antworten zu können. Ich behalte daher mir diese angenehme Unterhaltung vor. Vorläufig danke ich so wohl für Ihre interessanten Anmerkungen über meine kleine Symbb. crit. in Plat. Criton., als auch für Ihre scharfsinnige Conjectur zu Demosth. p. 602. - Die meinen Subscribenten zukommenden Exemplare des $3^{\underline{t}}$ Hefts der Reise in Italien, womit der $1^{\text {te }} \mathrm{Bd}$. (alle $2 \mathrm{Bg}$. stark) schließt, liegen in Ihrer Kiste. - Wegen des anderen Paquets ist wirkl. vom hiesigen Postamt $\backslash$ Nachforschung/ ${ }^{7}$ auf Requisiten \der/ hiesigen Universität geschehen, bis jetzt ohne weiteren Erfolg. Doch hoffen wir ${ }^{8}$ noch immer, da noch Vieles dieser Art ununtersucht von jener Zeit der Unordnung her liegen soll. Thun Sie von I Wilna aus \ auch/ Ihr Mögliches. Da ich beym $1^{\text {tn }}$ Bande über 18 Bogen mehr gab als ich ansprach, so sehn Sie (bey dem ohnehin nach Verhältniß jetziger Bücherpreise ${ }^{9}$ niedrig angesetzten Subsk. Preise) leicht meinen Schaden bey einer solchen Unternehmung in jetzigen Zeiten. Das 3te Heft hat wegen dieser noch gar nicht können nach Deutschland geschickt werden. An Geldri<... >sten ${ }^{10}$ wie dieser ist noch weniger zu denken. Dennoch $^{11}$ fängt der Druck des $1^{\underline{t}}$ Hfts des $2^{\text {ten }}$ Bands in Kurzem an. - Ich habe natürlich nur vollständige Exemplare, und ein einzelnes hier weggegeben ist für mich so gut als ein vollständiges weggegeben.

Ich will indeß vorläufig auf jeden Fall für Ihre Univ.Bibl. ein Ex. des $2^{\underline{t}}$ Hefts auf größerem Papier mit in die Kiste thun, damit Sie doch mein Werk bald im Zusammenhange übersehn können, soweit es heraus ist, auch vom $2^{2 \text { ten }}$ Heft (Florenz) that ich mir ein wenig zu Gute. Man hat doch keine solche \Reise/Schrift über Florenz, obwohl ich nur 3 Wochen dort war. 
In St. Petersb. besuchte mich Balin de Baller ${ }^{12}$. Er ist sehr frisch und munter für seine Jahre: ein lebhafter Alter. - Auf $\langle\ldots\rangle^{13}$ in der von Hn. v. Ouvaroff ${ }^{14}$ herausgegebenen Schrift: Des Nonnos Hymnen und Nikaea. St. Petersb. 1813 (Griech. und Deutsch von Prof. Gräfe ${ }^{15}$ mit gelehrten krit. und exeg. Anmerkg des Letzteren.) Da Gräfe sich sich gegen einen schlechten lat. Vers des Hn. Buhle in einer Eloge auf den Hn.v. Adelung erlaubt hatte, hat Buhle so eben geantwortet in einem <... ${ }^{16}$ gedruckten Bogen, den ich gestern aus Mitau erhielt, wo er gedruckt ist: „des Nonnos H. u Nik. Eine Beylage zu des Hn. Pr<of $>$. Gräfe deutscher metr. Übers. dieses Gedichts.“ $\mathrm{Er}^{17} \mathrm{r}<$. $>$ stirt $<$ ? $>^{18}$ darin manche Stelle in Gräfe's Bearbeitung zieml. pfars $<. .{ }^{18}$; nennt ihn übrigens den „Oberprosodiemeister“ in St.Petersb. - Doch ${ }^{19}<. . . .^{20}$ traf ich Ihren Hrn. Prof. Bojanus in Gesellschaft und trug ihm Grüße an Sie auf. Mit der größten Hochachtung Ihr ergebenster

$<$ Diener Morgenstern $>^{21}$

${ }^{22}$ Unser armes Danzig! - Wie viel mag der wackere Trendelenburg jetzt auszustehn haben!

\footnotetext{
${ }^{1}$ Von anderer Hand, Diktat. $-{ }^{2}$ Der Brief ist nicht bekannt. $-{ }^{3}$ Ellinger: Preußischer Konsul in Riga (?), vgl. Nr. 12 Anm. 2. $-{ }^{4}$ Von hier ab mit eigener Hand. $-{ }^{5}$ Wort nicht lesbar. $-{ }^{6}$ Danach gestrichen: zu sehr. - ${ }^{7}$ Über zwei gestrichenen Worten, nicht lesbar. $-{ }^{8}$ Danach gestrichen: und. $-{ }^{9}$ Danach gestrichen: zu. $-{ }^{10}$ Mitte und Ende des Wortes schwer lesbar. $-{ }^{11}$ Danach gestrichen: geht. $-{ }^{12}$ Ballin de Baller: nicht ermittelt. $-{ }^{13}$ Zwei Worte schwer lesbar: <...> Stichtag ? $-{ }^{14}$ Sergej Semjonovič Uvarov (1786-1855). War zunächst im diplomatischen Dienst, den er 1810 verließ. 1811 bis 1822 Kurator des Schulbezirks St. Petersburg. 1818 Präsident der Akademie der Wissenschaften. Hatte schon 1812 über die Eleusischen Mysterien publiziert. Bekannt mit den Brüdern Humboldt, Goethe, Herrmann. Die hier genannte Schrift wird sonst Gräfe allein zugeschrieben. Vgl. Süss S. 212. - ${ }^{15}$ Gräfe, in Rußland Fjodor Bogdanovič (1780-1851). Seit Gründung der Universität Petersburg Professor für Griechisch. Die deutsch geschriebene Abhandlung Des Nonnos Hymnos und Nikaea, Pbg. 1813, wird ausdrücklich als sein Werk genannt; s. auch Nr. 31 Anm. 1. Zu Gräfe und Uvarov vgl. Süss S. 249 Anm. 148. - ${ }^{16}$ Rest am linken Rande quer geschrieben. $-{ }^{17}$ Danach gestrichen: möchte. $-{ }^{18}$ Wort nicht lesbar. $-{ }^{19}$ Danach gestrichen: worauf. $-{ }^{20}$ Rest des Satzes nicht lesbar, z. T. unter Flecken. $-{ }^{21}$ Unterschrift in der unteren linken Ecke unter Flecken nicht lesbar. $-{ }^{22} \mathrm{Am}$ linken Rande der vorletzten Seite.
}

16. Groddeck an Karl Morgenstern, am 17. 8.1813

Wilna den 17 August 1813

Hochwohlgeborner

Hochzuverehrender Herr CollegienRath,

da der auf den 21 August angesetzte Termin der Bücherversteigerung des sel. Hofr. Pöschmanns in Dorpat heranrückt deren Verzeichniß mir vor ein paar Monaten vom Akademischen Gericht in Dorpat übersendet worden, und da ich aus eben diesem Verzeichniß ersehe daß Ew. Hochwohlgebor. die Mühe Aufträge dieserhalb anzunehmen die Gefälligkeit gehabt haben, so eile ich theils die Meinigen für die hiesige UBibl. 
theils einige für einen hiesigen iungen Gelehrten, für deßen Bezahlung ich gleichfalls mich verbürge, in beigeschloßenen beiden Zetteln Ihnen zu übersenden. ${ }^{2}$ Für die Universitätsaufträge hab ich freilich nur 70 R. Silber bestimmt, doch, wie sich's von selbst versteht, nicht à la rigeur.

Mit Ungeduld sehe ich einer gefälligen Antwort auf meine zu Anfang Juls an Ew. Hchwgb. abgelaßenen Briefe entgegen. Der erste vom $2^{\underline{t}} \mathrm{Jul}^{3}$ enthielt zugleich I hundert Rub. B.A., als den Rest meiner Schuld für die in der voriährigen BücherAuction erstandenen ${ }^{4}$ Bücher. (Die ersten 100 R. B. A. erhielten Ew. Hwgeboren im Maimonat dieses Jahres.) Über den richtigen Eingang beider $<$.>emeß $<$.. $>n^{5}$ hab ich aber noch keine sichere Nachricht erhalten. - Bald nach Absendung eben erwähnter beider Briefe erhielt ich ein Schreiben von Ihnen mit der Nachricht daß ${ }^{6}$ die Kiste mit den erstandenen Büchern mit ehesten von Dorpat \würde/ abgesendet werden und daß ich dieserhalb an den KPreuß. Consul in Riga mich zu wenden hätte. Ich that dieses unverzüglich, erhielt aber vom Hr. Ellinger zur Antwort, daß er sich mit diesem Auftrag nicht befaßen könnte. Wahrscheinlich ist diese Weigerung und der Mangel eines anderen Committenten in Riga die Ursache, daß die Bücher noch nicht haben abgeschickt werden können. Wenigstens habe ich noch nichts erhalten, und eile Ew. H. davon zu benachrichtigen. $\mathrm{Da}^{7}$ in der Kiste auch das $3^{\text {te }}$ Heft Ihrer Reise beigeschloßen seyn wird, und ich die 8 Exemplare des zweiten noch immer nicht bekommen habe, worüber ich (wenn Ew. Hwhlgb das fordern) einen officiellen Schein aus der hiesigen UKanzlei einzuliefern bereit bin, so seh' ich mich genöthigt, Sie dringend zu bitten, I sowohl der hiesigen Ubibliothek wegen, die unter den Pränumeranten sich befindet, als im Namen der übrigen Committenten, daß Sie uns die \baldige/ Nachlieferung der 8 Exemplare des zweiten Heftes nicht versagen, in der billigen Rücksicht daß wir an dem Nichtempfang derselben gänzlich unschuldig sind, und ein so schätzbares Werk dieser Art doch unmöglich defect besitzen können.

$\mathrm{Zu}$ meinem letzten Briefe, Hermanns Bemerkg über den Gebrauch von quum u. tum, \citate/ entkräftenden Beispielen hab ich seitdem eine ziemliche Nachlese gesammelt, die mich in meiner Meinung vollkommen bestärkt und mit der ich, sobald Sie mir die Ihrige werden mitgetheilt haben, aufzuwarten nicht ermangeln werde.

Ew. Hochwohlgeboren

hochachtungsvoll ergebener Diener Groddeck $^{8}$

\footnotetext{
${ }^{1}$ Adresse: Sr. Hochwohlgeboren I Herrn Collegienrath I und Professor I Morgenstern I auf der Kais. Universität I zu I Dorpat. - ${ }^{2}$ Die Zettel liegen nicht bei. - ${ }^{3}$ „der erste vom 2. Juli“ - nicht erhalten. Der nächste vom 6. Juli s.o. $-{ }^{4}$ Danach gestrichen: Hälfte. $-{ }^{5}$ Nicht lesbar. $-{ }^{6}$ Verbessert aus: Das. Danach gestrichen: das. $-{ }^{7}$ Danach gestrichen: ich. $-{ }^{8}$ Darunter von anderer Hand: Eingelangt d. 26 Augt 1813.
} 
17. Karl Morgenstern an Groddeck, am 29. 8.1813

Dorpat, 29 Aug 1813.

Hochwohlgeborner Herr Hofrath und Professor,

Meinen in den ersten Tagen dieses Monats Ihnen gesandten Brief werden Sie nun empfangen haben. ${ }^{1}$ Er muß Ihrem letzten vom 17. Aug. begegnet seyn. Diesen empfing ich d. 26. Aug. Die Pöschmannsche Bücherauction war an disem Tage schon so weit gediehen, daß alle Ihre Commissionen zu spät kamen, so daß ich weder für Sie noch für Ihren jungen Freund das Geringste habe erstehen können. Nur N ${ }^{\circ}$. 72 Feith Antiq< <uitates $>$ Hom $<$ ericae $><\ldots>^{2} 1743^{3}$ habe ich vom Ersteher zurück erhalten können und lasse es Ihrer Kiste so eben beypacken. Der Preis ist circa 2 SilbRbl. (Sollte es eine Kleinigkeit weniger seyn, so soll Ihnen dieß wenn auch deutlich \vom Auctionator zur Durchsicht $/{ }^{4}$ er<.. $>$ et ${ }^{5}$ (weil angezeigt und abgerechnet wurde: auf jeden Fall ist's eine unbedeutende Kleinigkeit.) Die Pöschmannsche Bibl. wurde im Ganzen recht theuer verkauft, so daß die Erben zufrieden seyn können. So eben ist noch die Auction der (kleinen) jurist. Bibl. von Joh. Möthe, wovon Sie den Katal. nicht erhalten haben, weil er nicht wichtig genug schien. I

Hiebey erfolgen beglaubigte $<. .>^{6}$ Empfang und Abgabe der 200 SlbRbl für die Doubl. Auction.

Ihre Bücherkiste geht (nach Versicherung des Altermanns der Fuhrleute allhier, Jäger) noch in dieser Woche von Dorpat ab: heute ist schon Freytag. Hr. Banas. <?> Klein in Riga (Zuckerbecker, Klein \& Co. in Riga, das bekannte große Haus) hat die Gefälligkeit gehabt, die Spedition Ihrer Kiste zu übernehmen. Sie zahlen in Wilna. So viel davon.

In der Kiste befinden sich die früher \von/ Ihnen wiederholt verlangten 5 Ex. der Commentt. de Plat. Republ. In Deutschl. ist der Ladenpreis 1Thr 8 grsch. $<\ldots .>^{6}$. Die hier befindl. Exemplare sind zu Lande hieher gekommen. Der Landtransp. beträgt im Durchschnitt jetzt 1/3 des Werths. Dennoch rechne ich nur 4 grsch. für jedes Ex., also nur 1/8 des Ladenpreises. So beträgt das Ex. 11/2 Silb.Rbl. Joder 1 Thlr 12 grsch.)/7, alle 5 aber 71/2 Silb.Rbl. - Von der Comment. crit. de Velleii Pater $<$ culi $>$ fide hist $<$ orica $>$ kann ich nichts senden, da sie vergriffen ist. Ebenso wenig von Quintilian. ${ }^{8}$, da der Buchhändler Grenzius (bey der Unordnung in seiner Officin) kein I Ex. mehr finden kann, obgl. er gewiß noch hat: er druckte die vorangeg<angenen> Bogen auf seine Kosten.

Von Ihren litt. Bemerkung. künftig. Für heute ist es bey vielen Geschäften und Zerstreuungen unmöglich.

In der Kiste liegen sämtl. \Subscr./Exemplare des $3^{\text {ten }}$ Hfts der Reise in Italien, neml. 7 auf ord. Pp. und 1 auf größerem, letztres für die U. bibl. $\quad-\quad$ S i e schrieben in Ihrem letzten Briefe ${ }^{9}$ : „Da ich die 8 Ex. des $2^{\text {ten }}$ noch immer nicht bekommen habe, worüber ich (wenn Ew. Hochgeb. es senden) einen officiellen Schein aus der hiesigen UKanzley einzureichen bereit bin, so sehe ich mich genöthigt Sie darum zu bitten, sowohl der hies. U.Bibl. wegen, die weiter der Pränumeranten sich befin- 
det, als im Namen der übrigen Committenten, daß Sie mir die baldige Nachsendung der ${ }^{10} 8$ Ex. des $2^{\text {ten }}$ Hfts nicht versagen, in der billigen Rücksicht, daß wir an dem Nichtempfangen derselben gänzlich unschuldig sind, und ein so schätzbares Werk dieser Art doch unmöglich defect besitzen können.“

Ich habe die Ehre hierauf zu erwidern: Es bedarf keines offic. Scheins Ihrer Leute. Wie sollte ich nicht Ihnen eben so sehr glauben als einem solchen Scheine? Ich verbitte $<. . .>^{6}$ einen solchen ausdrückl. - Daß ich einen Schein von richtiger Absendung von hier (\das/ am 7, Jul. 1813 geschah) sandte, war in der I Ordnung, da dieser Beweis mir oblag. Im Übrigen aber verzeihen Sie mir gütigst das Geständniß, daß ich in Ihrem und Ihrer Committenten Äußerung die Ihnen sonst so gewohnte Billigkeit vermisse. Bin ich denn nicht völlig eben so unschuldig ${ }^{11}$ am Nichtempfang des $2 \stackrel{\text { ten }}{ }$ Hefts? Ist's nicht eine calamitas publica, durch die die Subscribenten und resp. Pränumeranten (die bey Empfang des $3 \frac{\text { ten }}{}$ Hefts \contractmäßig/ zu entrichtende PreisHälfte habe ich übrigens noch nicht empfangen) \um/ jene 8 Ex. des $2^{\text {ten }}$ Heftes kamen? Ich habe auf allen Umschlägen der Hefte wiederholt drucken lassen, daß der Kanzl $<i s t>^{12}$ mit Spedition sich nicht befaßt. Aus achtungsvoller Rücksicht auf Ew Hchwgb habe ich eine Ausnahme gemacht: ich habe Ihnen, da Sie es so wünschten, die Ex. ohne Kosten für Sie und Ihre Committenten mit der Gelegenheit einer Absendung von Univers.-Schriften unsrer Univ. an die Ihrige /durch die Post/ in demselben Paquet gesandt. - Man könnte sagen, ich hätte den Preis darauf setzen sollen, damit im Nothfall die Post ihn wiße. Aber 1) hatte ich dazu keinen Auftrag $\mathrm{v}<\mathrm{on}>$ Ihnen 2) ist es bey \Druck/Sachen, die als publica gehen, nicht übrlich 3) hätte bey $\left\langle\right.$... $>^{6}$ Hefte der vollständige I Werth, den sie im ${ }^{13}$ unzertrennlichen Zusammenhange mit dem Ganzen haben, sich nicht wohl setzen lassen, auch hätte einen solchen die Post schwerl. bey Wiedererstattung anerkannt. Gleichwohl ist klar, da notorisch nur so viel Exemplare gedruckt sind, als vollständige des Ganzen ausmachen werden, daß der Defect eines Hefts ein ganzes Exemplar seines mer\kantilischen/ Preises und Werths völlig beraubt. Die Subscr. \ resp./ der Preis eines Ex. auf ord. Pp. ist 20 Rbl 13 Co., auf nicht größerm Pp. 24: also beträgt der Werth zusammen $\underline{164 \mathrm{Rbl} \mathrm{B}} \underline{\text { Co. }} \underline{\mathrm{A}}$. - Um diese würde ich (genau genommen)

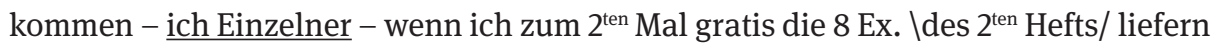
soll. Denn der \Kauf/Werth defecter Exemplare wird nicht viel mehr als Null seyn.

Ist nun wohl dieß billiger Weise vom Einzelnen zu verlangen; von dem Vf. zumal, der schon beym $1^{\text {ten }}$ Bande $161 / 2$ Bogen mehr geliefert hat (gegen gewöhnliche SiRbl) als wozu er sich anheischig gemacht?

Im schlimmsten Falle würde man die Sache der rechtlichen Entscheidung überlassen müssen. - Die Billigkeit scheint mir aber dafür zu sprechen, I daß beyde Theile den Schaden (woran der eine so unschuldig ist als der andere) theilen; d. i., daß wenn von mir das $2^{2^{114}}$ Heft noch einmal geliefert wird, ich die Hälfte der mir verloren gehenden $164 \mathrm{Rbl}$. von Ihren Committenten erhalte: d.i. 82 Rbl. $\mathrm{B}^{\mathrm{Co}}$. Zum Beweise, daß die einzelnen Hefte mir ganz unnütz sind, sollen dann statt \der 8 Ex./ des fehlenden $2^{\text {ten }}$ Heftes $\backslash 8$ Ex. ${ }^{15} \mathrm{des} /$ ganzen $^{15}$ Werks ${ }^{16}$ nach Wilna geliefert werden: versteht sich unbroschirt: denn broschirte Ex. mit den Umschlägen existiren weiter keine, als die ${ }^{17}$ 
den Subscr. resp. Prän<umeranden> schon verschickten. Damit aber Ihre Committenten mich nicht etwa durch mögliche Klage über die langsame Aufeinanderfolge der Hefte beunruhigen: so will ich, im Fall obiger Vorschlag angenommen wird, mit der Bezahlung jener 82 Rbl. B Co. oder der Hälfte des Subscr.-Preises fürs Ganze warten, bis der $2^{\underline{t}}$ Band oder die letzten 3 Hefte wirklich abgeschickt sind: worüber gewiß noch Jahr und Tag vergeht: bey der notorischen Langsamkeit der I einzigen hiesigen Druckerey etc. So würde dann Ihren Subscribenten, jedem einzelnen, das Ex. Ides

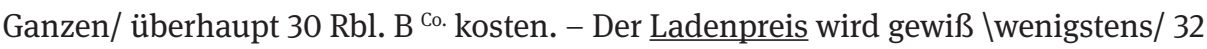
seyn, da der Ladenpreis des ersten schon $16 \mathrm{Rbl} \mathrm{B}{ }^{\text {Co. }}=4$ SilbRbl. ist.

Dixi.

Auf \jeden möglichen Fall $/{ }^{18}$ habe ich wenigstens (\zunächst/ für Ihren Gebrauch) in die Kiste ein $2^{\text {tes }}$ Exemplar des $2^{\text {ten }}$ Hefts auf großem Papier für Ihre Univ.=Bibl. beygelegt. Sie können dadurch am Besten sehen, lund Anderen berichten/ was ich bisher nach Kräften geleistet habe. - Die Sache ist keine Finanz.Speculation, wie in meinem Leben nie eine meiner litt. Unternehmungen war: ich werde zufrieden seyn, wenn ich keinen Schaden habe. Darauf zu sehn, aber ist doppelte Pflicht dessen, I auf/ dessen väterl. Vermögen so eben im Königr. Westphalen, der Zeitung nach (so Merkurs Zuschauer, № 832, 1 Aug. 1813) schon Sequester gelegt ist, weil er in Russ. K. Diensten steht, u.s.w. I

Mit der vollkommensten Hochachtung unverändert

Ew. Hochwohlgeborner

ergebenster Diener

Morgenstern

\footnotetext{
${ }^{1}$ Vielleicht Brief vom 14. 8. - ${ }^{2}$ Ein Wort (Ortsname?) nicht lesbar. $-{ }^{3}$ Everhardus Feith, Hellenist aus Geldern, Lebensdaten nicht bekannt. Lehrte Griechisch in Frankreich. Von ihm erschienen die Antiquitates Homericae in Leiden 1677. - ${ }^{4}$ Über einem gestrichenen unleserlichen Wort. $-{ }^{5}$ Ein Wort nicht lesbar. $-{ }^{6}$ Wort nicht lesbar. $-{ }^{7}$ Über dem Preis in Rubel geschrieben. $-{ }^{8}$ Das von Süss S. 129 genannte Programm von 1811 (K). $-{ }^{9} \mathrm{Vgl}$. vorigen Brief vom 17. 8. 1813. - ${ }^{10} \mathrm{Nach}$ gestrichenem: des. $-{ }^{11}$ Danach gestrichen: daran. $-{ }^{12}$ Oder: die Kanzlei. $-{ }^{13}$ Danach gestrichen: zum. $-{ }^{14}$ Verbessert aus: $1^{\mathrm{t}}$. $-{ }^{15-15}$ Verbessert aus: ein ganzes; danach gestrichen: Exemplar des. $-{ }^{16}$ Danach gestrichen: gelie〈fert>. $-{ }^{17}$ Danach verschmiert oder gestrichen: an. - ${ }^{18}$ Über drei gestrichenen nicht lesbaren Worten.
}

18. Karl Morgenstern an Groddeck, am 29. 9.1813

Dorpat, 29 Sept. 1813

Über alles Übrige mich auf meinen Brief vom 29 Aug. beziehend, habe ich die Ehre, Hochzuverehrender Herr Hofrath, anzuzeigen, daß ich außer Feith. Antiq<uitates> Hom<ericae>, welcher der von hier bereits abgegangenen Kiste der in der gleichen Doubl.-Auction für Sie erstandenen Bücher leinverleibt/ ${ }^{1}$ ist, Gelegenheit gefunden habe noch 3 der von Ihnen gewünschten Werke aus der Pöschmannschen Auction 
von dem Ersteher zurückzuerstehen, und selbige auf Ihren Namen schicken zu lassen, wie beygefügte Auctions-Nota à $34 \mathrm{Rbl} 60 \mathrm{Cop}$. $\mathrm{B}^{\mathrm{Co}}$ ts). (= 83/4 Silb.Rbl.) ausweist.

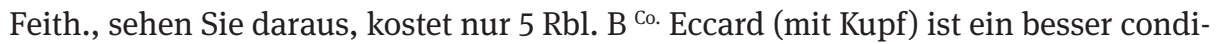
tionirtes Ex., als dasj. was unsre Un.Bibl. aus der Herderschen Auction besitzt. u.s.w. Wollen Sie nun diese Bücher zu den angef<orderten> Preisen: so belieben Sie es mir zu melden. So werde ich sie (doch ohne einiges Risico der Spedition zu übernehmen, als worauf ich mich niemals ${ }^{2}$ einlassen kann) dem eben fertigen lat. Lect.Katal., den unsre Univers. der Ihrigen \mit der Post/ schickt beypacken zu lassen Auftrag geben.

Mit unveränderlicher Hochachtung und Ergebenheit

Ew. Hochwohlgeb. ergebenster Diener Morgenstern.

${ }^{3}$ Sollten Sie, wider Erwarten, obige Bücher nun nicht /wollen/: so behalte ich sie selbst.

\footnotetext{
${ }^{1}$ Über gestrichenem: beygelegt. - ${ }^{2}$ Danach gestrichen: wieder. $-{ }^{3}$ Das Folgende am linken Rand geschrieben. $-{ }^{4}$ Auf gesondertem Blatt Anschrift: Sr. Hochwohlgeb. I Hn. Hofrath v. Groddeck I ord. Professor und Bibliothekar I der Kais. Univers. zu I Wilna
}

19. Groddeck an Karl Morgenstern, am 9.11.1813

Wilna den 9 November 1813

Ew. Hochwohlgeborenen zwei Briefe vom 29 August und 29 September $^{1}$ habe ich richtig erhalten, aber die mir gütigst zugesagte Sendung des in d. Dorpater Auction erstandenen $u$. übrigen Bücher und Schriften, so ungeduldig ich sie auch erwarte, sind mir noch bis diesen Augenblick nicht zu Händen gekommen. Ich eile daher Ew. Hochwohlgebor. davon Nachricht zu geben, aus Besorgniß, daß nicht etwa ein neuer Unstern auch über diese Sendung gewaltet hat, im Fall sie wirklich schon, wie ich aus Ihrem letzten Briefe schließen muß, von Dorpat abgegangen wäre. Eine ausführlichere Antwort auf die in Ihrem vorletzten Briefe enthaltenen Vorschläge in Rücksicht des verlohrenen 2 Hefts Ihrer Reise nach Italien behalte ich mir vor, sobald ich die Bücher erhalten habe. Inzwischen hab ich die Ehre Ihnen eine Kleinigkeit hier zu übersenden, die einer durch die fröhliche Siegesnachricht veran $\backslash$ laßten $/^{2}$ musikalischen Akademie die die Mitglieder der hiesigen Universität veranstaltete und bei welcher mehrere zusammen gedruckte Verse $u$. andre kleine Aufsätze einiger hiesiger Profeßoren unter die Anwesenden vertheilt wurden, ihren Ursprung verdankt. Daher kömmt die Pagination auf dem lateinischen Exemplar. Um der kleinen Schrift eine I ihres Inhalts wegen erforderliche Publicität zu verschaffen, entschloß ich mich, sie ins Deutsche zu übersetzen. Von beiden füg' ich nur Ein Exemplar für Ew. Hochwohlgebor. hinzu, um die Portokosten nicht zu vergrößern. Das berühmte Hic Marcellus erit $^{3}$ nebst der ganzen Vergilianischen Fiction schwebte mir vor und schien mir, so gewandt, wie ich's versucht habe, eine nicht unpaßende Anwendung auf ${ }^{4}$ unsern 
angebeteten von vielen Millionen Menschen mit Recht angebeteten Monarch<en> fähig zu seyn.

Mit wahrer Hochachtung u. unwandelbarer Ergebenheit

Ew. Hochwohlgeboren

gehorsamster Diener ${ }^{1}$ s. die beiden vorigen Briefe. $-{ }^{2}$ Über gestrichenem: ....stalteten. $-{ }^{3}$ s. Vergil, Aeneis VI 883: tu
Marcellus eris (K). $-{ }^{4}$ Danach gestrichen: den.

20. Groddeck an Karl Morgenstern, am 18.11.1813

Wilna den 18 November 1813

Hochwohlgeborener

Hochzuehrender Herr Collegienrath,

Hätte ich noch einige Tage gewartet ${ }^{1}$ mit meinem letzten Briefe an Ew. Hochwohlgeb. vom 9 November, so würde ich Ihnen statt meines Befremdens über das Ausbleiben des versprochenen Pack<et>s mit Büchern, die angenehme Nachricht von der glücklichen Ankunft derselben in Wilna haben mittheilen können. Wirklich erhielt ich sie vor acht Tagen, bezahlte die PortoGebühren an den hiesigen Kaufmann Schwarz mit 2 Rubeln und habe alles versprochene vollständig und wohl erhalten in der Kiste vorgefunden. Für das der hiesigen UBibliothek gütigst bestimmte und beigelegte zweite Exemplar des $2^{\underline{t}}$ Hefts Ihrer Reise sage ich Ihnen den verbindlichsten Dank, um so mehr; da die Lektüre desselben, mit der ich noch beschäftigt bin, mir sehr viele eben so angenehme als lehrreiche Augenblicke verschafft hat und noch verschaffen wird. Das in Ihrer Aufschrift ganz am Ende befindliche Wörtchen „,bis ietzt nicht in Wilna angekommen seyn

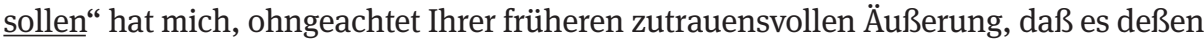
Ivon meiner Seite/ nicht bedürfe, gleichwohl bewogen, mir von der hiesigen Univers. Canzelei einen beglaubigten in Rußischer Sprache abgefaßten Schein ${ }^{2}$ ausfertigen \ $\mathrm{zu} /$ laßen daß das am 7 Junius vor. Jahres unter der Adreße der hiesigen Universität von Dorpat an mich \mit der Post/ an mich abgesendete Pack<et> in Wilna nicht angekommen und der Univ. von dem hiesigen Postammte nicht abgeliefert worden ist, auch nicht abgeliefert werden konnte, da notarisch den 16 Junius a. St. 1812 der I Feind in Wilna einrückte und das hiesige Postbureau schon am 13를 Junius auf erhaltene officielle Nachricht vom Übergange des Feindes über den Niemen geschloßen ${ }^{3}$ und von Wilna wegtransportirt wurde - die außer meinem, u. der UBibl. gehörigen, übrigen 6 Exemplare des 3 t Heftes Ihrer Reise habe ich, soweit die Umstände es zulaßen, unter die hiesigen Committenten vertheilt; denn zwei derselben, Hr CollR u. Ritter Tiefenbach und Hr. Kaufmann Heymann ${ }^{4}$ sind schon seit geraumer Zeit in Wilna nicht anwesend, sondern der erste in Kronsgeschäften in Bialystock, der zweite mit seiner Familie in Königsberg. Dieß ist auch die Ursache warum ich nicht mit allen Subskribenten über 
die von Ew. Hwhlgeb. gemachten Vorschläge in Hinsicht der Wiedererstattung des verlohrenen $2^{\underline{t}}$ Heftes gehörige Rücksprache nehmen kann. Was mich selbst betrifft, so erkläre ich Ihnen meine völlige Einstimmung. Von einigen meiner Committenten aber beauftragt halte ich mich verbunden, Ihnen einen Entwurf nicht zu verschweigen, den man gegen die \Billigkeit der/ Heilung des durch die öffentliche Calamität verursachten Schadens, von dem beide Theile für sich unschuldig sind; daraus hernimmt, daß der Feind, von dem Wilna mit allen seinen Einwohnern ohne Ausnahme soviel gelitten hat, Dorpat nicht besucht hat; daß folglich die ieder andern Rücksicht sonst billige Parität des Verlustes, in Rücksicht der viel größern Einbuße, die Wilna’s Ei<n>wohner eben dieser Calamität zuzuschreiben haben, eigentlich eine Imparität genannt werden müßte. Indeßen da Sie nicht auf die augenblickliche Nachzahlung bestehen, sondern sie bis zur völligen Beendigung des ganzen Werkes hinaus setzen, wo die geschlagenen Wunden schon größtentheils vernarbt seyn werden, so hoffe ich mit Recht, mit der Zeit alles zu Ihrer Zufriedenheit einleiten zu können. Was die rückständige Hälfte der Pränumeration für den zweiten Theil, die $20 \mathrm{u}$. einen halben Silberrubel beträgt, aber betrifft, so werden Sie die Güte haben, mir bis zu Ende dieses Jahrs Zeit zu laßen, um sie vollständig und zugleich mit dem Betrage der aus der letzten Dorpater Auction für meine Rechnung gütigst angekauften Bücher (Feith u. die übrigen drei) und den 71/2 SR. für die 5 Exemplare Ihres Werks De Platonis Republica, Ihnen zu übersenden. Die mir zugesandten Ex. Ihres Programms in Plat. Crit. für Hn. CgR. Frank u. CgR. Abicht hab ich unverzüglich beiden mir sehr werthen Collegen ausgehändigt. Beide empfehlen sich Ihnen dankbar. Sie wißen es wahrscheinlich nicht, daß der letzte (Abicht) der \im/ vorigen Jahre seine Frau durch einen plötzlichen Tod verlor, sich vor ein paar Monaten hier wieder und recht glücklich verheirathet hat. Sein Sohn, der Medicin auf der hiesigen U. studirt und schon die Klinik besucht, ist ein trefflicher Kopf und wird dem Vater einmal reine Freude machen. - Mit ausgezeichneter Hochachtung unwandelbar

der Ihrige Groddeck

${ }^{1}$ Danach gestrichen: ehe ich. $-{ }^{2}$ Danach gestrichen: habe. $-{ }^{3}$ Danach gestrichen: wurde. $-{ }^{4}$ Vielleicht Alexander Heymann, Vater des späteren Generals Vasilij, der in Grodno erzogen war.

21. Karl Morgenstern an Groddeck, am 2.1.1814

Dorpat, 2 Jan. 1814

P.P.

Auf Ihr letztes Schreiben vom $18^{\text {ten }}$ No erwiedere ich, daß es mir angenehm ist von Ew. Hochwohlgeb. zu erfahren, daß Sie die Bücherkiste empfangen haben.

Der beygelegte Schein Ihrer Univers.-Kanzelley ist in der That überflüssig. Das „bis jetzt nicht in Wilna angekommen seyn sollen“ ging natürlicherweise gar nicht auf ein Mitglied Ihrer Univers., am wenigsten auf Sie, sondern auf das abliefernde 
Postamt. Wie es aber auf Postämtern durch Nachlässigkeit von Unter-Offizianten zuweilen zu gehen pflegt, zumal in unruhigen Zeiten, weiß ja Jeder. Doch schon zu viel davon!

Dem Einwurf einiger Ihrer Committenten, daß Dorpat vom Feinde nicht gelitten habe, will ich, in Hinsicht auf Univers.-Mitglieder wenigstens nur entgegensetzen, daß die Herren Professoren, in Wilna nach wie vor in I Silb.Geld bezahlt werden, die Professoren in Dorpat aber durch den veränderten Cours des Papiergeldes im Vergleich mit Jvor mehr als/ 10 Jahren, wo sie (wie z. B. ich) angestellt wurden, auf 1/3 ihres Gehalts (nach dem Cours zum Auslande gerechnet) reducirt sind, was ohnehin schon Einige zum Abgange \in Geschäft. <?>/ bestimmt hat, z. B. jetzt Hr. Prof. Burdach ${ }^{1}$, der einen Ruf nach Königsberg annimmt; Hn. Pr. Kanzmann², der nach Riga gegangen ist, um dort als Chirurg und Arzt zu prakticiren. Auch Hr. Pr. Gundel ${ }^{2}$ hat Lust, zu seiner ehemal<igen> Apotheke nach Riga zurückzukehren. - Doch auch davon schon zu viel. Wer der Hn. Subscribenten in Wilna meine \sehr billigen/ Vorschläge nicht annehmen will, dem habe ich nichts - zu sagen, noch zu schicken. Dixi. Übrigens ist mir's allerdings lieber, wenn, wie Sie schreiben, Sie gelegentl. alles bey Allen zur Igegenseitigen/ Zufriedenheit einrichten ${ }^{3}$ und I beendigen. In der That aber könnte durch solche Weitläufigkeiten Mancher die Lust, Iwenn nicht/ zum Schreiben, ${ }^{4} \backslash$ doch zum $/{ }^{5}$ Drucken lassen, wohl vergehen.

Hiebey sende ich Ihnen Eichhorns ${ }^{6}$ Weltgesch<ichte> I. II. Theil, (2 Bd) Blumenbach $^{7}$ de gen. hum. variet. natio., und Eccard ${ }^{2}$ in $4^{\text {to }}$, aus der letzten Bücherauction. Die Erstehungspreise habe ich Ihnen schon gemeldet. Ferner sende ich Ihnen das Subscr. Ex. m<einer> Deutschen Beitr<äge> Jahrg. $18131^{\text {te }}$ Hälfte. (Egeb., wie alle Subscr. Exemplare) für die Wiln. Un. Bibl. Ebenso ein Ex. für Sie, das ich als Gegengeschenk gefälligst anzunehmen bitte.

Daß ich \über/ Ihre krit. Bemerk<ungen> über Plat. und Demosth. noch nichts Näheres gemeldet habe, halten Sie mir zu gut. Es wird aber zu seiner Zeit gewiß geschehen. Ich lege noch I die Anzeige der letzten Preisaufgaben von 12 Drr. bey.

Für Ihre lat. Dichtung auf Alexander meinen verbindlichsten Dank. Ich habe sie bereits auch mehreren Collegen mitzutheilen das Vergnügen gehabt.

Ich kann heute nichts weiter hinzu setzen, wenn dieser Brief noch mit dieser Post abgehen soll, als daß ich mit unwandelbarer Hochachtung bin der Ihrige

Morgenstern

\footnotetext{
${ }^{1}$ Karl Friedrich Burdach (1776-1847) aus Leipzig. Physiolog. 1811 Professor in Dorpat, 1814 in Königsberg. - ${ }^{2}$ Nicht nachgewiesen. $-{ }^{3}$ Danach gestrichen: zu. $-{ }^{4}$ Danach gestrichen: und. $-{ }^{5}$ Über gestrichenem: ab<er>. - ${ }^{6}$ Johann Gottfried Eichhorn (1752-1827) aus dem Hohenloheschen. 1775 Professor in Jena, 1778 in Göttingen. Gemeint wahrscheinlich seine Allgemeine Geschichte der Kultur und Litteratur des neueren Europa, Bd. 1-2, 1796, 1799. - ${ }^{7}$ Johann Friedrich Blumenbach (1752-1840) aus Gotha. 1776 in Göttingen Professor für Medizin. Berühmt als Magister Germaniae. Gemeint ist sein De generi humani varietate nativa, Göttingen 1775, 4. Aufl. 1795.
} 
22. Groddeck an Karl Morgenstern, am 5. 7.1814

Wilna den 5 Jul 1814

Hochwohlgeborener

Hochzuehrender Herr CollegienRath

Mit Beschämung muß ich Columella's Bemerkung unterschreiben: Verissime fertur dikisse Alphius Generator, vel optima nomina non appellando fieri mala. ${ }^{1}$ Doch könnte ich manches gültige zu meiner Entschuldigung vorbringen, wenn die Sache damit beßer gemacht würde. Indeßen Ihrer gütigen Nachsicht bisher mich erfreuend, hoffe ich sie mir auch für den gegenwärtigen Fall erbitten zu können, da ich nur erst ohngefähr die Hälfte meiner Schuld an Sie abtragen kann. Um dieses ins Licht zu setzen, wird folgende kleine Übersicht nothwendig seyn.

Ew. Hochwohlgebren haben von mir zu fodern

1. die $2^{\text {te }}$ Hälfte der Pränumerat. für die Reise nach Italien

7 Ex. auf gewöhnl. u. 1 Ex. auf größerm Papier ........

20 SR. 50 Kop.

2. den Subscriptionspreis für 1 Ex. der Dörpt. Beiträge .... .

3. für 5 Ex. Ihres Werks über Plato's Republik ........

$.7---$

$.7-50-$

4. für 4 in der Pöschmannschen Auktion im vorigen Jahre

in Dorpat für die Universitätsbib. erstandene Werke

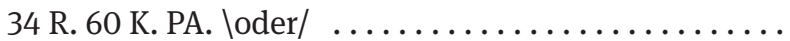

$.8-75-$

Welches zusammen beträgt $\ldots \ldots \ldots \ldots \ldots \ldots \ldots$

38 SR. $75-$ I

Von diesen 38 SR 75 Kop. habe ich die Ehre mit heutiger Post ${ }^{2}$ den unter Nr. 2.3.4. registrirten Betrag, der 18 RS. 25 Kop. ausmacht, zu übersenden, mit der Versicherung daß Nr. 1 oder die 2 $2^{\text {te }}$ Hälfte des Pränum. Geldes für Ihre Reise innerhalb 2 Monaten unfehlbar bei Ihnen einlaufen wird. Diesen kleinen Verzug werden Sie sich gütigst gefallen laßen in billiger Rücksicht auf meine obige Erklärung.

Zugleich mache ich mir ein Vergnügen Ew. Hochwohlgeb. eine literarische Kleinigkeit für Sie $\mathrm{u}$. für Hn. CR. Hetze zuzusenden, die gewiß manche Bemerkung bei Ihnen veranlaßen wird. Als vollständigen Schlüßel (außer dem was die kleine von mir verfaßte Vorrede enthält) muß ich erinnern daß da die Pluralität des URaths in dem auszuschreibenden Program $<\mathrm{m}>$ die Igründliche/ Kenntnis der hebräischen $\mathrm{u}$. griech. Sprache als unerläßliche Bedingung für den Concurrenten zur Exegetischen Professur festgesetzt hatte. Ein theologisches Mitglied des Raths u. Prof. Emeritus verzüglich (!) sich diesem Entschluß nicht nur in der Universität widersetzte, s<on $>$ dern auch an Sr. (!) Exc. den Minister d. Aufklärung sich unmittelbar mit seinen Klagen über den hebräischen u. griech. I Unfug sich wandte - worauf von Seite des Ministers, zu großem Befremden der Universität, die Weisung an die letzte erfolgte, das 
Program $<\mathrm{m}>$ in Rücksicht des exeget. Lehrstuhls nach der Meinung des besagten Profeßors abzuändern und die Bedingung wegzulaßen. Die Universität gehorchte wie natürlich und wie Sie aus beiliegendem Programm ersehen werden Facciolati's ${ }^{3}$ kräftige und ächt römische Rede aber ward vorgelesen, ${ }^{4}$ auf Befehl des UConseils gedruckt und nebst den übrigen Motionen zu den des erstern Beschluß, Sr. Exc. dem Minister überschickt.

Jetzt schmeichle ich mir mit der Hoffnung bald wieder mit einem Briefe von Ihnen erfreut zu werden,

Mit ausgezeichneter Hochachtung

Ihr

ergebenster Diener

Groddeck.

${ }^{1}$ Lucius Junius Moderatus Columella (1. Jh. n. Chr.), De re rustica I 7,2. Vgl. die zweite Epode von Horaz (K). - ${ }^{2}$ Danach gestrichen: die. $-{ }^{3}$ Jacopo Facciolati (1682-1769), seit 1704 Professor in Padua. Lexikograph. Lateinische Reden: drei Sammlungen 1723-1767. - ${ }^{4}$ Danach gestrichen: und.

\section{Karl Morgenstern an Groddeck, am 17. 7.1814}

An Hn Hofr. Prof. Dr. Groddeck

$$
\text { Hochwohlgeb Wilna }
$$

Dorpat, 17 Juli a. St.

1814

Hochwohlgeborner Herr HofRath

Gestern empfing ich Ihren werthen Brief nebst dem Gelde. Dank für beydes. Hiebey erfolgt die Quittung über die Zahlung der in der Pöschm<annschen> Auction erstandenen Bücher.

Ihre Zugabe zu Facciolati Or., so wie diese selbst, habe ich mit vielem Interesse gelesen und bin - erstaunt. Bey Ihnen dacht' ich wär' das anders. - Auch in dieser Hinsicht belieben Sie (was die Vernachlässigung des Lateins bei unsern Medicinern pp. anlangt) meine Jahreschronik von 1803 in $^{1} \backslash$ der/ $2^{\text {ten }}$ Hälfte der Dörptschen Beytr. genau zu lesen. Sie wird nächstens fertig, und Sie werden $\mathrm{Sie}^{2}$ dann erhalten. Über die $1^{\text {te }}$ haben Sie mir nicht geschrieben. Die Auszüge aus Ihrem Briefe sind Ihnen doch nicht unangenehm gewesen? Das Motto halte wenigstens ich, <...>, ${ }^{3} \mathrm{zu}$ öff <entlicher $>$ Mittheilung I sehr gut geeignet. - Auch die mir mitgetheilten philol. Bemerkk. über Plat. Criton und über die Stelle im Demosth. erhalten Sie nach nächster Antwort ${ }^{4}$. Hiebey sende ich Ihnen 2 Ex. meines Klopstock als vaterl. Dichter ${ }^{5}$, das 1 Ex. für Sie, das andere für die U.Bibl. Da Ihnen meine frühere Monographie über Kl. gefiel, so dürfte diese vielleicht noch mehr Interesse für Sie haben. Ich habe noch mehr Eigenes darin, und manches in Bezug auf unsre lieben Griechen. 
Mit der vollkommensten Hochachtung u. Ergebenheit

Ihr

gehorsamster Diener

Morgenstern.

In Eile, die Sie verzeihen

\begin{abstract}
${ }^{1}$ Verbessert aus: im. $-{ }^{2}$ im Ms.: Sie. $-{ }^{3}$ Zwei Worte schwer lesbar: für? mich? Unklar. $-{ }^{4}$ Über gestrichenem: Auskunft. $-{ }^{5}$ Klopstock als vaterländischer Dichter, Rede gehalten in der Universität Dorpat am 12. Dezember 1813, vgl. Süss S. $221 \mathrm{ff}$.
\end{abstract}

24. Groddeck an Karl Morgenstern, am 29. 7. 1814

Wilna 29 Juli 1814

Hochwohlgeborener Herr Collegien Rath,

Mit vielem Vergnügen hab ich vorgestern Ihren werthen Brief mit den literarischen Geschenken für mich $u$. die Ubibl. erhalten und sage Ihnen dafür den wärmsten Dank. Die Wahl des Gegenstandes zu Ihrer Rede war für den gegenwärtigen Zeitpunkt sehr glücklich, und der Inhalt selbst für mich sehr belehrend, da er nicht nur mannigfaltige angenehme Erinnerungen aus meiner früheren Lebensperiode auffrischte, sondern auch mehrere gehaltvolle Winke und Übersichten der neuern deutschen Litteratur darbietet ${ }^{1}$, die für mich, dem ihr seit 27 Jahren unter ${ }^{2}$ einem so ganz verschiedenen Volke beinahe entfremdeten, doppeltes Intereße haben. Doch hätte ich zu Note 55 manches auf dem Herzen, was nach meiner Ansicht sich zur Vertheidigung des von Ihnen gerügten Verfaßers, und deßen Aeußerung (mit Ausnahme Gessner's ${ }^{3}$, denn der wollte uns nur eine idealische Welt vorführen) ich völlig einverstanden zu seyn ${ }^{4}$ nicht leugne, vorbringen ließe - wenn | ein Brief dergleichen Ausführungen faßte. -

Dem $2^{\mathrm{t}}$ Hefte der Dörptischen Beiträge seh' ich mit vieler Ungeduld entgegen und mache bei dieser Gelegenheit einen Fehler gut den ich nicht absichtlich begangen habe. Ich glaubte Ew. Hwhlgebrn. schon in einem meiner früheren Briefe für das erste Stück, womit Sie sich selbst beschenkt haben, gedankt zu haben. Das allgemeine und lokale Intereße dieser Zeitschrift, der ich ein recht langes Leben wünsche, ist hier in eine $<\mathrm{m}>$ Bunde vereinigt. Meine Collegen, Frank u. Abicht, denen ich's mitgetheilt, sind derselben Meinung. Sehr zu wünschen wäre für unsre Univers. ein ähnliches Unternehmen; ich machte 1806 dazu einen Versuch mit einer in polnisch geschriebenen LiteraturZeitung ${ }^{5}$ die, wie die Göttinger, zugleich eine Annalistik der $U<$ niversität> war u. seyn sollte. Aber der bald darauf eintretende Krieg, die Unterbrechung aller Communication mit de $<\mathrm{m}>$ Auslande, die zu geringe Zahl der Subscribenten, der gänzliche Mangel an Unterstützung von Seiten d. Universität - bereiteten ${ }^{6}$ dem muthvoll begonnenen Unternehmen nach Jahresfrist eun unvermuthetes Ende. Ihrem Urtheile aber in Ansehung der eingerückten Brief-Fragmente darf man schon mit völliger 
Zuversicht trauen, bei welcher Gelegenheit ich es Ihnen nicht erst zu sagen brauche, daß die für mich höchst schmeichelhafte Berichtigung meiner Stelle in meinem Briefe die meine | Elemente betraf, keinen geringen Werth für mich hatte.

Beiliegend habe ich die Ehre Ihnen einige Exemplare einer lateinischen Flugschrift zu Lobe unsres Großen u. Guten Alexanders theils für Sie selbst theils zur Vertheilung unter Ihre dasigen Freunde zu zusenden. Es war mir Freude in Ihrem Klopstock manche auf den erhabenen Befreier Europas $u$. Deutschlands sich beziehende ähnliche Gedanken zu finden. Die Schrift selbst wurde durch die, wenigstens für den gegenwärtigen Augenblick, nun vereitelte Hoffnung, den angebeteten Monarchen in Wilna zu empfangen, veranlaßt und ist auf Kosten der U. gedruckt worden. ${ }^{7}$

Nun noch eine Bitte an Sie. Vielleicht besitzt Ihre Ubibliothek Gottleber's Ausgabe des Menexenus ${ }^{8}$. Die Mittheilung derselben auf ein paar Monate, wenn es anders nach den Gesetzen Ihrer U. möglich ist, wäre für \mich/ ein sehr wesentlicher Dienst, da ich gerade ietzt mit der ${ }^{9}$ Anfertigung eines für meine Zuhörer und die Lehrer d. gr. Spr. in den Kreisgymnasien berechneten Commentars dieses Dialogs, der hier unverzüglich gedruckt werden wird, beschäftigt bin. $\underline{\text { Heindorf }}^{10}$, soviel ich weiß, hat ihn noch nicht bearbeitet, denn in den 4 Theilen s. Plat. Dial., die die hiesige Ubibl. besitzt, finde ich ihn wenigstens nicht. Mit der ausgezeichnetesten Hochachtung $u$. Freundschaft

Ihr ergebener Diener Groddeck.

N.S. Für die Quittung \über/ die in der Auction erstandenen Bücher danke ich ergebenst. Eine ähnliche erbitte ich mir mit ehestem, in betreff der Dörptischen Beiträge für die hiesige Ubibliothek.

${ }^{1}$ Nach gestrichenem: enthält. $-{ }^{2}$ Über gestrichenem: in. $-{ }^{3}$ Salomon Geßner $(1730-1788)$ aus Zürich.
Idyllendichter. $-{ }^{4}$ Danach gestrichen: ich. $-{ }^{5}$ Die Gazeta literacka Wileńska, vgl. Elżbeta Aleksan-
drowska in: Dawni pisarze Polscy, Bd. I Warschau 2000, S. 375 a. $-{ }^{6}$ Nach gestrichenem: machten.
$-^{7}$ Lateinische Rede auf Kaiser Alexander in der polnischen Groddeck-Literatur nicht erwähnt; fehlt
auch im Schriftenverzeichnis von Wirth 1940, S. $162-167 .-{ }^{8}$ Johann Christoph Gottleber (1733-1785),
Ausgabe des Menexenos von Plato $1782 .{ }^{9}$ Nach gestrichenem: einer. $-{ }^{10}$ Ludwig Friedrich Heindorf
(1774-1816), Gymnasiallehrer, dann Professor in Berlin, 1811 in Breslau, 1816 in Halle, Platonis dialogi
selecti, Bd: I-IV; der Menexenos fehlt (K). $-{ }^{-11}$ Am linken Rande der vorherigen Seite quer geschrieben.

25. Karl Morgenstern an Groddeck, am 7. 9.1814

Hn Hofrath und Professor Groddeck

Hochwohlgeb.

in Wilna

Dorpat, 7 Sept. 1814

Hochwohlgeborner Herr Hofrath, 
Mit Vergnügen empfing ich Ihr Schreiben vom 29 Jul. und die beygelegte Schrift ad Somnium Scipionis. ${ }^{1}$ Ich habe die mir gütig mitgetheilten Ex. zweckmäßig zu vertheilen gesucht.

Heute erhalten Sie die $2^{\text {te }}$ Hälfte der Dörpt. Beyträge, sowohl ein SchenkeExemplar für Sie, als ein $<\mathrm{S}>$ der Subscr. Exemplare der Univers. Bibl. zu Wilna. - Auf den $2^{\text {ten }}$ Jahrgang 1814, wovon der $1^{\text {te }}$ Bogen so eben gedruckt wird, er $<\ldots>^{2}$ ich bereits Subscribenten an. Sollten nach Ansicht des $1{ }^{\text {ten }}$ Jahrgangs sich jetzt in Wilna nicht Subscribenten finden? Ich habe in Wilna außer Ihnen keinen Correspondenten. Wegen Plat. Menex. <?> ed. Gottleber lasse ich so eben auf der Univ. Bibl. nachsehen. Ist sie da, so \lasse ich Ihnen $/ 3$ solche zu Ihrem gemeinnützigen Zweck von da aus (Prof. Apel hat ihre Ausnahmen, galt wenigstens hier) ${ }^{4}$ noch mit heutiger Post zufertigen. Geht das nicht, so sollen Sie mein Ex., das ich jedoch freilich nicht wohl lange entbehren könnte, geliefert erhalten, welches ich dann mit nächstem sende.

Mit der vollkommensten Hochachtung

unveränderlich

Ihr

gehorsamster Diener

Morgenstern

${ }^{1}$ Ad somnium Sciponis monita, Wilna 1814, 2. Aufl. 1818. - ${ }^{2}$ Rest des Wortes nicht lesbar. $-{ }^{3}$ Über gestrichenem: erhalten Sie. $-{ }^{4}$ Danach gestrichen: Ihnen.

26. Groddeck an Karl Morgenstern, am 16. 3.1815

Hochwohlgeborener

Hochzuverehrender Herr Collegien Rath

Unverzeihlich würde mein beinahe halbjähriges Stillschweigen seyn, wenn nicht häusliche harte Unfälle, die mich wärend dieser Zeit trafen, nicht nur Ihren sonst gerechten Unwillen zu entwaffnen sondern selbst Ihre Misbilligung zu mildern im Stande wären. Seit August vorigen Jahres war ich mehr als 3monatlicher naher $u$. innig theilnehmender Zeuge eines schweren $u$. hartnäckigen Leidens ${ }^{1}$ der 28iährigen gefährtin meines Lebens, das aller angewandten Mittel der erfahrendsten Kunst und theilnehmendsten Freundschaft meines Franks u. noch eines hier berühmten Arztes ${ }^{2}$ Trotzbietend, in der Mitte /des/ Novembers ein für mich und meine beiden Kinder ein lange gefürchtetes trauriges Ende nahm - ein Verlust, deßen Bitterkeit auf meine kaum damals von Nervenfieber erst genesene älteste Tochter so heftig wirkte, daß ich lange mit einem neuen gleich peinlichen Verluste bedroht wurde. In dieser | Lage waren selbst meine Berufsgeschäfte oft eine, sonst nie gefühlte, Bürde für mich, um so mehr, da der Leidenden |vorzüglich/ meine Umgebung Linderung u. Erleichterung verschaffte. Mit Zutrauen darf ich's also von Ihnen, Mitfühlender Mann und geehrter 
Freund, hoffen, daß Sie's mir vergeben, wenn ich Ihnen erst heute für den ausgezeichneten Beweis Ihres Wohlwollens, den Sie mir durch die so bereitwillige Übersendung des Gottleb. Menexenos gegeben, aufs herzlichste danke; wenn ich erst heute die so lange schon versprochene zweite Hälfte d. Subskriptionspreises auf Ihre Reise in Italien in $\mathrm{Sb} \mathrm{Rbl}$ zu übersenden die Ehre habe. Die fehlenden $2 \mathrm{Rbl}$ werde ich zu den Portokosten verwenden.

Aber nicht nur verzeihen müßen Sie mir; ich will meine Schuld noch vergrößern, indem ich Sie um Ihre gütige Einwilligung ersuche, daß ich das mir geliehene Buch noch ein paar Monate bei mir behalten darf, denn erst dann hoffe ich die kleine litterarische Arbeit, die ich blos zu Bestem meiner Schüler übernommen und zur Hälfte schon ausgeführt habe, völlig endigen | zu können. Der Druck wird so erst im künftigen Monat s<einen> Anfang nehmen. Mitten unter diesen von allen Seiten mein blutendes Herz bestürmenden Bekümmernißen ward ich noch am Ausgang des vergangenen Jahres auf eine höchst unangenehme Weise genöthigt, zu einer litterarischen Fehde - das erste mal in meinem Leben - die Hand zu bieten und einen höchst unbequemen arroganten Angriff eines hiesigen Collegen $u$. damals Rectors d Universität ${ }^{3}$ kräftig aber ohne Unbescheidenheit abzuweisen. Diese kleine Schrift, an der ietzt in Petersburg gedruckt wird, werden Ew. Hochwohlgebor., sobald sie in meinen Händen ist, von mir erhalten.

Und nun sehe ich einer baldigen freundschaftlichen Antwort von Ew. Hochwohlgebor. entgegen mit der Versprechung meiner bleibenden ausgezeichneten Hochachtung und Ergebenheit Grodddeck

Wilna 16 März 1815

P. S. Beiliegend folgt ein Brief von unserm gemeinschaftlichen gelehrten Freunde Millin ${ }^{4}$ in Paris, den ich als Einschluß vor einer Woche $d<u r c>h$ einen bekannten Rußischen Officier, dem ich in \Augustmonat des/ vorigen Jahres | bei seiner Anwesenheit in Paris, anvertraut war, \hier in Wilna/ erhielt. Daher ${ }^{5}$ das wahrscheinliche Alter dieses Briefes, denn der Meinige war vom 16 August 1814. datiert.

${ }^{1}$ Danach gestrichen: meiner. $-{ }^{2}$ Danach gestrichen: zum. $-{ }^{3}$ Danach gestrichen: abzu-. $-{ }^{4}$ Aubin Louis Millin (1759-1818), Konservator des Pariser Antiken-Kabinetts. Hrg. des Magasin Encyclopédique ou Journal des Sciences, des Lettres et des Arts, Paris 1795-1816, 122 Bände. Seine Briefe an Groddeck hier 2. Abteilung. $-{ }^{5}$ Danach gestrichen: daß.

27. Karl Morgenstern an Groddeck, am 16. 4.1815

Dorpat, 4/16 Apr. 1815

Hochwohlgeborner Herr Hofrath,

Bald nach Absendung meiner letzten Zeilen ${ }^{1}$, mit welchen Sie außer dem Lat. Lectt.Katalog vom 1. Febr., dem ich einige Worte vorgesetzt habe, 1 Ex. meiner Dörpt. Bey- 


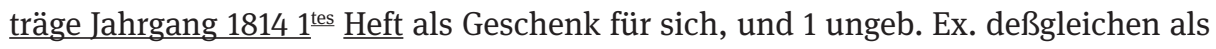
Subscr. Ex. für Ihre Univers.-Bibliothek erhielten, empfing ich Ihr geehrtes Schreiben vom 16. März ${ }^{2}$ mit einliegendem $<. . .>^{3}$. Ich danke für beydes.

Den traurigen Verlust Ihrer Gattin sowie übriges häusliches Leiden bedaure ich von Herzen. Mögen Sie jetzt sich einigermaßen beruhigt fühlen! Hoffentl. ist Ihre Tochter nun wieder ganz genesen, und erleichtert Ihr Schicksal durch Mitgefühl.

Die Übersendung von Platon Menexen. ed. Gottleber, ist eine Kleinigkeit, die kaum erwähnt zu werden verdient. Brauchen Sie das Buch zu Ihrem gemeinnützigen Zwecke nach Bequemlichkeit. Ich habe, als ich es von hiesiger Univ. Bibl. für Sie sandte, im Bibl. Archiv ausdrückl. bemerkt, an wen, und weshalb es gesandt ist, so daß einige Zögerung der Zurückgabe, die Sie, wenn ich nicht wäre, directe an die Univers.-Bibl. zu machen hätten, gar nicht anschlägt, \zumal/ da das Buch nicht über einen halben Silberrubel kosten wird. Überdieß ${ }^{4}$ befindet sich in einer Privatbibl. in Dp. (Sie erraten leicht, in welcher) noch ein Exemplar; so daß die erzeigte Gefälligkeit also eigentl. gar keine ist. I Für Übersendung des neuen von unserm gemeinschaftlichen Freunde Millin in Paris geschriebenen Buchs ${ }^{5}$ bin ich Ihnen sehr verbunden. Es enthielt Antwort auf einige ${ }^{6}$ mit kleinen literarischen Gedanken von mir an ihn durch einen kriegsgefangenen nach Frankreich zurück gekehrten General gesandten Zeilen.

Dagegen habe ich Ihnen aus einem Briefe Martyni Laguna ${ }^{7}$ an mich, dat. Zwickau 31. Aug. 1814 folgendes zu melden: „Ich sehe aus den Dörpt. Beytr., daß Sie mit Groddeck zu W. bekannt sind. Wäre dies keine Möglichkeit, seinen dort erwähnten Elementa hist. Gr. litt. etwa durch Sendung an Kummer in Leipzig hieher zu bekommen? Ich würde mir ein großes Vergnügen daraus machen, eine ausführliche Rezension davon in die Marburg. Theol. Annalen ${ }^{9}$ zu geben, da so selten aus jenen Gegenden Etwas hier vorkommt. Auch beschäftigt mich der neue krit. Ratgeb<e $>$ r des herrl. Dichters Sarbiewski ${ }^{10}$. Vielleicht hilft Hr. Groddeck sie auch in Polen verbreiten. Denn die höfischen Polen, die ich in Dresden kennen lernte, haben keinen Sinn dafür. $<$... $>^{11}$ liegt noch in der Bibliothek in Wilna Sarbiewski's (ungedruckte oder gedruckte?) Abhandlung de Acuto et Arguto ${ }^{12}$, die er zu seiner Zeit dem Petavius ${ }^{13}$ nach Paris zur Beurtheilung schickte. Könnte mir doch Hr. Groddeck entweder ein gedrucktes Exemplar oder $\langle\ldots\rangle^{14}$ Abschrift eines derselben verschaffen. Meine Ausgabe wird auch sonst durch manches seltene Buch das in der gewöhnlichen Ausgabe fehlt, bereichert seyn. Es würde mich unendl. freuen, wenn Hr. Gr. auch I ungedruckte Sachen von Belang, prosaische oder poetische v. Sarbiewski dort für meine Ausgabe auftriebe. Sollte es $\mathrm{ihm}^{15}$ gefallen, mich mit litterarischen Producten, auch in polnischer Sprache, für die Annalen zuweilen zu versehen, so rechne er auf meine aufrichtige Dankbarkeit.

Noch lege ich die Ankündigung meiner Briefe über Reinhard ${ }^{16}$ für Hrn Gr. bey.“

Haec ille. Thun Sie nun für den wackren Mann, was Sie können. Subscribenten für seine Briefe über Reinhard sind in hiesiger Gegend durch mich $u$ durch einen Probst auf dem Lande zusammengebracht. Ich kann nun weiter nichts hierin für ihn thun. Auch bitte ich Sie ausdrückl., wenn Sie ihm antworten oder ihm etwas Litterarisches schicken wollen, es directe zu thun. Denn ich erliege oft schon solchen 
Zerstreuungen, die der Gutwilligkeit des Dienstfertigen nicht selten auf Kosten des darüber liegend bleibenden Wesentlichern, Nothwendigen, von so manchen Seiten zugemuthet werden.

Hn. M<artynus> $\mathrm{E}<$ aguna > schätze ich, ohne ihn persönl. zu kennen, als Gelehrten sehr hoch; habe mich auch einst vor Jahren für sein Kommen nach R. verwandt, zuweilen aber späterhin besorgt, daß vieles Leiden ihm eine hypochondrische Stimmung gegeben, die ihm schwerl. irgendwo völlige Zufriedenheit vergönnen ${ }^{17}$ möchte.

Mit unveränderlicher Hochachtung und Ergebenheit

der Ihrige Morgenstern.

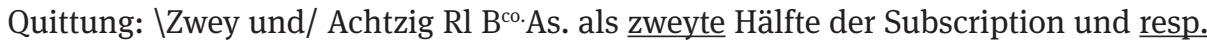
Pränumeration auf meine Reise in Italien, acht Exemplare (das eine für die Univ. Bibl. ist auf größerm Papier) empfangen zu haben bescheinige ich. Der erste Band in 8 Ex. ist längst abgeliefert. Die Hefte des zweyten werden geliefert, sobald sie erscheinen. Dorpat, 4 April 1815. Morgenstern, Coll.Rath und Professor

\footnotetext{
${ }^{1}$ Nicht erhalten. $-{ }^{2}$ s. vorigen Brief. $-{ }^{3}$ Drei Worte nicht lesbar. $-{ }^{4}$ Danach gestrichen: ist. $-{ }^{5}$ Millins neues Buch: vielleicht Gallerie mythologique, Bd. I-II, Paris 1811. $-{ }^{6}$ Danach gestrichen: ihm. $-^{7}$ Johann Aloys Martyni-Laguna (1755-1824), Schulrektor in Zwickau, schrieb vor allem über Cicero (K). $-{ }^{8}$ Paul Gotthelf Kummer (1750-1835) aus Grimma, Verlagsbuchhändler in Leipzig; bei inm wurden die Dörptischen Beyträge gedruckt. - ${ }^{9}$ Gemeint wohl die Annalen der theologischen Literatur und Kirchengeschichte, begründet in Marburg 1789 von dem Orientalisten Johann Matthäus Hassencamp (1743-1797), der in Marburg und Göttingen studiert hatte; fortgesetzt 1793 bis 1823 als Neue Theologische Annalen von Johann Ludwig Friedrich Wachler (1767-1838). $-{ }^{10}$ Matthias Kazimierz Sarbiewski (1595-1640). Ausbildung am Jesuiten-Collegium in Puttusk, Polock, Wilna, 1622-1624 in Rom. Danach Theologe in Polock und Wilna. In Frage kommen seine kritischen Studien: Characteres lyrici seu Homerus et Pindarus, vor 1626, kritische Ausgabe von S. Skimina 1958; De virtutibus et vitiis carminis elegiaci, seu Ovidius, vor 1626, kritische Ausgabe von S. Skimina 1958; De perfecta poesi, sive Vergilius et Homerus, 1626, Ausgabe von S. Skimina, Breslau 1954; Auswahl in: Teoretycy, historiografowie i artyści 1600-1700, Hrg. von J. Białostocki, Warschau 1994. - ${ }^{11}$ Ein Wort nicht lesbar. $-{ }^{12}$ Wahrscheinlich De acuto arguto liber unicus, sive Seneca et Martialis, Polock 1626/7, kritische Ausgabe von S. Skimina Breslau 1958. - ${ }^{13}$ Dionysius Petavius, d.i. Denis Petau (1583-1652), französischer Jesuit und Theologe. $-{ }^{14}$ Ein Wort nicht lesbar. $-{ }^{15}$ Danach gestrichen: gefällig seyn. $-{ }^{16}$ Wohl Franz Volkmar Reinhard (1753-1812), seit 1778 in Wittenberg, 1780 Professor. Berühmter Prediger, Ausgabe Sulzbach 1793-1813 in 35 Bänden. $-{ }^{17}$ Über gestrichenem: gewähren.
}

28. Groddeck an Karl Morgenstern, am 30.5.1815

Wilna den 30 $0_{\text {ten }}$ Mai 1815

Hochwohlgeborener Herr CollegienRath,

Für Ihren gütigen Brief vom 4 April $u$. die bald nachher zugleich mit dem Auctionskatal. erhaltene Dörptsche Beiträge ${ }^{1}$ - ein mir höchst werthes Geschenk - sage ich Ihnen den verbindlichsten Dank. Es bedurfte ${ }^{2}$ der kritischen Kleinigkeit zu Dem. um in diesem an intereßantesten Aufsätzen so reichen Hefte ein unbedeutendes Blatt zu 
füllen. Hätt’ ich indeßen vermuthen können, daß Ew. Hochwohlgebor. schmeichelhaftes Urtheil ihr diesen recht ehrenvollen Platz anweisen würden, so hätte ich nicht angestanden, Ihnen folgende am Rande meines \noch/ handschriftl. Commentars zu der Demosthenischen Rede später nachgetragenen Note mitzutheilen: nunc malim

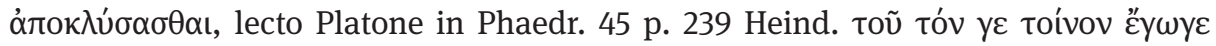

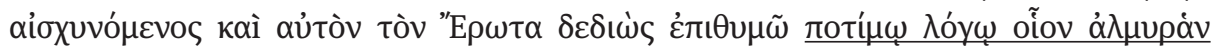
$\underline{\alpha} \pi$ ок $\lambda \dot{\sigma} \sigma \alpha \sigma \theta \alpha \mathrm{l}, \mathrm{zu}$ welcher Stelle ich die von Heindorf l.c. citirte Stelle von Wyttenb. Ep. Ep. crit. p. $55^{3}$ nachzusehen wünschte. - Gern hätte ich diesem Briefe die Pränumeration für den $2^{\text {ten }}$ Jahrg. d. D. b. im Namen der hiesi. Bibliothek beigelegt, aber da ich nicht ganz sicher weiß, ob der für d. $1^{\text {ten }}$ Jahrgang bestimmte Preiß von 2 SRubeln nicht für die folgenden Jahrgänge erhöht worden, so erwarte ich darüber noch Ihre gefällige Mittheilung. - In betreff des würdigen Łaguna hab ich mit meinem I Verleger Zawadski ${ }^{4}$ gesprochen. Er hat mir die Hoffnung gemacht es möglich zu machen daß ein Exemplar der Elementa Hist. Gr. litt. an Kummer in Leipzig geschickt werde. Übrigens beschäftige ich mich mit e. neuen $u$. sehr vermehrten auch hie $u$. da bedeutend veränderten Ausgabe dieses kleinen Handbuchs. Was Sarbiewski's Anecdota ${ }^{5}$, mit deren Sammlung dieser gründliche $u$. geschmackvolle Gelehrte sich beschäftigt, betrifft, so fand sich auf der hiesigen Bibliothek nichts vor. Mir selbst aber hat vor einigen Jahren ein damals sich hier aufhaltender Freund der polnischen Literatur ein paar kleine und dicht \in gespaltenen Columnen/ beschriebene Quartbogen mit lateinischen Gedichten Sarb., die noch nicht gedruckt seyn sollen, geschenkt, die ich, wenn ich nur eine sichere Gelegenheit wüßte, Hn. Łaguna gern zukommen lassen möchte. Sie enthalten 1) Sylvitudea Reverendi $<. . .>^{6}$ Matthiae Sarbiewskii Soc $<$ ieta $>$ tis Jesu 10 Nummern 2) Ad Sylvestrum Petra Santaei S.J. cum Illustre ac eruditum De Symbolis, Annulis, Numismatis, Sygillis etc. Opus in necesse adidisset. 3) De clade Svetica (sic) ad Pultavam anno 1709. 4) Epistola RP. Casimiri Sarbiewski SJ De Itinere Romano unterschrieben Romae 15 Novembris 1622 Suae Charitatis in Kto Servus Matthias Sarbiewski SJ. 5) Triumphale Epinikion B. Josaphat Martyri cum tranquillato bello Moschovitico corpus Ejus Vilnam inferretur. Ad illustriss. Rdum Gabrielem Kolęda Metropolit. Rossiae 6) Oda De B. Stanislao Kostka 7 . 7) Propempticon S. Ber-

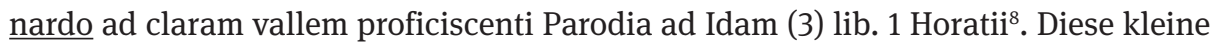
Handschrift so aufs Gerathewohl aus d. Händen zu laßen, wäre wohl nicht rathsam und eine Copie davon zu machen wäre auch sehr schwer I da die äußerst kleine und mit Abbreviaturen reichlich ${ }^{9}$ angefüllten Schrift einen sehr geschulten Copisten, der hier schwer zu finden seyn würde, erfordert, meine Zeit aber zu beschränkt ist, um mich damit zu befaßen.

Beiliegend hab ich die Ehre Ew. Hochwohlg. ein paar literarische Kleinigkeiten zu übersenden ein polemischer Aufsatz über dessen Veranlaßung ich mich schon in einem früheren Briefe Ihnen erklärt zu haben \mich/ erinnere $u$. eine Doctordissertation eines meiner Schüler, die ich nur der Seltenheit wegen aus hiesigen Gegenden, im antiquarischen Fach, beilege. Sie enthält einen kurzen Auszug seiner polnisch geschriebenen Abhandlung ${ }^{10} \mathrm{u}$. zeigt wenigstens gute Anlage, Fleiß u. eine schöne 
Belesenheit besonders, was hier sehr selten ist, in deutscher Literatur. Auch ist der Verf. ein so guter trefflicher iunger Mann, daß er schon umdeswillen alle Nachsicht $u$. Auf $<$ m $>$ unterung verdient.

Mit wahrer Hochachtung unwandelbar

Ew. Hochwohlgebor.

ergebenster Groddeck

\begin{abstract}
${ }^{1}$ Danach gestrichen: sage ich. $-{ }^{2}$ Über einem gestrichenen unlesbaren Wort. $-{ }^{3}$ Daniel Alb. Wyttenbach (1746-1820), 1771 Professor der griechischen Sprache in Amsterdam, 1779 der Philosophie ebd., 1799 Nachfolger von Runkenius in Leiden. Gemeint vielleicht seine Epistula critica super nonnullis locis Juliani ad D. Ruhnkenium, Göttingen 1769. (K). - ${ }^{4}$ Josef Zawadski (1778-1838) aus dem Posenschen, seit 1803 in Wilna als erfolgreicher Buchdrucker und Verleger. $-{ }^{5}$ So nicht nachgewiesen. Vielleicht (s. das folgende „mit lat. Gedichten“) Lyricorum libri IV, Leyden 1631, das aber unsicher ist; kein Exemplar nachgewiesen; s. T. Witczak in Dawni pisarze Polscy Bd. IV 2003, S. 14 a, Position 14. - ${ }^{6}$ Eine Abkürzung nicht lesbar. $-{ }^{7}$ Stanisław Kostka († 1587), Unterkämmerer des Bezirks Chetm. $-{ }^{8}$ Horaz Oden I 3 beginnt als Geleitgedicht (Propemptikon) für Vergil, der eine Seereise begann (K). ${ }^{9}$ Danach gestrichen: erf<üllten>. $-{ }^{10} \mathrm{Nicht} \mathrm{nachgewiesen.}$
\end{abstract}

29. Karl Morgenstern an Groddeck, undatiert, wohl 1815

Hn Hofr. und Prof. Dr. v. Groddeck in Wilna

Ew. Hochwohlgeboren

empfangen hiebey $<\ldots\rangle^{1}$ Ex. vom Lat. Lectt.

Katalog für die Univers. und für sich zugl.

1 broschirtes Ex. der Dörpter Beytr. 2ten Jahrgs 1ten Hefts und

1 ungeb. Ex. für die Univ.Bibl. als Subscr. Ex., wogegen ich (für den ganzen Jahrgg) ${ }^{2}$ Ihre letzten 10 Rbl Betrag erhalten.

Ihre treffliche Emendation im Demosth. ${ }^{3}$, welche ich billigen muß, finden Sie abgedruckt. Sie gereicht dem Blatte zur Zierde.

Mit aufrichtiger Verehrung

Ew. Hochwohlgeb.

gehors. Diener

Morgenstern

${ }^{4}$ Unser Senator Trendelenburg ist jetzt Präses der Schulcommission in Danzig.

${ }^{1}$ Ein Wort nicht lesbar. - ${ }^{2}$ Schlußklammer fehlt im Text. $-{ }^{3}$ Die Emendation ist abgedruckt in den Dörptischen Beyträgen. $-{ }^{4} \mathrm{Am}$ linken Rand quer geschrieben. 
30. Karl Morgenstern an Groddeck, am 22.11. 1815

Dorpat, 22 Nov. 1815

Hiebey, Verehrtester Herr und Freund, meine Symbolae criticae ad Platonis Politicam ab Astio ${ }^{1}$ denuo editam. ${ }^{2}$ Es wird mich freuen, wenn Sie dieselben Ihrer Prüfung würdigen und mir darüber schreiben. Sie wissen selbst, wie klein die Zahl derjenigen in unsrer Nähe ist, die an dergl. einigen Antheil nehmen.

Für die Observ. sur une Disput. ${ }^{3}$ danke ich Ihnen. Auch ohne die Schrift selbst, die hier kritisirt wird, und die Widerlegung dieser Observ. durch Hn. S. ${ }^{4}$ gelesen zu haben darf ich wol der Meinung seyn, daß Sie mit siegreichen Gründen bewiesen haben, was Sie beweisen wollten. Über die poln. Übers. einer Stelle aus Soph. Electr. kann ich, das Polnische nicht verstehend, zwar nicht urtheilen. Doch scheint mir schon aus dem weiter Gesagten | Daß Sie auch hier ganz Recht haben.

Die Schrift eines Ihrer Schüler de ingenio antiquitatis habe ich mit Vergnügen gelesen, und danke für Mittheilung derselben.

Zugleich erhalten Sie hiebey zwey Bogen von mir: Grundriß einer Einleitung zur Ästhetik p. Auch diese wage ich Ihrer Prüfung zu empfehlen.

Man erwartet hier in kurzem die Durchreise des Kaisers, der eben in Riga soll angelangt seyn, wenigstens so eben daselbst erwartet wurde.

Mit unveränderlicher größter Hochachtung du Ergebenheit der Ihrige

Morgenstern

${ }^{5}$ Von den Dörpt. Beytr. wird die $2^{\text {te }}$ Hälfte des $2^{\underline{\text { ten }}}$ Jahrgangs gegen Jahresschluß die Presse verlassen. 8 Bogen sind schon gedruckt.

\footnotetext{
${ }^{1}$ Georg Anton Friedrich Ast (1776-1841) aus Gotha. Philologe und Philosoph. 1805 Professor für Philologie in Landshut, mit der Universität 1826 in München. Vor allem Platonforscher, dessen Werke er 1819-1832 in elf Bänden mit lateinischer Übersetzung herausgab. Sein Handbuch der Ästhetik war in Leipzig 1805 erschienen. $-{ }^{2}$ Das Dorpater Universitätsprogramm von 1815, vgl. Süss S. 129. Asts Ausgabe der Politeia war 1814 erschienen (K). $-{ }^{3}$ Genau: Observations sur une dissertation présentée au concours pour la Chaire d'Eloquence de l'Université Impériale de Vilna, Wilna 1815; vgl. Wirth S. $165 .-{ }^{4} \mathrm{Hr}$. S.: nicht ermittelt. $-{ }^{5}$ Rest am linken Rande quer geschrieben.
}

\section{Karl Morgenstern an Groddeck, am 18.1.1816}

Dorpat, 18. Jan 1816

Hier, verehrtester Herr Hofrath, erhalten Sie die $2^{\text {te }}$ Hälfte der Dörpt. Bedyträge II Jahrg. Für den schätzbaren Beytrag danke ich Ihnen.

Der Preis der Dörptschen Beytr. 2 ${ }^{\mathrm{r}}$ Jahrg. ist für die Subscribenten 21/2 SR. oder 10 Rbl Bes. Ass. Diß zur Beantwortung Ihrer neulichen Anfrage wegen des Subscr. Ex. Ihrer Univers. Bibl. 
Heute bekam ich aus Ptbg: Epistola critica ad Bucolicos Enaeos ad V. Illustriss. Sergium Ouvaroff scripsit A. F. Gräffe Petrop. $1815 .{ }^{1} 4^{\text {to }}$, ein sehr wichtiges Werk. Doch vielleicht haben Sie es schon.

Ich bin im Begriff auf 14 Tage nach St. Petersb. zu reisen. So kann ich nur hinzufügen, daß ich mit unveränderlicher vorzüglicher Hochachtung und Ergebenheit bin Ew. Hochwohlgeb gehorsamster Diener Morgenstern $^{2}$

${ }^{1}$ Dazu vgl. Nr. 16 Anm. 14 und 15. $-{ }^{2}$ Adresse auf anderem Blatt: Sr. Hochwohlgeb | Herrn Hofrath und Professor | v. Groddeck | Wilna. | Nebst einem broschirten und einem ungebundenen Ex. der Dörpt. Beyträge. II. 2.

\section{Groddeck an Karl Morgenstern, am 7.5.1816}

Ew. Hochwohlgebor. vor kurzem an unsern Professor Abicht abgelaßenes Schreiben ${ }^{1}$ hat ihn leider! nicht mehr gefunden. Dieser treffliche, als Mensch, als Denker, als akademischer Lehrer, gleich ausgezeichnete Mann, ward uns seinen Freunden und unsrer Universität am 16. April ${ }^{2}$ a. St. frühe um 7 Uhr nach einer kurzen Krankheit von 8 Tagen (einer Lungenentzündung, der Folge eines etwas verwahrlosten Catarrhs) entrißen. In wenigen Tagen hätte er sein $54^{\text {tes }}$ Jahr geendigt. Er hinterließ eine Wittwe und zwei Söhne von denen der ältere noch das $2^{\text {te }}$ Jahr nicht geschloßen hat. Sein Sohn ersterer Ehe, ein hoffnungsvoller, durch Talente, Kenntniße und Fleiß seinen hiesigen Lehrern seit lange schon höchst empfohlener, iunger Mann, wird sich in diesem Jahre als Arzt habilitiren. Dieser bat mich, Ew. Hochwohlgebor. für Ihren freundschsaftlichen Brief an seinen verewigten Vater und die gütige Besorgung der Ihnen vor einiger Zeit von Ihm anvertrauten Handschriften ${ }^{3}$, die höchst wahrscheinlich ietzt ungedruckt, nach dem Willen des Sohnes, bleiben wird <!>, den ehrerbietigsten Dank zu sagen | und Sie zugleich zu ersuchen, diesen litterarischen Nachlaß so lange noch gütigst in Ihrer Verwahrung zu behalten, bis er ${ }^{4}$ Ihnen auf demselben Wege, auf dem Sie sie erhielten, dh einen Rigaer Buchhändler, deßen Namen ich vergeßen habe, abgenommen werden wird.

Für Ihre zahlreichen und höchst treffl. literarischen Geschenke mit denen Sie mich zu Ende des vorigen $\mathrm{u}$. am Anfange des gegenwärtigen Jahres beehrt u. erfreut haben, empfangen Ew. Hochwohlgebor. meinen wärmsten Dank. Daß eine so inhaltsreiche, durch mannigfaltig belehrende und unterhaltende Aufsätze ausgezeichnete periodische Schrift, wie Ihre Dörpt. Beiträge, schon mit dem $3^{\text {ten }}$ Jahrgang geschloßen seyn soll ${ }^{5}$, war mir eine sehr unwillkommene Nachricht. Ich verweile heute nur bei Ihren scharfsinnigen Symbolis Criticis ad Plat. Pol. die ich mit der älteren Edition von Ast (denn die neuere besitze ich noch nicht) sorgfältig verglich, und, wenn es dieser Aeußerung bedarf, bei weitem den größten Theil noch mit meinen eigenen Ansichten ent- 
sprechend gefunden habe. Von den wenigen Stellen | wo ich andrer Meinung bin, mag ${ }^{6}$ hier einiges aus meinem dem von Ihnen erhaltenen Exemplar beigeschriebenen kurzen Randbemerkungen, zu Ihrer weiteren gefälligen Prüfung den Rest des Briefes ausfüllen.

Pag. V Lib. X c. 3 wünschte ich lieber eine ن்rootıy zeichens. - Pag. VI pr. scheint mir die vorgeschlagene Construction sowohl als der Sinn

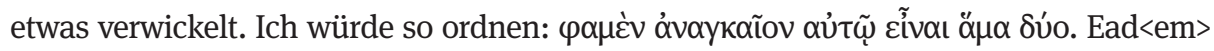

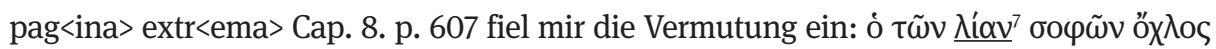
cf. Xen. Hell. II.1: 6. Oec. 20,21. - Pag. VIII stoße ich an das ع́v $\tilde{\dot{\omega}}$ vor $\Delta \mathrm{E} \Delta \mathrm{YKE}$, dem der

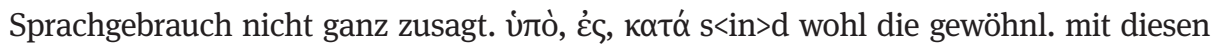

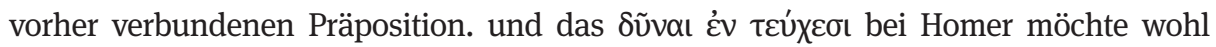
kaum hier zur Bestätigung dienen. - Ead. pag. p. 613 B. „Post $\alpha \dot{\pi} о \tau \rho \varepsilon ́ \chi\langle 0 v \tau \alpha>$. autem pro commate ed. Bip.“ In der Bip. ist ein punctum. - „Ib. D.p. 303 Ast. post $\pi \varepsilon \rho i ~ \tau \tilde{\omega} v \delta \varepsilon$, ubi omnis interp. abest ed. Ast.“ In der ersten Ausgabe von Ast $^{8}$ die ich besitze, ist $\mathrm{n}<\mathrm{ach}>$

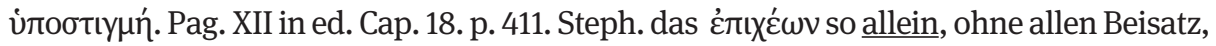

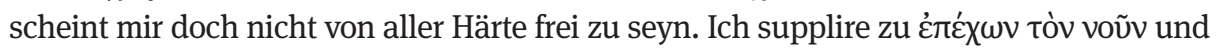

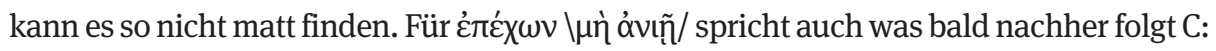

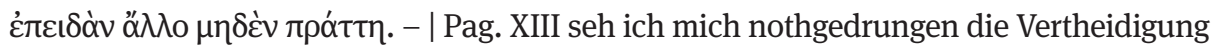

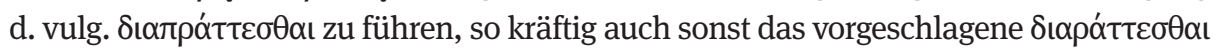
seyn mögte, der Ungewöhnlichkeit und Kühnheit des Tropus ungeachtet. Darf dann

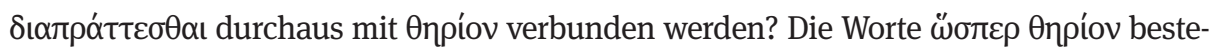

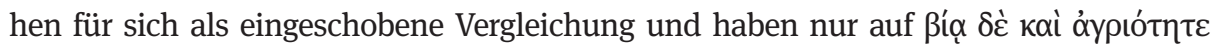
ihren Bezug. Aber gesetzt auch, man verbände es mit Onpíov, sollte es so unpaßend seyn? als allgemeiner Ausdruck für res magnas et graves peragit? Zu den am Ende dieses Arti-

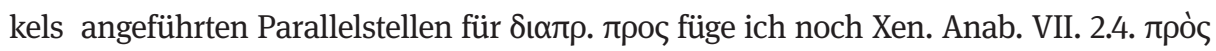

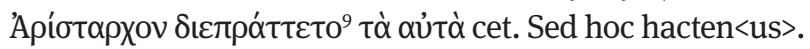

Mit diesem Briefe erhalten Ew. Hochwohlgebor. die für d. $2^{\text {ten }}$ Jahrgang d. Dörpt. Beitr. Bibliotheks Expl. rückständige 21/2 Rubel Silber zugleich mit Gottlebers Menex. den ich Ihrer Güte seit so langer Zeit verdanke, nun aber, da ich ihn für d. hiesige Bibl. angekauft habe, entbehren kann. Auch hab ich die Ehre Ihnen ein Ex. meiner kürzlich gehaltenen Vorlesung die e. Fortsetzung früherer Abhandlungen verwandten Inhalts ist, für sich zur gelegentl. Einsicht zu überreichen. Gräffe's Epist. in bucol. gr. hab ich erst gestern v. Petersb. erhalten und nach, freilich nur erst flüchtiger, Durchsicht möchte ich auf die Weise die schöne Stelle von Cic. De Or II. 21 „Volo enim se efferat in adolescente fecunditas" anwenden.

Mit ausgezeichneter Hochachtung

Ihr ergebenster Groddeck

\footnotetext{
${ }^{1}$ Nicht bekannt. - ${ }^{2}$ Über gestrichenem: Mai. $-{ }^{3}$ Nach gestrichenem: Schri<ften>. - ${ }^{4}$ Über gestrichenem: sie. $-{ }^{5}$ Über das Ende der Dörptschen Beyträge vgl. Süss S. 150. $-{ }^{6}$ Nach gestrichenem: nach. $-{ }^{7}$ Diese Konjektur wird in der Ausgabe von James Adam, The Republic of Plato, 1902, II 418, auch der Ausgabe von Burnet dem Holländer Herwerden (1831-1910) zugeschrieben (K); vgl. auch Nr. 10 Anm. 5. $-{ }^{8} 1804$ (K). - ${ }^{9}$ Im Text: бıапра́́tтєто (corr. K).
} 
33. Groddeck an Karl Morgenstern, am 15.10.1816

Hochwohlgeborener

Hochzuverehrender Herr CollegienRath

Obgleich die hiesige Ukanzellei schon seit einiger Zeit, ohne mein Wißen, das dießiährige Verzeichniß der Vorlesungen auf hies. Universität an die Ihrige abgesendet hat, so ergreife ich gleichwohl eine sich mir darbietende Gelegenheit, Ew. Hochwohlgebor. ein paar Exemplare derselben, wegen der vorgedruckten kleinen Abhandlung, hochachtungsvoll zu überschicken, mit der ergebendsten Bitte das eine, nebst der früheren Abhandlung de Parasceniis ${ }^{1}$, die ich vor einigen Monaten Ihnen zu übersenden die Ehre hatte, dem Hn. CR. Hetzel ${ }^{2}$ gefälligst einzuhändigen. Zu dieser Bitte mag ${ }^{3}$ sich dann noch eine andre gesellen. Besitzen Sie Thiersch Vorlesungen über die Gedichte \d./ Hesiodus ${ }^{4}$ ? Aller meiner wiederholten Aufträge ungeachtet kann ich bis zur Stunde noch diese mir sehr wichtige Abhandl. nicht verschaffen. Sollte sie also schon in Ihren Händen seyn, so würden Sie mir durch die gütige Mittheilung | derselben, nur auf ein paar Wochen, einen wesentl. Dienst erweisen. Ich hoffe, daß der Gottlebersche Menexenus wohlbehalten angekommen ist. Ihre zuvorkommende Gefälligkeit, die Sie mir durch die Mittheilung desselben vor einigen Jahren bewiesen, läßt mich hoffen, daß ich auch itzt, im Falle des eigenen Besitzes, keine Fehlbitte thun werde. Übrigens können Sie versichert seyn, daß ich den gesetzten Termin der Rücksendung diesmal pünktlich halten werde.

Was das Ew. Hochwohlgebor. übersendete Lektions Verzeichniß betrifft, so $<\mathrm{m}>\mathrm{u} ß$ ich mich noch gegen eine leicht bei Ihnen entstehen könnende Ver $<$ m $>$ uthung, als ob ich der Redactor des ganzen Verzeichnißes wäre, bei dieser Gelegenheit aufs geziemendste verwahren ${ }^{5}$. Vor einigen Jahren \zwar/ übernahm ich freiwillig dieß undankbare Geschhäfte - da ich aber nicht nur keinen Dank, sondern häufige Unzufriedenheit und höchst unverständige Kriteleien erfahren $<m>$ ußte, so überließ ich die Redaction der Canzelei und ließ (mit wenigen Ausnahmen) einen ieden schreiben, wie er's für gut fand, wenn's ${ }^{6}$ praefiscini $^{7}$ dixerim - (unter uns gesagt!) gar nicht zur Ehre der | auf unserer Alma herrschenden Latinität ausfallen $<$ m $>$ ußte.

Unsere Hoffnung, Alexandern bei seiner Rückreise von Warschau in Wilna zu sehen, ist leider fehlgeschlagen! Er ist von Grodno über Kowno gegangen.

Mit der ausgezeichnetesten Hochachtung hab ich die Ehre zu seyn

Ew. Hochwohlgebor.

Wilna 15. October 1816

ergebenster Diener Groddeck

\footnotetext{
${ }^{1}$ Gemeint: De theatri Graecorum partibus imprimis de parasceniis, 1816. $-{ }^{2}$ Johann Wilhelm Friedrich Hetzel oder Hezel (1754-1824) aus Franken. 1786-1802 Professor der orientalischen Sprachen in Gießen; 1802-1813 Professor für Exegetik und 1802-1820 für orientalische Sprachen in Dorpat. Zu ihm vgl. Süss 197 f., passim. ${ }^{3}$ Nach gestrichenem: mag. $-{ }^{4}$ Friedrich Wilhelm v. Thiersch (1784-1860), hatte in Göttingen bei Heyne studiert, wurde dann Hofrat und Professor für alte Literatur in München. Über die Gedichte des Hesiodus erschien in den Denkschriften der Akademie zu München 1813. ${ }^{5}$ Nach gestrichenem: Ver. ${ }^{6}$ Danach gestrichen: auch. ${ }^{7}$ Im Text: praefiscine (corr. K).
} 
34. Karl Morgenstern an Groddeck, am 7.3.1818

Dorpat, d. 7. März a. St. 1818

Hochwohlgeborener Herr Hofrath, Verehrter Herr und Freund,

Es ist lange her, daß ich Ihnen nicht geschrieben, mithin auch keinen Brief von Ihnen erhalten habe. Ihre letzten Briefe, die vor mir liegen, sind die vom $7 \stackrel{\text { ten }}{ }$ May und 15 Oct. 1816. so viel mir erinnerl. ist, habe ich leider! seitdem nicht geantwortet, wenigstens nur flüchtig, wenn es geschehen ist. Dieß ging so zu. Im Anfang des J. 1817, oder vielmehr seit dem Ende Januars 1817 bis zum Anfange Aprils war ich in Geschäften in St. Petersburg; nachher kamen so manche neue Einrichtungen unter der Curatel dieser Universität ${ }^{1}$, die meine Zeit beschränkten; wohin vorzügl. auch gehörte, daß ich die Zahl meiner Vorlesungen beträchtl. zu vermehren mich veranlaßt sah, welches auch noch jetzt fortdauert. Im Sommer des vorigen Jahres war ich in der Ferienzeit in Estland beim Weltumsegler $\underline{\text { Krusenstern }}^{2}$ auf seinem Gute Aß, und auf einigen anderen Gütern, wo ich auch die nähere | Bekanntschaft meiner Frau machte. ${ }^{3}$ Dann d. 23. December des verfloßnen Jahres war meine Hochzeit mit der zweyten Tochter des Majors von Lesedow auf Mückenhof in Estland. Seitdem bin ich, obgleich ich so spät im Leben zum ehelichen Verhältniß schritt, da meine liebe Frau allerdings zu den selteneren ihres Geschlechts gehört, ein glücklicher Ehemann.

Sie begreifen leicht, wie sehr durch dieß alles, um von manchem andern zu schweigen, meine Zeit beschränkt wurde, und wie manches von meinen gewöhnlichen Beschäftigungen zurückbleiben mußte. So bin ich auch in Briefschulden gerathen, rechne aber, wenigstens bey Ihnen, auf Nachsicht.

Abicht's Handschrift habe ich, wie Sie wissen werden, zu seiner Zeit, einem dazu beauftragten Gelehrten aus Wilna ${ }^{4}$, der mich hier besuchte, gegen Empfangschein zurückgesand. | Wenn Sie mir antworten, bitte ich mir die richtige Zurückgabe an Abicht den Sohn oder an Sie, zu melden. Ich sollte auf demselben Wege, wie ich erhalten hatte, zurück senden, laut Ihrem Briefe vom 7. May 1816. Dieß that ich auch. Der Wilnaische junge Gelehrte, der mir das Mspt. abforderte, kam mit Auftrag von dem Rigaischen Buchh. Meinshausen ${ }^{5}$, der mir das Mspt. zugefertigt hatte.

Für Ihre gelehrten Bemerkungen über einige Stellen von Plat. de Republ. habe ich Ihnen noch einen Dank zu sagen. Sie waren mir um so schätzbarer, da ich in keiner Litt. Zeitung bis jetzt auch nur eine Sylbe über jene Symbb. criticas gelesen habe.

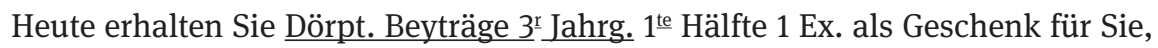
wie gewöhnl.; das andere Ex. für die Univers. Bibl., wofür ich (inclus. der $2^{\text {ten }}$ Hälfte,

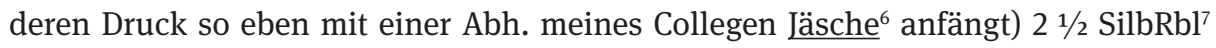
erhalte.

Für Ihre gelehrte Abhandlung mit deren \Mittheilung/ Sie mich erfreut haben, habe ich Ihnen noch den aufrichtigsten Dank zu sagen. Sobald der Gang meiner litt. Beschäftigungen | mich wieder an die darin behandelten Materien führt, werde ich sie 
studieren und gewiß daraus nicht wenig lernen. Für jetzt mußte ich mich mit flüchtiger Durchsicht begnügen.

Das für Hn. Ch. Hezel Übersandte ist zu seiner Zeit sogleich abgegeben.Thiersch. Schrift über Hesiodos hätte ich Ihnen gern gesandt; nur hatten sie aber nicht einzelne, und den vollst. Band der Abhandl. der Bayerischen Akademie wo sie steht, durfte ich wegen Coll.ferien, des Bedürfnisses hiesiger Professoren die weite Reise nicht machen lassen.

Erhalten Sie mir Ihr gütiges, freundschaftliches Wohlwollen, worauf ich großen Werth lege. Mit der vollkommensten Hochachtung

Ew. Hochwohlgeb.

ganz ergebenster Diener

Morgenstern

\begin{abstract}
${ }^{1}$ Klinger hatte das Amt des Kurators der Universität zum 1. 7.1817 aufgegeben. Sein Nachfolger, Fürst Karl Andrejevič Lieven, trat es erst 1819 an. Vgl. Süss S. 206 ff. und Busch, Der Fürst Karl Lieven und die Kaiserliche Universität Dorpat unter seiner Oberleitung, 1846. $-{ }^{2}$ Adam Johann v. Krusenstjern (1770-1846). Hatte vom 7. August 1803 bis 19. August 1806 die Welt in kaiserlichem Auftrag umsegelt, um Handelsbeziehungen mit Amerika und Japan anzuknüpfen. $-{ }^{3}$ Zur Hochzeit Morgensterns $\mathrm{s}$. Süss S. 270, 279. $-{ }^{4}$ Vielleicht Danilovič? Vgl. Nr. 36 Anm. 1. ${ }^{5}$ Johann Friedrich Meinshausen im ersten Drittel des 19. Jahrhunderts Buchhändler und erfolgreicher und gesuchter Verleger in Riga, in Dorpat Filiale als Universitätsbuchhändler. ${ }^{6}$ Gottlieb Benjamin Jaesche (*1762), Bekannter aus Danzig. Später Privatdozent in Königsberg, seit 1802 Professor für Philosophie in Dorpat. Lehrte Philosophie nach Kant. Morgenstern hielt ihm die Grabrede. Vgl. Süss S. 29, 106, 209, passim. - ${ }^{7}$ Danach gestrichen: zu.
\end{abstract}

35. Groddeck an Karl Morgenstern, am 3. 6.1818

Wilna den 3 Junius 1818

Hochgeborener,

Hochzuverehrender Herr CollegienRath,

Je angenehmer mir die Wiederanknüpfung unsres so lange unterbrochenen Briefwechsels, durch Ihren freundschaftlichen Brief vom 7 März d. J. war, desto schneller hätte ich Ihnen sowohl hierüber meine Freude, als meinen Dank für das höchst intereßante beigelegte litterarische Geschenk zu erkennen gegeben, wenn ich nicht auf den diesem Briefe beigeschloßenen Empfangsschein des jungen Doktor Abicht, der nicht in Wilna lebt, und nur vor wenigen Tagen, wie Sie aus $d e<m>$ Datum sich überzeugen werden, mir ihn zusandte, hätte warten müßen. Es wäre Schade, wenn Sie die Dörptische Beiträge nicht weiter fortsetzen wollten. Sie enthalten viel gutes und anziehendes, sind auf mehre Claßen von Lehrern berechnet, unterhalten durch die, doch sehr gewählte | Mannigfaltigkeit ihres Inhalts, und können als stehende Annalen Ihrer Universität betrachtet werden. Einer so reichlich ${ }^{1}$ ausgestatteten Zeitschrift sollte es doch an Lesern und Käufern in Deutschland nicht fehlen. 
Recht innigen Antheil nehme ich an den Sie persönlich betreffenden glücklichen Veränderungen, von denen Sie mir Nachricht zu geben die Güte gehabt haben. Aus langer eigener Erfahrung den Werth häusl. Freuden kennend, und mich fast auf sie beschränkend, wünsch ich Ihnen zu Ihrer getroffenen Wahl aufs herzlichste Glück.

Für den $3^{\text {ten }}$ Jahrgang der D.B. folgt hier der SubscriptionsPreiß von 21/2 SR. für die hiesige Bibliothek über deren Empfang sowohl, als über den der Ihnen i. J. 1816 zugesandten, wie ich glaube, ähnlichen Summe, \ich mir/ ${ }^{2}$ einen kleinen Schein, den ich den BibliotheksRechnungen der Vorschrift gemäß beilegen muß ${ }^{3}$, von Ihnen erbitte. ${ }^{4}$

Da ich mich nicht erinnern kann, ob ich Ihnen, mein verehrter Freund, im vorigen Jahre das hiesige Lections|Verzeichniß zugesandt habe, so lege ich ein Exemplar für Sie und ein zweites für Hn. CR. Hetzel, deßen verdienten Sohn ich hier vor einiger Zeit kennen zu lernen die Gelegenheit gehabt habe, bei.

Mit der ausgezeichnetesten Hochachtung und aufrichtiger Freundschaft

Ihr

ergebenster Diener

Groddeck $^{5}$

\footnotetext{
${ }^{1}$ Am Zeilenende: reicch, über gestrichenem: viel. $-{ }^{2}$ Am Rande links nachträglich hinzugefügt. $-{ }^{3}$ Danach gestrichen: noch. $-{ }^{4}$ Am Rande links: geschickt $M<0 n>$ tag. $-{ }^{5}$ Darunter von der Hand Morgensterns: Beantw. d. 20. Jan. 1819. Mstn
}

36. Karl Morgenstern an Groddeck, am 20.1.1819

Dorpat, d. 20. Jan. 1819

Hochwohlgeborner,

Hochzuverehrender Herr Hofrath,

Da Hr. $M<a g>$. Danilowicz ${ }^{1}$ nach Wilna von hier zurückreist, dessen Bekanntschaft gemacht zu haben mir in mehreren Hinsichten interessant war, so benutze ich die gute Gelegenheit, Ihnen für Ihr werthes Schreiben vom 3. Junius vorigen Jahres zu danken.

Von der $2^{\text {ten }}$ Hälfte des $3^{\text {ten }}$ Bandes der Dörpt. Beyträge sind mehrere Bogen schon gedruckt. Ich hoffe sie in diesem Frühjahr im Drucke zu beendigen. Der Empfangsschein über $21 / 2$ SilbRbl für den $\backslash 2^{\frac{\text { ten }}{2}} /$ Jahrgang, so wie für den $3^{\text {ten }}$ ein gleichlautender auf einem Zettel, erfolgt hiebey in Bezug auf das Subscr. Exemplar Ihrer Univ.-Bibl.

Neulich sah ich Ihr gelehrtes, gehaltvolles Programm über Zamolxis ${ }^{2}$. Ihre Universität sandte 2 Ex. an die unsrige, die mir für die hiesige Univ.-Bibl. abgegeben wurden, | an die ich sie auch sogleich verabfolgen ließ. Doch bitte ich Sie, verehrter Freund, ausdrückl. um 1 Ex. für mich bey nächster Gelegenheit.

Den ersten Abschnitt meines Programms: Enumeratio numorum familiarum Romanarum etc. ${ }^{3}$ haben Sie, wie Ihr Brief beweist, erhalten - wahrscheinlich durch 
mich auch den $2^{\frac{\text { ten }}{}}$ Abschnitt, gedruckt im August 1818. Zum Überfluß lege ich letzteren auf jeden Fall noch einmal bey.

Zugleich überreiche ich Ihnen etwas Anderes zum freundschaftlichen Andenken, was sie schwerlich jetzt von mir erwarteten: eine kleine Sammlung Gedichte p.: Töne vom Lebenspfade. ${ }^{4}$ Das Büchlein rechnet auf wohlwollende Nachsicht.

Mit unveränderlicher Hochachtung u. Ergebenheit

Ew. Hochwohlgeb

gehorsamster Diener

Morgenstern.

\begin{abstract}
${ }^{1}$ Ignatij Nikolaevič Danilovič (1787-1843) aus Litauen, Sohn eines unierten Geistlichen. Ausbildung in Wilna zum Magister der Rechte. 1824, nach den bekannten Studentenunruhen, aus dem polnischen Landesteil Rußlands ausgewiesen. Seit 1825 Professor der Rechte an der Universität Charkov. $-{ }^{2}$ Ein griechischer „Weiser“ des 6. Jahrhunderts v. Chr., soll Schüler des Pythagoras gewesen sein und als Erster die Unsterblichkeit der Seele gelehrt haben. $-{ }^{3}$ Vgl. Süss S. 129: numismatisches Programm 1818. $-{ }^{4}$ Vgl. Süss S. 143 f.: „Von Spöttern „Fade Töne vom Leben“ umbenannt.“
\end{abstract}

37. Groddeck an Karl Morgenstern, am 24. 3./ 5. 4.1819

Hochzuverehrender Herr Geheime Rath

Ihre leise geäußerte Ahndung ist vielleicht wirklich eingetroffen. Den am 1 . Jul<i> vorigen Jahres durch Herrn Wölk ${ }^{1}$ an mich gesendeten Brief ${ }^{2}$ mit dem Igütigst/ beygefügten $2^{\text {ten }}$ und $3^{\text {ten }}$ Stück der Literar<ischen $>$ Analekten ${ }^{3}$ erhielt ich mit einem recht schön geschriebenen lateinischen Briefe des jetzt als Professor am Gymnasium zu Lublin (24 Meilen von Warschau) angestellten Hn. Wölk, am 10 März neuen Styls 1819 in Wilna. Wie gut, daß ich bei Zeiten die Analekten für die hiesige U Bibliothek hatte anschaffen laßen! Ob ich überall Ihren für mich schmeichelhaften Wunsch, mir manches Neue zu entlocken, zu befriedigen im Stande seyn werde, daran muß ich billig zweifeln. Am wenigsten aber fühle ich mich

$|<\ldots>|^{4}$

schen Buchhandel kommen wird, wiewohl in Deutschland an dergleichen Werken kein Mangel ist. - Die litterärisch-merkantilische Verbindung zwischen Berlin und Wilna die Ew: Wohlgeboren wünschen, ist wirklich angeknüpft und zwar namentlich zwischen dem dortigen Verleger Nauk ${ }^{5}$ und dem hiesigen Buchhändler Moritz ${ }^{6}$, einem unternehmenden, höchst thätigen und braven jungen Mann der mir schon viele Dienste für die hiesige Ubibliothek geleistet hat.

Mit der ausgezeichnetesten Hochachtung und Verehrung hab ich die Ehre zu seyn

Wilna den 24 März 1819

5 April
Ew. Wohlgeboren

ergebenster Diener

Groddeck $^{7}$ 
${ }^{1}$ Wölk, später Gymnasialprofessor in Lublin. Mehr nicht zu ermitteln. $-{ }^{2}$ Nicht erhalten. $-{ }^{3}$ Literarische Analekten, eine von F. A. Wolf 1816 begründete Zeitschrift. $-{ }^{4}$ Mindestens eine Seite fehlt. $-{ }^{5}$ Berliner Buchhändler Nauck, s. Reuters Register III 316. ${ }^{6}$ Friedrich Moritz, Buchhändler in Wilna, Konkurrent von Zawadski. - ${ }^{7}$ Bei diesem Brief ein Blatt mit der Aufschrift von anderer Hand, „Groddeck I geboren zu Danzig 1763; I gestorben zu Wilna 1825, als Rußischer Etats.Rath I und Professor.“

\section{Groddeck an Karl Morgenstern, am 20. 9.1820}

Erlauben Ew. Hochwohlgeboren, daß ich bei Übersendung des zweiten Theils meines Zamolxis, dessen erster sich einer gütigen Aufnahme bei Ihnen erfreute, meinen, wiewohl durch mannigfaltige Ursachen sehr verspäteten, aber darum nicht minder herzlichen Dank darbringen <!> für mehre mir höchst angenehme litterarische Geschenke, die ich im Verlauf von beinahe zwei Jahren von Ihnen zu erhalten das Glück hatte. Ich begreife darunter sowohl die Beschreibung Ihrer antiken Münzsammlung ${ }^{1}$ (die gerade in der Zeit in meine Hände kam, wo ich mit dem Sortiren und dem Ordnen unsres kleinen Vorraths griechischer und Römischer Münzen beschäftigt war), Ihre höchst schätzbaren Anmerkungen zu den Tusculanen und Paradoxa des $\underline{\text { Cicero }}^{2}$; als die eben so reichhaltige als geschmackvolle Auswahl von Gedichten, die mich um so mehr ansprechen, da ein Theil derselben den schönen Umgebungen meines Geburtsorts seinen Ursprung verdankt.

Ein glücklicher Zufall ließ mich verfloßenen Sommer in Libau die \persönliche/ Bekanntschaft Ihres würdigen Collegen des CR. von $\underline{\text { Rambach }}^{3}$ machen. Zwar nur wenige Tage, oder vielmehr Stunden, konnte ich mich seines Umganges und seiner lehrreichen Unterhaltung freuen, aber sie waren hinlänglich, um mich mit Hochachtung und mit inniger Werthschätzung dieses trefflichen Mannes, dem ich mich recht | angelegentlich zu empfehlen bitte, zu erfüllen.

Es würde \mir/ höchst erwünscht seyn, wenn Sie die Güte hätten, mir Ihr unpartheiisches Urtheil über meine Ansichten des Mythus von Zamolxis, besonders über den letzten Theil und die lange Note auf der zweiten Seite der gegenwärtigen Abhandlung gegen $\underline{\text { Creutzer }}^{4}$, wißen zu laßen. Beigeschloßene Exemplare an die HHnn. Collegienräthe Hetzel und Rambach empfehle ich Ew. Hochwohlgeboren zur gütigen Versendung. Mit inniger Verehrung

Wilna den $20^{\text {ten }}$ Sept. 1820

Ihr ergebenster Groddeck ${ }^{5}$

\footnotetext{
${ }^{1}$ Dazu Süss S. 129. - ${ }^{2}$ Dazu Süss s. 129 f. $-{ }^{3}$ Friedrich Eberhard Rambach (1767-1826) aus Quedlinburg. Schule im Johanneum in Hamburg, Studium der Theologie in Halle. 1791 bis 1803 in Berlin, dann Professor für klassische Philologie in Dorpat; vgl. Süss S. 244. $-{ }^{4}$ Friedrich Creuzer (1771-1858) aus Marburg, Altertumsforscher, 1800 Professor in Marburg, 1804 in Heidelberg. Gemeint wohl seine Symbolik und Mythologie der alten Völker, Bd. I-IV, Leipzig und Darmstadt 1810-1812. - ${ }^{5}$ Darunter von Morgensterns Hand: „Beantw. d. 20 Nov. 20.“
} 
39. Karl Morgenstern an Groddeck, am 20.11.1820

Dorpat, d 20. Nov. a.St. 1820

Indem ich Ew. Hochwohlgeb. meine Recensio numorum imperatoriorum aeneorum a Jul. Caes. usque ad Domitian. qui in Mus. acad. servantur von dem neuesten Lat. Lectt. Katalog unsrer Univers. zu übersenden mir die Freyheit nehme, danke ich Ihnen verbindlichst für Ihr freundschaftl. Schreiben vom $20^{\text {ten }}$ Sept. Ihren Gruß von Libau aus (wo ich vor Jahren auch selbst mehr als Ein Mal das Seebad gebraucht habe) hatte mein College Rambach mir richtig bestellt, so wie ich neulich Ihren schriftln., welchen er erwiedert. Er hatte mir längst erzählt, wie angenehm ihm Ihre persönl. Bekanntschaft gewesen. Möcht' ich zugl. dort gewesen seyn! Zunächst möcht’ ich aber noch schwerl. wieder nach Libau kommen, bey manchen veränderten Verhältnissen.

Vor etwa einem halben Jahre hat unser alter Freund | Trendelenburg aus Danzig aus Veranlassung eines Geschäfts mir einmal wieder geschrieben. Der liebe Alte befindet sich wohl.

Für beyde Theile Ihres Zamolxis sage ich Ihnen den verbindlichsten Dank. Sie haben mir Belehrung u angenehme Unterhaltung gewährt. Die Exemplare an die Hr, p Hezel u Rambach sind abgegeben. -

Sie verlangen mein Urtheil über die lange Note im $2^{\text {ten }}$ Theil gegen Creuzer. Ich muß Ihnen beystimmen. Jener treffliche Forscher überläßt sich nur $\mathrm{zu}$ oft seiner ${ }^{1}$ seltenen Combinazionsgabe zu sehr, $\mathrm{u}$ folgert häufig zu viel aus Zusammenstellung ungleichartiger Schriftsteller. Gewundert hat mich, daß Sie des scharfsinnigen Ast's Verdammungsurtheile des Platonischen | Charmides unbedingt beytreten. Bey mehreren \der/ Platonischen Dialoge die er geradehin für unecht erklärt, habe ich mich von der Unechtheit noch nicht überzeugen können. Am wenigsten bey der Apologie, worüber schon Thiersch in den Wiener Jahrbüchern ${ }^{2}$ gegen Ast viele richtige Bemerkungen gemacht hat, die mir um so mehr einleuchten, da ich bey Erklärung des Char$\underline{\text { mides }} \mathrm{u}$ der Apologie in diesem Halbjahr in Hinsicht letzterer mündlich Ähnliches, nur weniger durchdacht $u$ ausgeführt, erinnert hatte. Auch von der Unechtheit des älteren Hippias, von welchem ich vor etwa 22 Jahren einen kritischen berichtigten Abdruck in Halle anfing (wovon 2 Bogen | unter meinen Sachen sich noch finden, der aber bey meiner damaligen Ortsveränderung unvollendet liegen blieb u nun schwerl. je erscheinen wird) habe ich mich noch keineswegs überzeugt. Doch ich gerathe ins Schwatzen. Der Schluß der Dörpt. Beyträge wird hoffentl. noch vor Jahresschluß erscheinen, wenn die gehäuften officiellen Arbeiten es erlauben.

Mit unveränderlicher Hochachtung

Ihr

ergebenster

Morgenstern

${ }^{1}$ Verbessert aus: seinen. $-{ }^{2}$ Eine Arbeit in den Wiener Jahrbüchern nicht ermittelt. Vgl. Nr. 33 Anm. 4. 
40. Groddeck an Karl Morgenstern, am 19. 9. 1821

Hochwohlgeborener

Hochzuverehrender Herr CollegienRath u Ritter

In dankbarer Erwiederung der durch Ihre Güte vor mehren Monaten und ohnlängst mir zugekommenen akademischen Schriften (in der letzten ist Deterius eine Capital Emendation, die werth wäre, durch irgend eine noch nicht eingesehene Handschrift bestätigt, ihren Platz im Texte des Dichters ${ }^{1}$ einzunehmen) hab ich die Ehre Ew.Hochwohlgeboren, außer der gewöhnlichen Vorrede zum hiesigen \neuen/ Lectionsverzeichniß, auch die erste Hälfte meines in diesem Frühling endlich fertig gewordenen neu aufgelegten Handbuchs der griech. Literärgeschichte mit eben der Hochachtung zuzusenden, die ich in der kurzen Vorrede auch öffentlich zu äußern für meine angenehmste Pflicht hielt. | Es sey mir erlaubt, bei dieser Gelegenheit um die Fortsetzung der Dörptischen Beiträge, von der ich durch die öffentl. literarischen Blätter benachrichtigt bin, für die hiesige Ubibliothek, die auf die frühere pränummerirt hat, zu bitten.

So wie ich's gestehen muß, daß Ast's Gründe gegen die Ächtheit des Charmides für mich überzeugend waren, so mach' ich's auch kein Hehl haben, daß Dilthey's ${ }^{2}$ Gründe so wenig als die Trümpfe des Gött. Recensenten mich in meinen längst gehegten, und durch Ast's Untersuchung nur noch mehr verstärkten und begründeten Zweifeln an der Aechtheit der Gesetze wankend gemacht haben. Überhaupt sollte \ doch/ alles Leidenschaftliche, was leider! auch in der Philologie zum Geist der gegenwärtigen Zeit gehört, aus solchen blos wissenschaftlichen Erörterungen, die die größte Ruhe, Unpartheilichkeit und Freiheit des Geistes erfordern, verbannt werden.

Mit aufrichtiger Verehrung

Ew. Hochwohlgeboren

Wilna den 19 ${ }^{\text {ten }}$ September 1821

ergebenster

Groddeck.

${ }^{1}$ Horaz, in den Lectionsprogrammen I und II, vgl. Süss S. 129 (K). $-{ }^{2}$ Julius Friedrich Karl Dilthey (1797-1857), Platonicorum librorum de legibus examen, Göttingen 1820.

41. Karl Morgenstern an Groddeck, am 3.1.1822

Hochwohlgeborner,

Hochzuverehrender Herr Staatsrath u Ritter,

Für Ihr erwünschtes Geschenk des ersten Bandes Ihrer vortrefflichen Initia Historiae Graecor. litterariae in der neuen Ausgabe bin ich Ihnen recht sehr verbunden, beschämt zugleich durch die sehr ehrenvolle Art, wie es Ihnen gefallen hat, meiner darin zu erwähnen. Zugleich danke ich ergebenst für Ihr gelehrtes Programm de 
aulaeo et proedria in theatr. Graecor., welches, wie Ihre frühere über das gr. Theaterwesen, so viel Belehrendes aus gründlicher Forschung enthält. Angezeigt finden Sie die frühere im letzten Theile der Dörptischen Beyträge S. $418 \mathrm{f}$, welchen ich hiebey zugleich zu übersenden das Vergnügen habe nebst ${ }^{1}$ dem Ihrer Universitäts-Bibliothek schuldigen Exemplare. Verzeihen Sie gütigst, daß die Übersendung nicht schon früher geschah. Ich wollte aber zugleich das letzte Programm schicken, dessen Druck sich verzögerte. Decanats- und andere officielle Geschäfte hießen mich dann ein paar Monate fast auf alles Briefschreiben Verzicht thun, zumal da die Bibliothek-Geschäfte durch indeß angekommene Bücherkisten aus Deutschland u England sich gerade ungewöhnl. häuften. Doch Sie versetzen sich leicht mit gewohnter Güte in meine Lage, $u$ entschuldigen, wie andere meiner Freunde in ähnlichen Fällen, den Verzug. Hiebey erfolgt also auch das 4 1 2 Bogen stark gewordene Programm Symbb criticar. in quaedam loca Platonis et Horatii Partic. II. ${ }^{2}$ Es war mir angenehm, in den Litterarnotizen, die sich unter den $\S \S$ Ihrer Gesch. der Gr. Litt. finden, auch ein paar meiner Dörptischen Programme zu sehen ${ }^{3}$, zumal da sie anderwärts wenig bekannt geworden. $\mathrm{Zu}$ dem Übrigen was pag. XIII-XIV von krit. | Bemerkk. über Stellen in Platonis Gorgias steht, denke ich gelegentl. andere hinzuzufügen; z. B, c. 44 \ad Heind./ u an andern

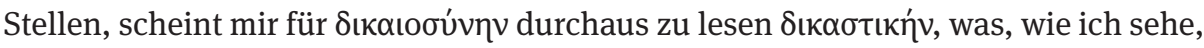
$\underline{\text { Schleiermacher, Bekker }}{ }^{4} \mathrm{u}$ Ast auch schon vorgezogen haben. c. 47 vermuthe ich für

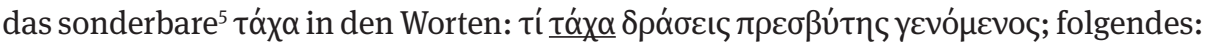

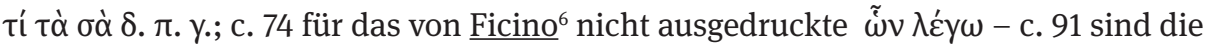

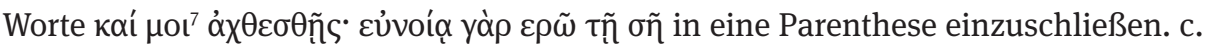

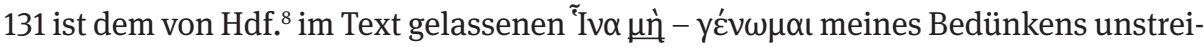

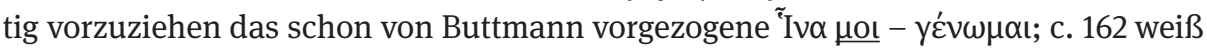

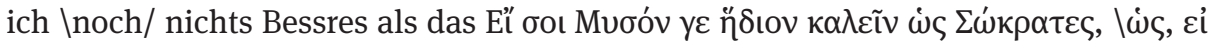

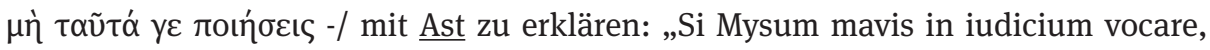

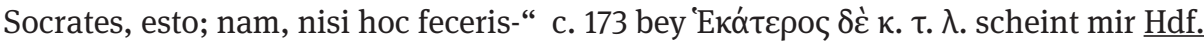
hypokritisch: Der Zusatz ist höchstwahrscheinl. doch von Platon selbst. Vgl. Schleierm. S. 488. - od. dgl. Kleinigkeiten mehr. Doch, womit unterhalte ich Sie? In diesem Halbjahr werde ich von Platonicis Phädros erklären, \an/ den bey mir noch nicht die Reihe gekommen war. Ist Ihre früher gegen mich erwähnte Ausgabe des Menexenos erschienen? Ich habe sie bis jetzt nirgends öffentl. erwähnt gefunden.

Es freut mich, daß in Horat. Serm. 1. g. Ihnen mein deterius gefallen hat. Ein Gleiches wünscht' ich für meinen alten, noch einmal mit verstärkten Gründen vorgeführten Einfall üb. Horazens Damosippus ${ }^{9}$ in dem hiebey erfolgenden Programm p. XI-XIII. Ich gestehe, daß der noch von keinem öffentl. gebilligte Gedanke mir noch immer $<\ldots>^{10}$ scheint. Ich wünschte Ihr Kennerurtheil, auch wenn es dem meinigen widersprechen sollte hierüber, so wie über manches Andere in den Horatianis, die ich bey Gelegenheit auch auf die Epp. ${ }^{11}$ ausdehnen werde. | Bey den Schriften über Socrates hätte vielleicht in der Note ein Plätzchen verdient: $\underline{\text { I. H. L. Meierotto }}{ }^{12}$ de $^{2}$ Socrate, et num aevi nostris videntur, Socratem quem gignere et producore, ${ }^{13}$ Berol. 1794 fol. Vgl. Dörpt. Beitr. I. Bd. S. 82 ff. - Bey Thucydides S. 92 Ihres gewiß auch die 3te 
Aufl. erlebenden Werks ist $\underline{4 \text { maj. }}$ bey Haacke’s Ausgabe ${ }^{14}$ ein Druckfehler für 8 maj., der lunter/ hinten ${ }^{15}$ angezeigten vergessen worden. Bey den Schriftstellern üb. die Gesch. der Gr. Philosophie hätten Sie mitanführen können ein auch v. Eichhorn nicht gekanntes Werk, das vor mir liegt: The Philosophy of ancient Greece investigated in its origin and progress etc. By Walther Anderson ${ }^{16}$, D. D. Edinburgh, 1791. 588 S. gr. qto.

In Böttiger's ${ }^{17}$ letztem Briefe an mich (Dat. Dresden, 11. Oct. 21) findet sich folgende Stelle, die ich Ihnen wörtl. mittheile. Vielleicht gefällt es Ihnen, auf die eine oder andere Art über Leipzig seinen Wunsch zu erfüllen: „Ein großes Anliegen habe ich an Sie. Könnten Sie mir nicht Groddek’s Philoktet u Trachinierinnen verschaffen, so wie sein Programm üb. den Zamolxis? Herzlich gern will ich jede Auslage vergüten. Sie sind durchaus in unsrer Gegend nicht aufzutreiben.“

Im September besuchte mich Hr. M/ag \r. Onascewicz ${ }^{18}$ auf seiner Rückreise von Petersburg nach Wilna. Es war mir sehr angenehm, ihn mündl. auch von Ihrem Wohlbefinden erzählen zu hören. Ich gab ihm ein vollständiges Ex. der Dörpt. Beyträge auf Verlangen mit. Er scheint indeß mich schon vergessen zu haben.

Erhalten Sie mir Ihr freundschaftliches Wohlwollen. Mit unveränderlicher Verehrung Ew. Hochwohlgeb.

Dorpat, d. 3. Jan. 1822 ergebenster

Morgenstern.

\footnotetext{
${ }^{1}$ Über gestrichenem: zugleich mit. $-{ }^{2}$ Symbolarum criticarum in quaedam loca Platonis et Horatii, Particula II; vgl. Süss S. 129 (K). $-{ }^{3}$ Über gestrichenem: finden. $-{ }^{4}$ Immanuel Bekker (1785-1871), Wolfschüler, 1820 in Berlin. $-{ }^{5}$ Nach gestrichenem: unbequem. $-{ }^{6}$ Marsilio Ficino (1433-1499) Arzt und (1476) Priester. Lehrte als einer der Ersten in der neueren Philosophiegeschichte Philosophie nach Platon; übersetzte ihn ins Lateinische. ${ }^{-7}$ Danach gestrichen: $\mu \eta \delta \varepsilon v . ~-{ }^{8}$ d.i. Heindorf. ${ }^{9}$ Horaz Satiren II $3(\mathrm{~K}) .-{ }^{10}$ Ein Wort wegen Tintenflecks nicht lesbar. $-{ }^{11}$ Epoden. $-{ }^{12}$ Johann Heinrich Ludwig Meierotto (1742-1800), Philolog, Rektor; zusammen mit Gedike Schulreformer. $-{ }^{13}$ Danach gestrichen: 179. $-{ }^{14}$ Christoph Friedrich Ferdinand Haacke (1781-1855), hatte den Peloponnesischen Krieg herausgegeben, Bd. I-II, Leipzig 1820; vgl. Groddeck, Initia I 1821, S. 92 und II 1823, S. 239 (K). $-{ }^{15}$ Danach gestrichen: nicht. $-{ }^{16}$ Walther Anderson: nicht ermittelt. $-{ }^{17}$ Karl August Böttiger (1760-1835) aus Sachsen, Archäologe, 1791 Gymnasialdirektor in Weimar, 1804 Studiendirektor der kurfüstlichen Pagen in Dresden, 1814 Direktor der königlichen Museen. ${ }^{-18}$ Ignacy Żegota Onacewicz (1780 oder 1781-1845), Pole unierten Bekenntnisses, studierte in Königsberg, wo er Lektor für Polnisch war. später in Wilna, 1821 in Petersburg, 1827 ao. Prof. in Wilna, dann in Studentenunruhen dort verwickelt, 1818 verhaftet, 1834 freigelassen; 1838 Mitarbeiter des Rumjancev-Museums in Petersburg. Vgl. Ludwik Bazylow, Polacy w Petersburgu, Ossolineum 1984, S. 126.
} 
42. Karl Morgenstern an Groddeck, am 3. 2. 1822

Hochwohlgeborener Herr Staatsrath und Ritter, Verehrtester Freund,

Die Gelegenheit Ihnen heute zu schreiben, gibt mir ein reisender Virtuose, der von hier nach Wilna geht, $u$ der mich ersucht, ihm einige Zeilen zur Empfehlung mitzugeben. Es ist Herr Kohaut ${ }^{1}$ aus Böhmen, Kapellmeister der Chevaliergarde in St. Petersburg; der hier in Dorpat auf seinem Hauptinstrument, dem Waldhorn u einem andern von ihm selbst angegebenen Blasinstrument, dem Trombino, mit sehr vielem Beyfall Conzerte gegeben hat. Da er in Wilna keine persönliche Bekanntschaft hat, so würde er sich glücklich schätzen, wenn er sich dort Ihrer Protection erfreuen dürfte, auch wenn Sie die Güte hätten, ihn ihrem <! > Collegen Herrn Staatsrath von Frank, dem er bekannt zu werden wünscht, | gefälligst bekannt zu machen. Er gedenkt sich auch in Wilna öffentlich hören zu lassen, $u$ ich zweifle nicht, daß er es mit Erfolg thun wird. Er scheint übrigens ein sehr wackerer Mann, und hat seine musikalische und übrige Bildung, wie ich höre, vorzüglich in Wien erhalten.

Es wird mich freuen, wenn Sie, Verehrter Freund, mir Veranlassung schaffen², Ihnen Beweise meiner steten Bereitwilligkeit zu geben, in irgend einem ähnlichen Falle Ihnen meine gewisse Gefälligkeit einigermaßen zu erwidern. Empfehlen Sie mich Hn. Staatsrath v. Frank, auch Hn. Staatsrath v. Bojanus ${ }^{3}$, von welchem letzteren unsre Bibliothek vor kurzem eine gelehrte | Schrift zu erhalten das Vergnügen hatte, eben so auch Hrn. Mag. v. Onascewicz ${ }^{4}$, dem ich nächstens für seinen neulichen Brief selbst schriftlich Dank sagen werde.

\author{
Mit unveränderlicher Verehrung \\ Ew. Hochwohlgeb. \\ ergebenster \\ Morgenstern
}

Dorpat, d. 3. Febr. 1822

\begin{abstract}
${ }^{1}$ Über gestrichenem: geben. $-{ }^{2}$ Stammt wohl aus einer bekannten Musikerfamilie, wie z.B. noch Josef Kohout (1736-1793) Posaunist in Paris. - ${ }^{3}$ Wohl Ludwig Heinrich v. Bojanus (1776-1827) aus dem Elsaß. Nach Studium der Medizin in Jena zunächst Arzt in Darmstadt; 1804 als Professor für Tiermedizin nach Wilna berufen, dort bis 1825, dann wieder in Darmstadt. Bei der erwähnten „gelehrten Schrift“ wird es sich um sein Hauptwerk Anatomia testudinis Europeae, Bd. 1-2, Wilna 1819 und 1821, handeln. - 4 Verbessert aus: Onaszewicz.
\end{abstract}

43. Groddeck an Karl Morgenstern, am 1.10.1822

Hochgeborener

Hochzuverehrender Herr Staats Rath und Ritter

Indem ich mir die Freiheit nehme, Ew. Hochgeboren eine kleine, vom trefflichen Verfaßer ${ }^{1}$ der Quaestionum Sophoclearum mir beinahe abgedrungenen, Polemik über 
den ethischen u. politischen Zweck der Aeschylischen und Sophokleischen Tragödie, die dem heurigen Lections Verzeichniß vorgedruckt ist, Ihrem unpartheiischen und zugleich strengen Urtheil zu unterwerfen, entledige ich mich der höchst angenehmen Pflicht, Ihnen für die zu Anfange dieses Jahres mir gütigst zugesandten litterarischen Geschenke, den ${ }^{2}$ leider! letzten Theil der Dörptischen Beiträge, und die zweite Particula Symbolarum criticar. in quaedam loca Platonis et Horatii, | so wie für die schätzbaren handschriftlichen Mittheilungen in Ihrem freundschaftlichen Briefe vom $3^{\mathrm{t}}$ Januar, den verbindlichsten Dank zu sagen.

Was die acht der 10 $\underline{\text { ten }}$ Satire des 1 Buchs in einigen Handschriften und Editionen, neuerlichst von Heindorf, vorgesetzten Verse $^{3}$ betrifft, so stimme ich, sobald diese Verse einmal als Horazische anerkannt werden sollen, Ihrer Annahme einer doppelten Recension, oder vielmer einer solchen Revision des Dichters, völlig bei, besonders der Bemerkung p. XI. „His tamen minime negamus omissis dativo exordium abruptius illud - - multo et fortius esse et Persius.“ Denn jede Amalgamation ${ }^{3}$ mit den übrigen Theilen der Satire, sei es zu Anfange, wie J. H. Voß neuerlichst gethan hat ${ }^{4}$, oder nach dem $51^{\text {ten }}$ V., wie Ihr gelehrter und scharfsinniger College, Hr. Hofr. Francke ${ }^{5}$ glaubt, scheint mir aus mehreren Gründen, deren Auseinandersetzung mich hier zu weit führen würde, nicht zuläßig zu seyn. Übrigens gestehe ich in den genannten acht Versen, besonders in den Worten: multum puer loris et funibus exoratus - contra fastidia nostra - Grammaticorum equitum doctissimus - mehr den Ausdruck und die Farbe der Persiusschen Satire, als | die weniger gesuchte Sprache unsres Horaz zu finden, so daß ich sie, ihren innren Werth völig unbeschadet, dem letzten gleichwohl abzusprechen geneigt seyn möchte. - In Serm. II.1.59 möchte ich doch in diesem Zusammenhange, die vulgata iusserit vorziehen: das nachdrückliche in dem letzten Worte scheint hier mehr an seiner Stelle, als das, besonders auf exul bezogene, mehr spielende inferit, wofür illudere rebus humanis und Ludum Fortunae, keine hinreichende Gewähr mir zu geben scheint. - Auch kann ich Fea nicht beistimmen, wenn er II.2.129. proprie statt propriae tell. herum in den Text aufnimmt. Denn das simplere telluris herum, ohne das beschränkende Beiwort eines mit zugehörigen Theils der Erde, auf dem ich wohne, enthält einen Gedanken, der hier unangemeßen wäre. An einen Herrn der Erde überhaupt konnte Asellus hier nicht denken, sondern an einen Herrn des winzigen Theils der Erde, den jemand erworben, oder durch Erbschaft erhalten, als sein Eigenthum ansieht. Daher propriae telluris, welchen Ausdruck Sie selbst, mit Zurückweisung Fea's, hinlänglich gerechtfertigt haben. Endlich scheint mir proprie, in diesem Sinne, mehr der Prose, als der Poesie anzugehören, was ich doch vom griechischen i $\delta i ́ \omega s$, | nach Ihrer glücklichen Conjectur in dem dem Lucian zugeschriebenen Epigramm, statt des höchst matten u. prosaischen ö $\lambda \omega \varsigma$, nicht behaupten möchte. Übrigens findet sich das Adverb i $\delta^{\prime} \omega^{\omega} \omega \varsigma^{6}$ bei Passow ${ }^{7}$ p. 729 col. B., zwar nicht

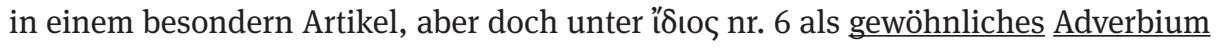
vor $^{8}$ i $\delta i ́ \alpha$ aufgeführt. - Der in der $3^{\text {t }}$ Satire lib. II von Ihnen schon vor zwanzig Jahren gemachte, und jetzt mit verstärkten Gründen unterstützte Vorschlag, die 4 Verse 27-31 Atque - ut libet, dem Horaz und nicht dem Damasipp ${ }^{9}$ zuzuschreiben, hat alles für 
sich, und läßt sich, so ausgeführt, leicht gegen Heindorf's Einwürfe behaupten. Bei welcher Gelegenheit ich so dreist bin, Ew. Hochgeboren, im Fall noch ein übriges Exemplar Ihres Danziger Programms De Satirae atque Epistolae Horat. discrimine, das ich längst vergebens zu erhalten gesucht habe, bei Ihnen vorräthig seyn sollte, um die gütige Mittheilung desselben ergebenst zu bitten. - Bei Serm. II.6.47 sq. kann ich noch nicht mit mir einig werden, welche interpunction vorzuziehen seyn möchte. Härte der Construction bleibt in beiden Fällen, man mag noster zu subiectior invidiae, oder zu ludos spectaverit ziehen. Doch gefällt mir Ihr Vorschlag, noster mit spectaverit zu verbindden, beßer, nur daß ich nach Invidiae die volle Interpunction mit dem comma, welches den Zusammenhang der beiden Sätze noch verwickelter macht, nicht vertauschen würde. Bei dem reichen Stoff zu kritischen Bemerkungen, den Ihre Schrift darbietet, seh' ich mich genöthigt hier abzubrechen, ne patientia tua abutar. - Der Menexenus ist nicht nur nicht erschienen, sondern wird wahrscheinlich, da er noch unvollendet ist, mit dem | Augustinschen Ajax ${ }^{10}$ ein Schicksal haben. Wegen des mir gütigst mitgetheilten Verlangens des würdigen Hn. Hofr. Böttiger's hab ich mich an den hiesigen Buchhändler Hn. Moritz gewandt, da ich selbst keine Exemplare des $\underline{\text { Philoktets }} \mathrm{u}$. der $\underline{\text { Trachinierinnen }}^{11} \mathrm{zu}$ meiner Disposition habe. Mit den beiden Programmen über Zamolxis steh' ich gern zu Diensten, si tanti est. Sehr angenehm war \

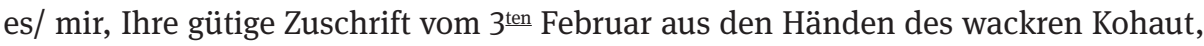
wiewohl erst um die Mitte Aprils, zu erhalten. Er hat auch hier ein zahlreiches Publicum vereinigt, und, wie er's verdient, viel Beifall geerndtet. Seine Bekanntschaft hat mir recht viel Freude gemacht.

Mit inniger Verehrung

Ew. Hochgeboren

Wilna den 1 October

ergebenster

1822

Groddeck

${ }^{1}$ A. Jacob, Quaestionum etc., Warschau 1821. $-{ }^{2}$ Verbessertaus: denn. $-{ }^{-3}$ Danach ein Komma gestrichen.
$-{ }^{4}$ Übersetzung des Horaz von Voss, 2. Aufl. $1820 .-{ }^{5}$ Johann Valentin Francke (1752-1830) seit 1821
Professor in Dorpat, vgl. Süss S. 147, $249 \mathrm{ff} .-{ }^{6}$ Nach gestrichenem: $0 \lambda \omega .-{ }^{7}$ Franz Passow (1786-1833)
aus Ludwigslust, 1815 Professor für Griechisch in Breslau, Handwörterbuch der griechischen Sprache,
Bd. I-II, Leipzig 1819 und $1824 .-{ }^{8}$ Nach gestrichenem: per. $-{ }^{9}$ Fiktiver Gesprächspartner in Horaz'
Satiren I 10. $-{ }^{10}$ Bei Sueton, Aug. 85,2 (K). $-{ }^{11}$ Groddeck hatte die Trachinierinnen 1808, den Philoktet
1806 herausgegeben (K).

44. Groddeck an Karl Morgenstern, am 10.1.1823

Hochgeborener

Hochzuverehrender Herr StaatsRath u Ritter

Ein junger talentvoller Künstler, Herr Smokowski $^{1}$ der sich hier unter unsern Russen im Zeichnen u. Malerei gebildet, auch in der Sculptur gute Fortschritte gemacht hat, 
und jetzt von unsrer Universität nach Petersburg zur weitern Ausbildung u. Vervollkommnung auf ihre Kosten geschickt wird, hat mich ersucht, da er seine Reise über Dorpat macht $\mathrm{u}$. dort ein paar Tage zu bleiben gedenkt, ihm die Gelegenheit zu verschaffen Ew. Hochgeboren Bekanntschaft zu machen, u. mit Ihrer gütigen Bewilligung $u$. besonderen Empfehlung das dasige Museum $u$. andre Merkwürdigkeiten in Augenschein ${ }^{2}$ nehmen zu können. Er ist daher der Überbringer dieses Briefes, den ich ihm, als einem hoffnungsvollen und gesitteten Zögling unsrer Universität um so weniger | verweigern konnte, je inniger ich von Ihren wohlwollenden Gesinnungen und Ihrem unermüdeten Eifer für alles Edle Schöne $u$. Gute in Wissenschaft $u$. Kunst überzeugt bin, und je angenehmer mir die sich darbietende Gelegenheit ist, mich Ihrem gütigen $u$. freundschaftlichen Andenken aus Neue zu empfehlen.

Mit wahrer Hochachtung hab ich die Ehre zu seyn

Ew. Hochgeboren

Wilna den $10^{\text {ten }}$ Januar

1823 ergebenster Diener

Groddeck

${ }^{1}$ Wincenty Smokowski (1797-1876), polnischer Maler, Zeichenlehrer in Wilna, später Ausbildung in Petersburg. - ${ }^{2}$ Danach gestrichen: zu.

\section{Karl Morgenstern an Groddeck, undatiert}

\section{Hochgeborner}

Hochzuverehrender Herr Hofrath und Ritter,

Hr. Smokowski war mir ein angenehmer Besuch, da er $\mathrm{w}<\ldots>^{1}$ kam. Ich zeigte ihm einiges von Kunstsachen in meiner Wohnung, wies ihn auch hin zu unserm Prof. Senff ${ }^{2}$. Auch versprach er, am nächsten Morgen in das große Auditorium unsrer Universität zu kommen, wo Reden gehalten werden sollten, wobey ich zugegen seyn mußte. Nach Endigung derselben versprach ich ihm, ${ }^{3}$ das an das Auditorium dicht anstoßende Museum zu zeigen. Ich fand ihn aber nicht in jener Versammlung, obwohl er kommen wollte, muß also vermuthen, daß er schon abgereist war. Es lag mithin nicht an mir, daß er unser kleines Museum nicht gesehen hat. Ich hatte ihm auch einen Brief an meinen Freund, Karl v. Kügelgen ${ }^{4}$, den berühmten Landschhaftsmaler des Kaiserl. Cabinets der Hermitage in St. Petersburg, angeboten, den er zugleich sich abholen wollte. Doch wie gesagt, er kam nicht.

Hiebey habe ich die Ehre Ihnen mein neuestes Programm $<\ldots>^{5} \mid$ amten kleine Schrift behalte ich mir vor, Ihnen bey nächster Univers.-Post beyzulegen, neml. ein Ex. meines Versuchs über Rafael's Verklärung ${ }^{6}$, geheftet, ehemals in Paris entworfen im J. 1810, erst jetzt mit litt. Anm. in Dp. gedruckt. Zugl. werde ich auch für Sie meinen Versuch über die $\underline{\mathrm{P}<. .>\mathrm{schen}^{7}}$ (Gr. und lat.) Inschriften, zu den vom Rector $\mathrm{G}<. .>$ ren $^{7}$ 
herausgegebenen Wallfahrten ins Morgenland von Otto Richter ${ }^{8}$ gehörig, beylegen, da ich ein paar Exemplare für $<\ldots>^{9}$ besonders habe abziehen lassen.

Für heute kann ich nur die Versicherung meiner unwandelbaren Hochachtung hinzufügen, mit welcher ich bin Ew. Hochgeboren ergebenster Diener

Morgenstern |

Recht sehr danke ich Ihnen noch für Ihr gütiges Schreiben vom 1. Oct. 1822, das mir erst in diesem Augenblick wieder in die Hand fällt, so wie für Ihr lehrreiches Programm de fine Tragoediae Gr. p. Meine Ansicht behalte ich mir vor, Ihnen mitzutheilen, sobald ich \acob. In aest. Sophocl. werde gelesen haben, was leider nicht der Fall seyn konnte, da ich sie vor kurtzem, aus Deutschl. verschrieben, erhalten habe. Sehr willkommen waren mir Ihre speciellen Urtheile über einzelne meiner Bemerkk. über Horat. Serm. Eben so erwünscht wären mir ähnliche über die Platonische Stellen gewesen. Wie angenehm, wenn ein unpartheyischer so gelehrter und kritischer Freund uns dergl. mittheilt, wie Sie mir schon mehrmals gütig haben zukommen lassen!

Mstn.

Die Schrift über die Inschriften lege ich gleich noch bey, da ich vom Buchbinder so eben ein geheftetes Ex. bekommen. Ihr Urtheil über das Einzelne, das ich Ihrer strengsten Prüfung zu empfehlen wage, wird mir um so lieber seyn, je mehr es ins Detail | geht. Was Sie mir mittheilen, ist übrigens zunächst nur für mich geschrieben, so daß niemand compromittirt wird. Bey dem was ich p. 639 sage, bedaure ich, als ich schrieb, nicht an Ihr sehr gelehrtes Programm, das auch in den Miscellan. v. Tiedem $<$ ann $>{ }^{10}$ und Seebode wieder abgedruckt ist, gedacht $\mathrm{zu}$ haben. Sonst hätte ich bey der Stelle aus Jul. Poll. unfehlbar darauf Rücksicht genommen. Ich erinnerte mich aber zu spät, als dieß schon abgedruckt war. Unfehlbar hätte ich sonst das Gesagte noch anders modificirt $u$ ausdrückl auf Sie verwiesen.

${ }^{1}$ Wort nicht lesbar. $-{ }^{2}$ Karl August Senff (1770-1838) aus Merseburg, seit 1802 in Dorpat, 1803 Universitätszeichenmeister, 1818 Professor für Malkunst, 1825 Kollegienrat. Mit Morgenstern befreundet, s. Süss S. 136. $-{ }^{3}$ Danach gestrichen: ihm. $-{ }^{4}$ Karl v. Kügelgen (1772-1832), erzogen im Jesuitenkollegium von Bonn, Freund von Morgenstern, Hofmaler in Petersburg, zeichnete und malte in kaiserlichem Auftrag Landschaften auf der Krim, vgl. Süss S. 277 f. und 281. $-{ }^{5}$ Letzte Zeile der Seite nicht lesbar. $-{ }^{6}$ Dazu Süss S. 202. $-{ }^{7}$ Name nicht lesbar. $-{ }^{8}$ Otto Friedrich v. Richter (1792-1816) aus dem Dorpatischen, Philologe und Forschungsreisender, zeitweise russischer Diplomat; zu ihm Süss S. 247 f. $-{ }^{9}$ Wort nicht lesbar. $-{ }^{10}$ Dazu Süss S. 92.

46. Karl Morgenstern an Groddeck, am 17.3.1823

Dorpat, d. 17. März 1823

Durch Hn. Ignaz v. Terlecki ${ }^{1}$, stud. Jur., der über Wilna nach Paris reisen wollte, nahm ich mir die Freiheit, Ew. Hochgeb. einen Brief zu senden, zugl. mit 1 Ex. meines Pra- 
gramms von dem Lectt.Katal. vom Januar 1823 (Ruhnk. Epp.)² und worin Gedrucktes über die Ruhnkenischen Schriften

Heute überreiche ich Ihnen, Verehrtester Herr und Freund, meine Monographie über Rafaels Verklärung. Möge sie Ihnen reiche Unterhaltung gewähren! Ich bitte das kleine Geschenk mit gewohnter Güte aufzunehmen.

Da sie auf meine Kosten gedruckt ist, so ist mir der Absatz nicht gleichgültig. Es sind nur 300 Ex. gedruckt; der $\underline{\mathrm{L}<. .>\text { tepreis }}$ ist 1 Silb.Rbl. Sollten sich nicht vielleicht in Wilna einige Liebhaber finden?

Noch erlaube ich mir eine Anfrage. Bey mir steht eben verkäuflich: Histoire générale d'Allemagne par le P. Barre, à Paris 1748, 4 to, eilf Bände. Dieß Werk, sehr wohl conditionirt, in ganzen Marmorband gebunden, zu dem geringen Preis von 12 SilberRbl. was beynahe der Druck gekostet haben mag.

Ad. Smith \Theory/ of moral sentiments. The sec. Ed. London $1761^{3}$ q 8. Engl. Band | Brulker. Institt. Historiae philosophicae. ed. Born. Lips. 1790 qu 8. broschirt à 2 SilbRbl

Rob. Scharrock de Officiis secundum Naturae Ius. Oxon. 1660. 8. Prg.bd. 1 SilbRbl.

Diese Bücher gehören nicht der Universität, werden aber für die Un.Bibl. nicht gekauft, weil sie <!> schon hat. Sollte Ihre UBibl. vielleicht etwas zu den bemerkten Preisen brauchen können? In diesem Falle bäte ich um baldige Antwort. Im $<\ldots>$ falle ${ }^{4}$ bedarf es gar keiner $<\ldots>^{4}$ Ich bin nur gebeten, den Verkauf für den Eigenthümer zu besorgen.

Erhalten Sie mir stets Ihr freundschaftliches, mir so theures Wohlwollen. Unveränderlich mit Verehrung

$$
\begin{gathered}
\text { Ihr ergebenster Diener } \\
\text { Morgenstern }
\end{gathered}
$$

\footnotetext{
${ }^{1}$ Ignacy Terlecki (1797-1867), aus altem russischen, dann polonisierten Adelsgeschlecht in Litauen. Als Autor (Heroldia i porzadek otrzymywania od niej utwierdzienia szlachetstwa, 1832) von Estreicher IV S. 500 genannt. Ehrenrat in Petersburg. $-{ }^{2}$ Ruhnkenii Epistolae, von Morgenstern publiziert in dem Programm der Universität 1823 II; dazu Süss S. 130. $-{ }^{3}$ Es ist die zweite Aufl., die erste 1759. $-{ }^{4}$ Wort nicht lesbar.
}

47. Groddeck an Karl Morgenstern, am 15. 11. 1823

Hochgeborener

Hochzuverehrender Herr StaatsRth und Ritter

daß ich Ew. Hochgeboren so spät erst meinen wärmsten Dank für die im Laufe dieses Jahres von Ihnen erhaltenen Geschenke, die Epp. Ruhnkenii ${ }^{1}$, über Raphaels Verklärung $^{2}$, und Ihre Entzifferung u. Erklärung der Richterschen Inschriften ${ }^{3}$, bezeige dafür weiß ich keine andere Entschuldigung als dieienige, die bei einem Manne von Ihrem Geist u. Herzen gewiß als gültig wird befunden werden. Ein herbes häusliches 
Leiden - mein erstgeborner Großsohn, an den <! > mein ganzes Herz hing ward mir u. der unendlich leidenden Mutter im achtzehnten Monat seines Lebens \nach 3monatiger Krankeit/ entrißen - und mancherley öffentliche Bedrängniße, von denen der Ruf vielleicht auch schon zu Ihnen gedrungen ist, hatten $u$. haben mich so verstimmt, daß ich nur in der pünktlichen Erfüllung meiner täglichen Berufsgeschäfte die einzige mir zusagende Erholung u. Linderung meines Unmuths finden konnte. Dennoch hab ich Ihre treffliche Erläuterung der Richterschen Inschrift auf Eulalios ${ }^{4}$ mit eben so viel Vergnügen als Belehrung gelesen $u$. wieder gelesen, $u$. ich wüßte keinen Punct in Ihrer gelehrten Untersuchung, in dem ich andrer Meinung wäre, oder Ihren Gründen

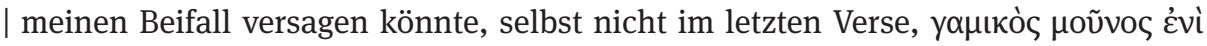
$\varphi \theta \mu \varepsilon^{\prime}$ oıs, wo die nur beinahe natürliche Abneigung gegen allen Mysticismus, den Abgott unsrer Tage, mir leicht einen Streich hätte spielen können.

Ihre Schrift über Raphaels Verklärung ist ein schönes Seitenstück zu ähnlichen künstlerischen Ausführungen die wir Ihnen verdanken. Gleichwohl wäre die Zugabe eines schön gestochenen Kupferstiches für das größere Publicum nicht überflüßig gewesen, und mir selbst wär' es leichter gewesen, Ihrem Verlangen, hier einige Liebhaber zu finden - wo man fast sagen könnte: Germanica sunt, non leguntur ${ }^{5}$; einigermaßen zu genügen. Jetzt schäme ich mich fast, nur um ein Exemplar für die hiesige Bibliothek Sie zu bitten, deßen Betrag ich mit erster Gelegenheit Ihnen zuzustellen die Ehre haben werde. - Die Epp. Ruhnkenii, wie alles was aus des großen Mannes Feder kam, haben mir einen sehr angenehmen Genuß gewährt.

Um nun diesen Spätling nicht so ganz ohne Begleitung den langen Weg zu Ihnen machen zu laßen, hab ich ihm aufgetragen, bei ${ }^{6}$ Ew. Hochgeboren für sich und seine beiden Brudergefährten die Paralipomena Apolloniana ${ }^{7}$ und den zweiten $\mathrm{u}$. letzten Theil der Initia in meinem Namen zu bitten. Man könnte den letzten auch mit Recht auch einen Spätling nennen, denn meinem Vorsatz $u$. Versprechen gemäß hätte er schon im Frühling des vorigen Jahres ans Tageslicht kommen sollen. Doch diese | halb verschuldete, halb unwillkührliche Zögerung wird durch die reicheren Addenda zum Ersten Theil, zu denen auch Ihre Belesenheit, wie ich dankbar erkenne, freigebig gesteuert hat, gewißermaßen vergütet - wiewohl der letzte Meßcatalog, den ich beim Abdruck noch nicht benutzen konnte, wieder eine $<\mathrm{n}>^{8}$ beträchtlichen Nachlaß gebracht hat. - Aber was in aller Welt sagen Sie zu dem Troer Homer ${ }^{9}$ ? und zu der einige 40 Seiten langen Anpreisung dieses Wunderkindes in der Jenaischen Zeitung? Zum Glück hat der scharfsinnige Erfinder deßelben durch einen wirklich ingeniösen Einfall uns von der Furcht befreit, noch eine Troische Literaturgeschichte in unserm Alter lernen zu müßen. Desto einziger steht dafür dieser Troianische Hofpoet des Pius Aeneas Majestät als glänzender Meteor am litterarischen Himmel da. Übrigens scheint es mir mit der Polemik gegen Wolf, die doch eigentlich die Hauptsache der Schubarthschen Schrift ${ }^{10}$ ist, nicht viel auf sich zu haben. Neues hab' ich, so viel ich mich erinnere, nichts darin gefunden, des aufgewärmten $u$. oft genug widerlegten desto mehr. Und $^{12} 1$ was mich am meisten wundert, weder beim Verfaßer, noch bei ${ }^{12}$ seinen <!> Sachwalter-Recensenten nicht die geringste Rücksicht oder auch nur Erwähnung der 
trefflichen Abhandlung \von Thiersch/ über die Gedichte des Hesiodus, die ihm über viele Zweifel hinlänglichen Aufschluß hätten geben können. Doch genug über einen gewiß bald vergeßenen Traum in einer wahrscheinlich langen Winternacht, über den ich gleichwohl Ihr Urtheil zu hören sehr begierig bin.

Mit unwandelbarer Hochachtung und Verehrung

Ew. Hochgeboren

Wilna den 15 November 1823

ergebenster Groddeck

\begin{abstract}
${ }^{1}$ Vgl. Süss S. 130. $-{ }^{2}$ Zu Raphaels Verklärung s. Süss S. 202. $-{ }^{3}$ Zu Richter s. zu Nr. 45 Anm. $8 .-{ }^{4}$ Sie steht im 2. Bd. von Boeckhs Corpus Inscriptionum graecarum, 1843 als Nr. 2647; dort Morgenstern mehrfach mit Lob genannt; dann bei Kaibel, Epigammata graeca ek lapidibus conlecta, 1878, mit einer Erklärung des von Morgenstern zitierten Verses, die von Wilamowitz stammt und nach Süss S. 253 mit der von Morgenstern vorgetragenen übereinstimmt (K). $-{ }^{5} \mathrm{Im}$ Mittelalter: Graeca sunt, non leguntur. $-{ }^{6}$ Über einem gestrichenen, nicht lesbaren Wort. $-{ }^{7}$ Aus diesem Jahr stammt von Groddeck: Disputatio de Apollonii Rhodii fontibus, 1823. ${ }^{8}$ Nach , wieder' über der Zeile hinzugefügt: noch zu, dann unverbessert geblieben: einer. ${ }^{9}$ Zum Troer gemacht wird Homer in der gleich genannten Schrift von Schubarth (K). $-{ }^{10}$ Karl Ernst Schubarth (1796-1861), Ideen über Homer und sein Zeitalter, Breslau $1821(\mathrm{~K}) .-{ }^{11}$ Nach gestrichenem: W. $-{ }^{12}$ Verbessert aus: beim.
\end{abstract}

48. Karl Morgenstern an Groddeck, am 31. 5. 1824

Dorpat, d. 31. May 1824

Hochgeborener Herr Staatsrath und Ritter,

Theurer Freund,

Hiebey sende ich Ihnen mein Programm de numismate Basilii Tschernigoviae nuper et $\langle\ldots\rangle^{1}$ P. I. II., ${ }^{2}$ wovon P. III. in kurzem auch gedruckt werden soll. In Hinsicht der $3^{\text {ten }}$ dunkeln Inschrift glaube ich, (mit Delbrück) ${ }^{3}$, auch etwas weiter gekommen zu seyn, wie sich weiterhin zeigen wird. Ihr nachtrag Ihres $<. . .>^{4}$ bey einem Gegenstand, der seiner Natur nach viel Problematisches ahnen läßt, und mir vorzügl. willkommen seyn, und ich bitte Sie ausdrücklich darum.

Für Ihr gelehrtes Programm über Apollon. Rhod. Argon. in dem Sie ihn erstmals sich $\langle\ldots\rangle^{1}$ machten, hab ich Ihnen wol schon früher meinen Dank gesagt. Den Betrag für das Ex. der Schrift üb. Rafaels Verklärung für die Un. Bibl. in Wilna habe | ich zu seiner Zeit durch Hn. Secr. v. Notte ${ }^{5}$ erhalten.

Für einen von Hn. Raupach ${ }^{6}$ hier abgegebenen Journal7, der so eben gedruckt wird, werden Sie im nächsten Heft von mir einen Vortrag zur Geschichte des Bildungsromans finden, den ich hier hielt, und der vorigen Jahres über den $\langle\ldots\rangle^{1}$ des Bildungsromans im lifländischen Museum ergänzte. Auch dieser Aufsatz $<$... $>^{8}$ ländischen Museum. |

$$
<\ldots>\text { ich Ihnen gestern }<. . .>9
$$


Ich muß schließen, da heute noch Mehreres abgesandt werden muß. Mit alter großer Hochachtung und immer Ergebenheit

der Ihrige

Morgenstern ${ }^{10}$

\begin{abstract}
${ }^{1}$ Ein Wort nicht lesbar. $-{ }^{2}$ Zu den numismatischen Arbeiten Morgensterns s. Süss S. 129. $-{ }^{3}$ Schlußklammer fehlt. Unklar, ob es sich um den Superintendenten von Zeitz Johann Friedrich Gottlieb Delbrück († 1830) handelt, 1800-1809 Prinzenerzieher am preußischen Hof. $-{ }^{4}$ Ein Wort nicht lesbar. Der ganze Satz kaum lesbar, Entzifferung daher fraglich. $-{ }^{5}$ Oder Nolte? $-{ }^{6} \mathrm{C}$. Raupach: seit 1819 Lektor der deutschen Sprache in Dorpat, Herausgeber der Zeitschrift Neues Museum, in der Morgenstern seine Aufsätze über den Bildungsroman veröffentlichte; s. auch Süss S. 140, 145. - ${ }^{7}$ Kaum lesbar; fraglich. $-{ }^{8}$ Letzte Zeile kaum lesbar. $-{ }^{9}$ Die ganze Zeile kaum lesbar. $-{ }^{10}$ Auf gesondertem Blatt die Anschrift: Sr. Hochgeb. I Hn. Staatsrath und Ritter I v. Groddeck I ord. Prof. u. Bibl. I zu I Wilna.
\end{abstract}

49. Groddeck an Karl Morgenstern, am 20. 9. 1824

Hochgeborener

Hochzuverehrender Herr Staatsrath und Ritter, Kaum wenige Wochen sind verfloßen, als ich so frei war, Ihre Güte u. Freundschaft in einigen litterärischen Bedürfnißen in Anspruch zu nehmen, und schon wieder wag' ich eine ähnliche Bitte für einen jungen wißbegierigen und gebildeten Mann, der die Ehre hat Ihnen diesen Brief einzuhändigen, Ludwig von Bernatowicz ${ }^{1}$, ehemals wie man in Deutschland zu sagen pflegt, unser gelehrter Mitbürger, und mit zwei seiner Brüder, als mein Großneffe (petit-neveu), meiner besonderen Aufsicht von seiner trefflichen Mutter anvertraut. Er reist nach Petersburg um dort in einem MinisterBureau eine Anstellung zu suchen, und da ihn sein Weg über Dorpat führt, so hat er mich um eine Empfehlung an Sie, Hochgeschätzter I Freund, ersucht, durch die er den Zutritt zu den Instituten Ihrer Universität sih nicht nur zu erleichtern, sondern auch nützlicher zu machen hofft.

\title{
Quod si
}

Depositura laudas ob amici iussa perdorem,

Scribe tui gregis hunc, et fortem crede bonumque.

Morgen verläßt uns unser trefflicher Bojanus, der nach schweren fünf vierteljährigen körperlichen Leiden endlich doch so weit gekommen ist, daß er zu seiner völligen Wiederherstellung eine eise nach Italien oder ins südliche Frankreich zu machen sich vorgesetzt hat. Möge der Erfolg glücklicher seyn, als der unsres Wolfs ${ }^{2}$, I dessen für die Wissenschaft viel zu früher Hintritt auch Sie gewiß vorzüglich erschüttert haben wird. Andre unser Wilna betreffende Neuigkeiten erfahren Sie beßer von meinem jungen Freunde, der hinlänglich von allem unterrichtet ist. 


\title{
Mit inniger Verehrung unwandelbar der Ihrige
}

Wilna den $20^{\text {ten }}$ September Groddeck

$1824^{3}$

\begin{abstract}
${ }^{1}$ Ludwik v. Bernatowicz ( ${ }^{*}$ ca. 1800), später im Novemberaufstand aktiv. Vielleicht Bruder des Geschichts- und Romanschreibers Feliks Bernatowicz (1786-1836). - ${ }^{2}$ F. A. Wolf war während einer Erholungsreise zur Kur am 8. August 1824 in Marseille gestorben. $-{ }^{3}$ Darunter von Morgensterns Hand: beantw. d. $4^{\mathrm{t}}$ October.
\end{abstract}

50. Groddeck an Karl Morgenstern, am 5.10.1824

Hochgeborener Herr StaatsRath und Ritter

Würdigster Freund,

Ihre eben so glückliche als mit seltener Gelehrsamkeit ausgestattete Erklärung der Chernigowischen Schaumünze, für deren gütige Mittheilung ich Ihnen aufs verbind-

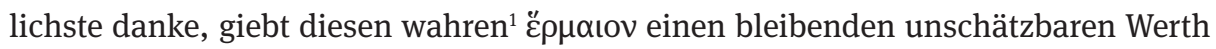
unter den Denkmälern des Rußischen Alterthums. Sie ist so umfaßend, so befriedigend, daß ich, wiewohl ein Laie in diesen öden byzantinischen Steppen, nicht nur mit Beifall, sondern mit wahrer Bewunderung sie gelesen und wiedergelesen habe. Auch die Wilnaer Universität erhielt vor ziemlich geraumer Zeit einen zinnernen Abguß durch den hochverdienten Canzler Rumanzov². Ich hab' ihn sorgfältig | mit Ihrem Kupferstich verglichen und unterschreibe völlig Ihr ${ }^{4}$ Urtheil pag. XXVII Note 36. Aber nicht blos verschönert, sondern auch hie und da verändert schien mir der Stich zu seyn. Besonders auf der Kehrseite, wo nicht nur die Brust des Ungeheuers von Kopfe fast ganz getrennt erscheint, sondern auch keine Spur einer weiblichen Brust verräth, die auf dem zinnernen Ectypon, was ich vor mir habe, ganz unverkennbar ist, so daß ich nicht umhin kann, gegen die Bewertung p. VIII.II. „pectus dignoscitur, quod mammam nonnulli, sine causa tamen idonea esse putant“ $\mathrm{zu}$ protestieren. Was die dritte höchst räthselhafte Inschrift betrifft, so sehe \ich/ dem versprochenen dritten Theil Ihrer Abhandlung begierig entgegen. Doch bin ich völlig Ihrer Meinung, daß sie griechsich ist. Zu denen von Ihnen $\S$ IV u. VIII aufgezeichneten griechischen Wörtern würde ich noch hinzusetzen EПANON (52) vor Évíov, weiter $\Theta E O \Sigma$ vor . $\triangle$ PAKON 5 . Am schwierigsten scheint mir das erste und letzte ${ }^{6}$ Wort der Inschrift, wo ich noch nicht überzeugt bin. Immer höchst auffallend ist die frappante Aehnlichkeit der Inschrift bei Montfaucon7, gerade am Anfang und Ende derselben, so wie des Bildes auf der Vorderseite der Gemme. Sollte sie dem byzantinischen Künstler als Modell | gedient haben?

Erlauben Ew. Hochgeboren mir noch eine Bitte. Ich beschäftige mich eben itzt mit einer kleinen Abhandlung über die Fackelfeste oder Lampadophorion der Griechen, zu der ich die nächste Veranlaßung bei der vorjährigen Erklärung des Persia- 
nischen Verses Sat. VI. qui prior es, cur me in decursu lampada poscis? ${ }^{8}$ fand. Aber es gehen mir leider einige Bücher ab, die ich der Vollständigkeit der Unterrichtung wegen nothwendig vergleichen muß. Besonders folgende zwei: Ast's Igrößere/ Ausgabe der platonischen Republik mit einem ausführlichen Commentar und der $6^{\text {te }}$ Theil der Schneiderschen Ausgabe von Xenophons Werken, der die intereßante Schrift de vectigalibus enthält. Da ich mit der größten Wahrscheinlichkeit voraussetzen darf, daß beide Werke in der Dorpater Bibliothek nicht fehlen, so bin ich so frei, Sie um den freundschaftlichen Dienst ergebenst zu ersuchen, mir die Note Ast's zu

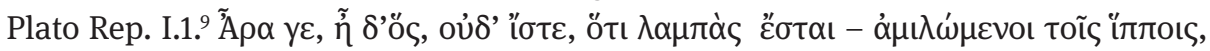

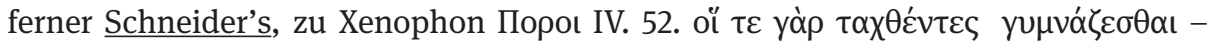

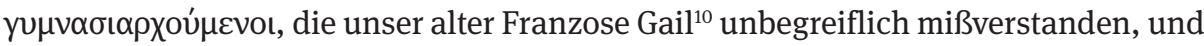
nicht zu seinem Ruhme verunstaltet hat, durch ${ }^{11}$ einen Ihrer Zöglinge abcopieren | und mir möglichstbald ${ }^{12}$ zukommen zu laßen.

Mit inniger Hochachtung und wahrer Verehrung bin ich zeitlebens

Ew. Hochgeboren

Wilna den $14^{\text {ten }}$ August 1824

ergebenster

\section{Groddeck $^{13}$}

\footnotetext{
${ }^{1}$ Nach gestrichenem: seltenen. - ${ }^{2}$ Nikolaj Petrovič Rumjancev (1754-1826), war von 1807 bis 1814 Außenminister und Kanzler des russischen Kaiserreiches. $-{ }^{3} \mathrm{Im}$ Text unklar: Ihren. $-{ }^{4}$ Nachträglich ergänzt zu: Ihren. $-{ }^{5}$ Nach gestrichenem $\Delta$ P. Am Rande: Neutrum I probo. $-{ }^{6}$ Von hier an 5 Zeilen am linken Rande senkrecht angestrichen. ${ }^{7}$ Bernard de Montfaucon (Montefalco<nius $>$ ) (1655-1741), Bendediktiner, Altertumsforscher. Welches seiner Werke hier gemeint, ist unklar. ${ }^{8}$ Persius 6,61 (K). $-{ }^{9}$ Die Stelle ist: Politeia 1328 a. $-{ }^{10}$ Jean Baptiste Gail (1755-1829). $-{ }^{11}$ Nach gestrichenem: durch. $-{ }^{12}$ Nach gestrichenem: bald. $-{ }^{13}$ Darunter von der Hand Morgensterns: Beantwortet d. 5. Oct. 24.
}

51. Karl Morgenstern an Groddeck, am 29.11.1824

Dorpat. d. 29. Nov. 1824

Ew.Hochgeboren

habe ich das Vergnügen hiebey meine, schon in dem Briefe vom 5. Octob., den Sie hoffentlich erhalten haben, angekündigte Curas secundas in numisma<te> Basilii Ew. zu überreichen. Mögen sie Ihnen einige Unterhaltung schaffen! Ihr unpartheiliches Urtheil wird mir sehr willkommen seyn, und um so mehr, je mehr es in Einzelnes eingeht.

Neulich sprach ich den wirkl. Staatsrath Christian v. Beck ${ }^{1}$ aus St. Petersburg, da er ein paar Tage in Dorpat war. Ich erwähnte gegen ${ }^{2}$ ihn auch $<. . .>^{3}$ des Hn. v. Bernatowicz, den ich vor etwa zwey Monaten zu sehn das Vergnügen hatte. Hr. v. Beck (beym Depart. der ausw. Angelegenheiten) versprach, ihm zu diesem Zweck behülfl. zu seyn.

Mit unwandelbarer größter Hochachtung und freundschaftlicher Ergebenheit der Ihrige Morgenstern. 
${ }^{1}$ Christian v. Beck: wohl der Philologe Christian Daniel v. Beck (1757-1832), der 1779 in Leipzig Privatdozent, 1782 ao. und 1785 ord. Professor war. $-{ }^{2}$ Nach gestrichenem: für. $-{ }^{3}$ Ein Wort nicht lesbar. $-{ }^{4}$ Auf gesondertem Blatt die Adresse: Sr. Hochgeboren I Hn. Staatsrath u Ritter I v. Groddeck I Prof. u Bibl.Dir. der K. Univers. I zu I Wilna.

52. Groddeck an Karl Morgenstern, am 20.12.1824

\section{Hochgeborner}

Hochzuverehrender Herr StaatsRath und Ritter,

Mit meinem wärmsten Danke für Ihre gütigen theils schriftlichen theils gedruckten Mittheilungen huldige ich zugleich der großmüthig aufgewandten Zeit und Mühe Ihrer vortrefflichen Gattin zum Besten meines ungekannten aber von Ihnen empfohlenen Freundes ${ }^{1}$. Ihre Curae secundae zu der vielbesprochenen Goldmünze hab' ich mit vielem Vergnügen in diesen Tagen erhalten und behalte mir bei meiner sparsam zugemeßenen Zeit vor sie in den nahe bevorstehenden Weihnachtsferien gründlich zu studieren. Soviel ich bei der ersten flüchtigen Durchsicht abnehmen konnte, so bin

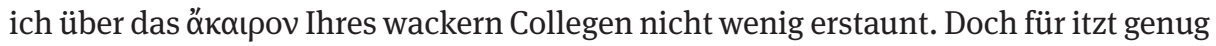
davon, indem ich eile, Ihrem scharf|sinnigen Urtheile eine so viel ich weiß neue Erklärung einer bisher mißverstandenen Stelle des Pausanias die Lampadephoria betreffend, vorzulegen, und Sie über Ihr \unpartheiisches/ Gutachten zu befragen. Ich sehe mich genöthigt um Sie vollkommen zu instruiren, ein Fragment meiner noch ungedruckten Abhandlung über den Fackellauf hier wörtlich anzuwenden:

„Sed maior oritur difficultas si de certantium vel numero vel ordine quo singuli cursum perfecerint, quodeus $<$ ? $>$ certisque argumentis definire velis, utrum, quotquot currerent, semper alius post alium, dispositis stationibus, ardentem facem cursans iactarit, an interdum una et simul, licet per certa intervalla, currentes ad metam properaverint; denique cuinam cursorum: uni an pluribus, victoriae praemium adiudicatum sit. - Ut de numero certantium incipiam, an Pausaniae loco allato (1. 30.) recte quidem Meursius collegisse videtur, in Prometheis tres fuisse qui certarent; sed parum considerate ita pergit: Tradebant nempe inter currendum alter alteri. Id enim

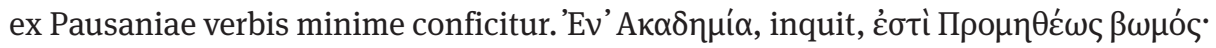

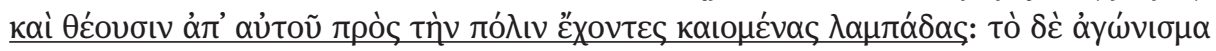

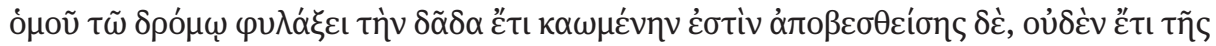

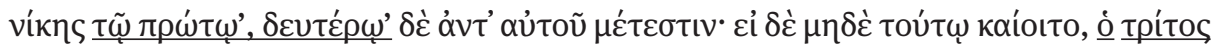

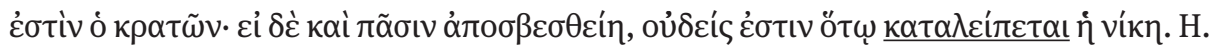
e. In Academia ara est Promethei: a qua ${ }^{2}$ ad urbem currunt ardentes taedas tenentes. ${ }^{3}$ Certaminis vero ea ratio est, ut inter currendum ardens fax non exstinguatur. Qua quidem extincta, iam nullum amplius in victoriam ius competit primo ${ }^{4}$ (currentium); $\underline{\text { sed in se eius locum cedit secundo }}{ }^{4}$. Quodsi vel huic flamma concidat, tertius ${ }^{4}$ victor est. Si autem omnibus extincta fuerit, I nullus est cui victoria supersit ${ }^{4}$. - Patet hinc tres a Pausania commemoravi cursores, qui cuncti accensas faces manu tenentes 


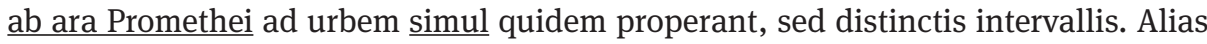
non primum, secundum, tertium cursorem nominasset scriptor, sed unum, alterum,

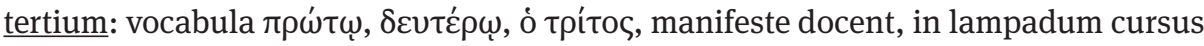
hocnon minus quam in aliis ludis gymnicis ${ }^{\star}$,

* V. c. in ducta, pugilatu et pancratio, ubi, $\mathrm{n}<\mathrm{i}>$ si plures luctatores, ut Boeckhii ${ }^{5}$ verbis utar in egregio Commentario ad Pind. Pyth. VIII. 85/117.) pag. 318) „si igitur plures luctatores vel pugilas vel pancratiastae nomen professi erant, forte componebantur paria; quodsi impar eorum qui certaturi erant, numerus reperiebatur, cui sors nullum dederat adversarium, is $\varepsilon \varphi \varepsilon \delta \rho o \varsigma$ supererat.“ Vide Lucianum in Hermotimo c. 40. cuius de $\dot{\varepsilon} \varphi \varepsilon^{\delta} \delta \rho o u$ illius commodis et felicitate haec ibi leguntur verba:

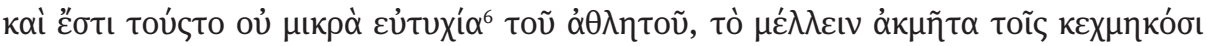

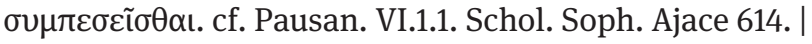

sortis seu fortunae aliquod munus fuisse, cui victoria aliquatenus deberetur. Rem sic se habuisse mihi fingo. Quamvis multa in certamen essent descensuri, tamen non nisi tres semper una currebant, e quibus, quis ordine primus, qui secundus tertiusve curreret, sors decernebat. Itaque primo certantium cursum incipienti, brevi, ut opinor, temporis spatio interiecto, secundus processit, quem simili intervallo tertius sequeretur. Iam ponamus, omnium trium simul currentium eamdem tum pedum velocitatem, tum munuum quae faces iactabant dexteritatem fuisse, ita ut eorumquisque haud extincta face urbem attingeret; non nisi unus tamen victor extitit, nimirum is qui sortis decreto primus cursum incipiens, idem ad metam primus pervenisset. Contra si, Pausania auctore, accideret, ut primi currentis fax exstingueretur ${ }^{7}$, secundo cessit victoriae spes, qua ${ }^{8}$ vel hoc, si res ita cecidisset, destituto, victoriae potiri poterat; si omnes adverso fato currerent, nemini victoria contigit, seu potius relinquebatur,

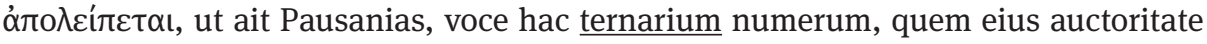
posuimus, abunde confirmans. Sic universus Pausaniae locus, adhunc parum intellectus, in clarissima luce positus est, nec amplius erit, opinor, qui cum Meursio aliisque interpretibus (Cayles, Larcher ${ }^{9}$ cet.) manifestam scriptoris sententiam obscure et corrumpere velit, ${ }^{10} \mid$ contendens, inter currendum primum secundo, hunc item tertio tradidisse taedam, scilicet extinctam! Quod quam absurdum sit statuere „nemo non videt. Quorsum enim, ,amabo'.“ alteri facem traderet quae ardere iam desierat? ut alter eam rursus accenderet? Ubi? Et currens? At trium cursorum quisque suam facem, in ara Promethei accensam, manu versabat, neque aliena, eaque etiam extincta, opus habebat etc. Die Ursache des seltsamen Irthums ist offenbar die vorgefaßte Meinung als hätt' es nur Eine Gattung des Fackellaufs gegeben, die berühmteste nämlich auf die Herodot VIII.98. anspielt, u. die zu so vielen ernsten u. zum Theil rührenden Vergleichen beim Lucrez, in der Anthologie u.a. Veranlaßung gegeben hat. Schon Jacobs Animadv. in Epigr. vol III. p. 320 sq., nachdem er <... $>^{11} \backslash$ die gewöhnliche $\langle\ldots\rangle^{11}$ weniger/ vage Erklärung angeführt hat, bemerkt richtig: Ex veterum locis .. apparet, plura aliis instituendi fuisse genera, aber setzt gleich mit Reis $<$ ke $>^{12}$ hinzu: quae nunc explicare nihil attinet. - Nach meiner Erklärung der Stelle des Pausanias läßt sich auch, wie mir scheint, einiges licht in die \sonst/ seltsame Anmerkung des 
alten Scholiasten zu Persius Sat. VI.61. bringen. Er sagt: Apud Athenas quum invenes ludos cursu celebrabant, qui victor esset, primus facem tollebat, worüber sich schon Caylus den Kopf zerbrochen hat, wiewohl er eine ziemlich glückliche Ahndung hat, die er nur nicht verfolgt. Ich verstehe die Stelle so: der Junge, der der Sieger seyn sollte (nach Bestimmung des Looses) $\underline{\text { hob }}^{13}$ der erste die Fackel nehmlich vom Altar des Prometheus, wo er sie anzündete. Nur gleich darauf fällt er in den ${ }^{14}$ eben gerügten Irthum: deinde sequenti se tradebat et secundus tertio: similiter omnes, donec currentium numerus impleretur. Offenbar \aber/ hat er die Stelle des Pausanias vor Augen gehabt. - Doch ich fürchte Sie schon mit diesem langen Detail zu ermüden, wenn ich gleich Ihrer Nachsicht selbst in solchen dem Anschein nach kleinlichen Untersuchungen (wiewohl dem ächten Philologen nichts kleinlich scheinen sollte, was auf irgend eine Art zum beßern Verstehen der Alten behülflich ist oder werden kann) gewiß bin. Für Ihr wiederholtes gütiges Andenken an meinen Bernatowius danke ich Ihnen herzlich, biederer Mann! und bleibe mit inniger Hochachtung und Verehrung unwandelbar Ihr ergebenster

Wilna den 20 $\underline{\text { ten }}$ December 1824

Groddeck

Viel Glück u. Freude zum heute angefangenen Neuen Jahre!

\footnotetext{
${ }^{1}$ Bernatowicz? - ${ }^{2}$ Die letzten beiden Worte doppelt unterstrichen. $-{ }^{3}$ Die letzten vier Worte doppelt unterstrichen. $-{ }^{4}$ Doppelt unterstrichen. $-{ }^{5}$ Es handelt sich um die Pindarausgabe mit Kommentar von Boeckh. $-{ }^{6}$ Danach ein Komma gestrichen. $-{ }^{7}$ Nach gestrichenem: es. $-{ }^{8}$ Nach gestrichenem: quae. $-{ }^{9}$ Darüber ein Name gestrichen, nicht lesbar. $-{ }^{10}$ Es folgt bis zum Schluß der Seite die Anm. mit *, s.o. $-{ }^{11}$ Ein Wort nicht lesbar. $-{ }^{12} \mathrm{Im}$ Text: Reist. $-{ }^{13}$ Danach gestrichen: die. $-{ }^{14} \mathrm{Im}$ Text anscheinend: dem (unter Strich).
}

\subsection{Aubin Louis Millin an Groddeck 1806-1816}

\section{Aubin Louis Millin an Groddeck, am 2.1.1806}

Monsieur, j'ai recu avec une vive reconnaissance les marques de souvenir que vous avez bien voulu me donner. j'ai inseré dans le magazin le prospectus du journal polonais que vous m'avez fait parvenir et voici le morceau sur la manière de traiter les mythes qui a ete inseré dans le magazin de décembre 1805. j'ai pris la liberté d'y faire de legers changemens seulement le style <.> j'se esperer que vous ne les des approuverez pas. je serai tres flatte de recevoir les faire connaitre a mes concitoyens. ${ }^{1}$

Un autre numero contiendra une notice de votre dissertation de Scena in theatro graecorum ${ }^{2}$ et j'aurai l'honneur de vous l'adresser.

je joins a ma lettre une dissertation entrante de mon grand recueil des monuments antiques inedits $^{3}$ et j'ajoute encore quelques dissertations entrantes du magazin ${ }^{4}$ que 
vous serez bienaise sns doute d'avoir separement. comme j'aime beaucoup a recueillir de ces sortes de prèces je juge de votre gout pour le même.

je serai empressé de faire connaitre en france la production de vas savantes et les travaux de votre universite comme je recois une notice de ceux de l'academie de Goettingue.

avec ma première lettre vous recevrez d'autres dissertations dont deux ${ }^{5}$ de ma sur le temple de Montmorillon ${ }^{6}$ et sur le diptyque de Sens ${ }^{6}$ accompagnees de belles figures.

j'ai fait chercher vainement vos dissertations ${ }^{7}$ de hymnis homericis - in primum Idyllium Theocriti - de morte voluntaria - de oraculis Herodoti ${ }^{7}$ - en auriez vous encore quelque copie dont vous pourriez disposer.

agreez l'assurance de l'attachement et du respect avec les quels j'ai l'honneur d'etre

\title{
Monsieur
}

votre tres humble

et tres obeissant serviteur

\author{
A. L. Millin
}

\begin{abstract}
${ }^{1}$ Am unteren Rande von anderer Hand: M. Grodeck. $-{ }^{2}$ De scena in theatro graecorum imprimis de tertiarum partium auctore sive tritagonista praeeunte Julio Polluce, von Groddeck 1805 in Wilna veröffentlicht. $-{ }^{3}$ Bezieht sich auf seine Introduction a l'étude des monumens antiques, des pierres gravées, des médailles et des vases peints, die seit 1796 in Paris erschien, bis dahin drei Bände, deutsch 1798; der letzte Band erschien 1811. - ${ }^{4}$ Bezieht sich auf sein Magasin encyclopédique, ou Journal des Sciences, des Lettres et des Arts, das er seit 1795, zuerst mit Anderen, dann allein, herausgab; s. u. $-{ }^{5}$ Nicht eindeutig zu lesen. $-{ }^{6}$ Südfranzösische Provinzhauptstädte, reich an römischen Altertümern, später beschrieben in seinem Voyage dans les Départements du midi de la France, Bd. I-V, Paris 1807-1811. - ${ }^{7-7}$ Gemeint wohl De hymnorum Homericorum reliquiis commentatio, Göttingen 1786.
\end{abstract}

2. Aubin Louis Millin an Groddeck, am 30.9.1809

Paris $307^{\text {bre }^{1}} 1809$

Monsieur

Si j'ai tardé si longtems a vous adresser mes remercimens de l'honneur que m'a fait la celebre academie de Vilna ${ }^{2}$ c'est que j'ai toujours attendu l'occasion que Monsieur Znosko $^{3}$ devoit me procurer <.> vous ne pouvez croire que je n'aie pas été tres sensible a cette marque d'estime de la part d'un corps qui renferme des membres aussi distingués et Monsieur Znosko vous dire avec quelle reconnaissance réçu cette distinction a laquelle j'attache un tres grand prix. je me fais gloire d'etre celui qui dans ces derniers tems a le plus contribué a I faire connoitre en france la litterature etrangere et particulierement celle du nord. Si j’ai parlé peu souvent dans le magazin encyclopedique, que je redige depuis douze ans gratuitement et pour le seul avantage des lettres \} 
de l'academie de Vilna/, c'est de deffault de communication qui eu a ete la cause, mais a present que j'ai l'honneur d'appartenir a cette savante academie je ferai tout ce qui sere en moi pour lui prouver mon zele et mon devouement. j'ai inseré dans mon journal quelques morceaux de M. Groddeck parce qu'il a eu la bonté de me les adresser et je serai charmé de pouvoir faire connaitre de meme les ouvrages des autres professeurs de cette université.

Comme dans un pareil eloignement les I communications sont plus difficiles je prends la liberté de vous indiquer dans l'allemagne les personnes auxquels l'academie et l'universite peuvent faire remetre par des voyageurs ce qu'elle auroit a m'adresser. a Koenigsberg M. le comte de Henckel de Donnersmarck ${ }^{4}$, a Weimar M. Bertuch ${ }^{5}$ au comptoir d'industrie; a Dresde M. Boettiger ${ }^{6}$ directeur des pages; a Goettingue MM. Heyne $^{7}$, Blumenbach ${ }^{8}$ etc. a Tubingue M. Cotta ${ }^{9}$, a Nuremberg M. de Murrro ${ }^{10}$ a Vienne le Comte de Metternich, j'indique ces divers points parce que il me semble plus facile d'en recevoir des lettres et des petits paquets que de Vilna et cela vous prouve les desirs que j'ai de Correspondre exactement avec l'academie a laquelle j'ai l'honneur d'appartenir

L'estime des gens de lettres et la plus douce recompense de mon zêle et c'est ce seul zele I qui m'a merite < !> leurs attention et l'avantage d'avoir des relations avec ceux qui honorent le plus les sciences<.> je prie mes illustres confreres de l'academie de Vilna de vouloir bien le mettre à c'epreuve.

je dois compte a mes nouveaux confreres de mes occupations actuelles. je continue le magazin encyclopedique, je publie une tres belle collection des vases peints dites etrusques, inedits<,> cette collection aura 24 livraisons $<$, > la seizième parait a present<.> j'en joins icy le prospectus, le quatrième et dernier volume de mon voyage au midi de la france paraitra cet hyver et au printems je donnerai une collection de 100 piece gravée presque toutes inedites<.> je joins icy quelques unes des gravures. je donne aussi quelques articles pour une nouveau dictionnaire biographique. ${ }^{11}$

agreez monsieur pour vous meme l'assurance de la respectueuse considerations avec laquelle j'ai l'honneur d'être votre tres humble

et tres obeissant serviteur

l’academie de Vilna.

A. L. Millin correspondent de l'univer. et de

\footnotetext{
${ }^{1}$ d. i. septembre. $-{ }^{2}$ Millin war auf Groddecks Vorschlag korrespondierendes Mitglied der Universität Wilna geworden; s. Schluß und Nr. 4. $-{ }^{3}$ s. Heyne Nr. 2 Anm. 1. $-{ }^{4}$ Wilhelm Ludwig Victor Henckel von Donnersmarck (1779-1852), preußischer Offizier im Kabinett des Königs. $-{ }^{5}$ Friedrich Justin Bertuch (1747-1822), Kunst- und Buchhändler in Weimar. ${ }^{6}$ Boettiger: s. Grod.-Morg. Nr. 41 Anm. 17. $-{ }^{7}$ Heyne: s. Grod.-Morg. Nr. 8 Anm. 4. $-{ }^{8}$ Blumenbach : s. Grod.-Morg. Nr. 21 Anm. 7. $-{ }^{9}$ Johann Friedrich Cotta Freiherr v. Cottendorf (1764-1832), Buchhändler in Tübingen. $-{ }^{10}$ Murr: nicht ermittelt. - ${ }^{11}$ Gemeint wohl sein Dictionnaire des beaux arts, Bd. 1-2, Paris 1806.
} 
3. Aubin Louis Millin an Groddeck, am 1. 9.1810

Monsieur

je profite de l'occasion que me presente monsieur Oberlin ${ }^{1}$ pour me rappeller a votre souvenir et a celui de mes respectables confreres de l'academie. j'aurois voulu pouvoir vous ecrire avec details - mais il ne m'en reste pas le tems je vous dirai seulement que je viens de terminer mon grand recueil de vases peints dits Etrusques², en deux volumes in-folio. et que je vais faire paraitre le quatrieme et dernier volume de mon voyage dans le midi de la france ${ }^{3}$. j'aurais desire recevoir quelque communication de l'academie par les voies que j'ai eu l'honneur de vous indiquer dans ma dernière lettre. je voudrois aussi pouvoir lui adresser quelques opuscules mais monsieur Oberlin ne peut s'en charger I je me borne a lui envoyer la description d'un superbe vase qui est aujourd'hui a Londres dans le Cabinet de M. Edward libraire qui l'a paye mille guinee! je vous prie de vouloir bien faire agreer mon respect a l'academie et de vouloir bien aussi recevoir particulièrement l'assurance de celui avec lequel j'ai l'honneur d'être Monsieur

votre tres humble et tres obeissant Serviteur

A, L. Millin

$1^{\text {er }}$ Septembre 1810

${ }^{1}$ Deutsche Familie von Gelehrten und Pfarrern in Straßburg. Gemeint vielleicht Johann Friedrich Oberlin (1740-1826), der dann evangelischer Pfarrer im Elsaß war. Sein Bruder Jeremia Jakob Oberlin (1735-1806), Philologe und Bibliothekar. 1778 ao. und 1782 o. Professor für Logik und Metaphysik ebd., lebte nicht mehr und kommt daher nicht in Frage. $-{ }^{2}$ Vgl. Nr. 1 Anm. 3. $-{ }^{3}$ Vgl. Nr. 1 Anm. 6.

4. Aubin Louis Millin an Groddeck, am 11. 4.1811

Paris ce 11 Avril 1811

Monsieur et cher Confrère

J'ai reçu avec bien de la satisfaction la dernière lettre que Vous m'avez fait l'honneur de m'écrire en réponse à celle qui Vous a été remise de ma part par M. l'adjoint Znosko. je suis bien aise que les petits articles, que j’y ai ajoutés Vous aient fait quelque plaisir. Je conçois que mendant la guerre il ait été impossible de recevoir les journeaux français et que ainsi le Magasin n’a pu Vous parvenir; mais actuellement que les communications sont rouvertes, l'académie de Vilna peut le recevoir; ainsi je ne Vous donnerai point les nouvelles littéraires, que Vous pouvez facilement y lire.

Il est bien fâcheux que Vous ayez été obligé par une suite des mêmes événements à abondonner la continuation de Votre feuille littéraire polonaise; elle ne pouvait pas 
m'être d'une grande utilité, puis que j'ignore entièrement cette langue; mais je sens de quel I avantage elle pouvait être pour Vos compatriotes, et je suis étonné, qils aient $\mathrm{pu}$ la laisser tomber. Je pourrais cependant dire la même chose du Magasin qui ne se soutient presque que pas artifice.

Votre dissertation sur le Thymelé et celle qui la précède sur le Tritagonista n'ont donc pas été mises dans le commerce, car je ne les ai point vues dans la catalogue de Schoell ${ }^{1}$, qui fait venir ici presque toutes les nouvelles dissertations publiées en Allemagne et qui me les fournit; je n'aurais certainement pas manque de me les procurer.

Je reconnais l'utilité dont peuvent être les Séminaires philologiques pour faire revivre l'tude de la Littérature classique; elle a été très bien démontrée par $\mathrm{M}$. Beck² dans sa dissertation sur ce sujet.

Quand à la demande que Vous me faites I au nom de l'univerité de Wilna, qui a eu la boulé de me recevoir parmi ses membres, je voudrais bien pouvoir la remplir, mais j'y vois de grandes difficultés. L'Iconographie grecque de mon illustre confrère M. Visconti ${ }^{3}$ n'a point été mise dans le commerce, ainsi il n'est pas possible de Vous la

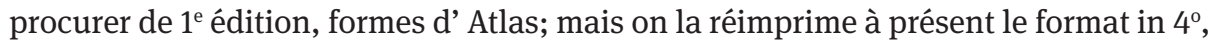
et on pourra se la procurer à peu près dans six mois.

La description de l'Egypte sur papier velin estamper colorées est un ouvrage extrêmement cher; c'est à dire que la $1^{\text {ère }}$ livraison coute a peu près 1900 fr. et que le tout reviendra à plus de $6000 \mathrm{fr}$. Je sais que l'Université est riche et qu'elle peut facilement faire cette acquisition, mais les commissaires qui sont chargés de la vente de ce grand ouvrage au compte du gouvernement ne veulent donner qu'au comptant et l'état actuel de commerce général et particulerement de la librairie peut justifier leur méfiance. J'airais facilement fait I moi-même cette avance pour l'université si j'avais été sûr de l'époque de la rentrée de mes fonds; mais les indications que Vous me donnez ne sont pas assez précises. Vous me dites, que l'université trouvera facilement le moyen de faire parvenir les fonds à M. de Serra, résidant de France à Varsovie. mais voyez combien tout cela entraine de lenteurs. de Serra n'est plus à Varsovie. N'aurait-il pas été plus simple d'indicer ici un banquier, qui aurait pû donner les fonds ou du moins de désigner une maison sur la que on aurait pû tirer soit à Wilna, soit à Varsovie. Enfin il me semble que Vous auriez pû prendre les mêmes arrangemens que ceux que Vous avez avec M. de Choiseuil ${ }^{4}$, qui a fait faire pour l'Uiversité beucoup d'instrumens de physique ce qui aurait pu acquitter la dépense sur les fonds que Vous lui faites passer. J'aurais aussi désiré savoir comment et par quelle voie on peut Vous adresser des paquets. Lorsque Vous aurez bien voulu me donner I ces renseignemens je m'empresserer d'exécuter les ordres de l'Académie. Le libraire qui rend mon ouvrage ne ferait pas tant de difficultés, mais il voudrait avoir le nom du correspondant à qui il doit adresser cet ouvrage à Varsovie.

Le libraire qui a entrepris la collection de mes vases sais bien que Vous ne derez en avoir que quatre <...>césor ${ }^{5}$, le libraire qui les faisait venir pour Vous de Varsovie je crois, ne lui en ayant point demandé d'avantage. J'ai employé cet hiver à finir les travaux que j'avais commencés; je viens de donner le dernier volume de mon Voyage 
et j'ai terminé entièrement mon ouvrage sur les vases paints; j’ai donné outre cela un recueil intitulé: Galérie Mythologique ${ }^{6}$, qui contient un grand nombre de monumens, environ 800, avec de courtes explications et un discours général, qui renvoie continuellement aux monumens qui lui servent d'autorité. Actuellement que je vais avoir plus de liberté je voudrais en profiter pour une I excursion en Italie ; mais il n'est guère possible que ce soit autrement que dans le courant de Juillet. au surplus Vous pouvez toujours m'écrire, parcequ'on fera passer mes lettres franches en Italie.

Je Vous prie de vouloir bien renouveller à l'Université l'hommage de mon respectueux dévouement et de recevoir pour Vous même l'assurance de la parfaite estime et du sincère attachement avec lesquels j'ai l'honneur d'être

Votre très humble et

très obéissant Serviteur

A. L. Millin

\begin{abstract}
${ }^{1}$ Wohl Maximilian Samson Friedrich Schoell (1766-1833). War 1814 auf Empfehlung Hardenbergs im Kabinett des Königs von Preußen angestellt. Nahm am Wiener Kongreß teil. War dann bis 1818 preußischer Gesandter in Paris. 1819 Vortragender Rat bei Hardenberg in Berlin. Von ihm zahlreiche Arbeiten zur griech. und lat. Literatur. Zu ihm Pihan de la Forest, Essai sur la vie et les Ouvrages de Schoell, Paris 1834. - ${ }^{2}$ Beck, s. Groddeck-Morgenstern Nr. 51 Anm. 1. $-{ }^{3}$ Ennius Quirinus Visconti (1751-1818), Archäologe. Für Millin von Interesse seine Description des vases peints du Musée, 1802. $-{ }^{4}$ Marie Gabriel Auguste Laurent, Graf von Choiseul-Gouffier (1752-1817). Diplomat und Altertumsforscher. Seit 1793 emigriert in Rußland, dort Direktor der Kunstakademie und Bibliothekar. Nach 1801 wieder in Paris. $-{ }^{5}$ Anfang des Wortes nicht lesbar. $-{ }^{6}$ Bd. I-II, Paris 1811.
\end{abstract}

5. Aubin Louis Millin an Groddeck, undatiert; 1812 oder 1813

\title{
Monsieur et cher Confrere
}

je n'ai point eu l'honneur de vous ecrire depuis longtems et je profite aujourd'hui du depart de Monsieur Znosko pour vous dire combien je suis satisfait d'etre devenu votre confrere par l'honneur que l'academie de Vilna m'a fait de m'admetre au nombre de ses correspondans $<$.> j'ai insere dans le magazin encyclopedique les divers morceaux que vous avez bien voulu m'adresser le dernier etoit une critique de la pretendue Clytemnestre publiée par M. Matthäi ${ }^{1}$. j'ignore a present quelles sont vos occupations. la guerre qui a porté un coup fatal a la librairie doit vous avoir empeché de rien publier. je serai bien aise d'avoir de nouvelles de votre santé<.> I la ettre que j'adresse a l'academie et qui y sera probablement me dispense de vous parler de mes travaux puis qu'ils y sont detaillés<.>

je joins a cette faite le magazin d'une critique, que j'ai faite dans le magazin d'une epouvantable traduction du bel ouvrage de M. Sprengel ${ }^{2}$ intitulé Histoire de la medecine vous approuverez surement le zêle avec lequel je me suis montré le deffenseur de la littérature germanique. 
agreez l'assurance de la haute consideration et du sincere attachement avec lesquels j'ai l'honneur d'etre Monsieur et illustre confrere

votre tres humble

et obeissant Serviteur

A. L. Millin

\begin{abstract}
${ }^{1}$ Matthäi : s. Buhle Nr. 16 Anm. 28. $-{ }^{2}$ Kurt Sprengel (1766-1833) aus Anklam. Professor der Medizin in Halle. Gemeint wohl sein Versuch einer pragmatischen Geschichte der Arzneikunde, Bd. 1-5, Halle 1792-1803. Vielleicht auch die Institutiones medicae, Bd. 1-6, Halle 1809-1816.
\end{abstract}

\title{
6. Aubin Louis Millin an Groddeck, am 16. 8. $1814^{1}$
}

Paris 16 Août 1814

Monsier et digne Confrère,

Après une longue interruption dans notre correspondance J'ai été bien agréablement surpris de voir arriver une lettre de Vous. C'est un véritable service que m’a rendu M. Dessaix $^{2}$ qui a heureux rencontrer des hommes c omme Vous, dans la situation où il l'est trové, ce qui rend ici les témoignages les plus honorables de Vous et de Monsieurs Vos confrères. Il ajoute encore à la bonté qu'il a eue pour moi, en me procurant la facilité de Vous répondre. Vous me demandez à quelle époque je suis revenu d'Italie. J'ai revu Paris le 18 de Nov. dernier, lorsque nous étions au plus fort de l'orage. J'ai rapporté en effet un nombre considérable de dessins relatifs à l'histore de l'art et à l'antiquité; et J'ai des matériaux considérables pour la redaction complette de mon voyage sous ces deux rapports. Tout cela demande pour paraître un temps assez long et des circonstances plus heureuses, non pas sous le rapport politique, mais sous celui des finances. Il m'a fallu beaucoup de temps pour remettre en ordre mes manuscrits et mes livres, après d'événement dont Vous avez la bonté de parler avec entérêt. J'ai publié quelques dissertations accompagnees de gravures, et j'en prépare de bien plus considérables. Je compte faire paraître ces divers ouvrages successivement quant à la relation génélrale, plus j’y travaille, et plus je vois combien il me faut encore de temps pour la terminer. Il a paru dans le Magazin Encyclop. au commencement de cette année 1814, un précis de mes recherches et de mon itinéraire.

J'ai reçu avec bien de la reconnaissance votre ouvrage élémentaire sur l'histoire littéraire des grecs. ${ }^{3}$ Quoique cette matière ait été souvent traitée la précision, la clarté et la méthode qu'on remarque dans Votre livre doivent encore le faire rechercher. J'aurai grand plaisir d'en donner une notice dans le mag. Encycl. et je trouverai une occasion agréable de rappeler l'estime que j’ai pour son auteur.

C'est une peine pour moi, de ne pouvoir Vous adresser comme ce serait mon intention, le précis de mon voyage, et différentes dissertations dont j'ai eu l'honneur de Vous parler; mais la personne qui veut bien se charger de cette lettre, ne peut 
prendre un paquet d'un volume un peu considérable. Il me faut attendre un autre occasion, à moins que Vous n'ayez ici quelques correspondans que Vous voudrez bien m’indiquer.

Agréez l'assurance des sentimens de la haute considération avec laquelle j'ai l'honneur d'être

Monsieur et digne confrère

$$
\begin{aligned}
& \text { Votre tres humble } \\
& \text { et obéissant }
\end{aligned}
$$

Serviteur

${ }^{4} \mathrm{~A}$. L. Millin

Je me sers d'une main étrangère parceque Ses caracteres sont plus lisibles. pourriez vous adresser cette lettre a M. Morgenstern

\footnotetext{
${ }^{1}$ Von anderer Hand, nach Diktat. Der Brief ist am rechten Rand beschnitten, so daß einige Zeilenenden ergänzt werden müssen; das wird nicht gekennzeichnet. $-{ }^{2}$ Oder: Dessaise? $-{ }^{3} \mathrm{Gemeint}$ die Historiae Graecorum litterariae elementa in usum lectionum, Wilna 1811. $-{ }^{4}$ Unterschrift und das Folgende von eigener Hand.
}

\section{Aubin Louis Millin an Groddeck, am 5. 5.1816}

Paris le 5 Mai 1816

Monsieur et digne confrere

j'ai recu probablement par M. chevalier de Horn² et il y a huit jours seulement votre lettre du 9 Septembre 1815 et la reimpression du discours de facciolati ${ }^{3}$ y etait jointe, cette reimpression rejouira beaucoup les Padouans qui ont toujours la memoire de facciolati en grand honneur. Je vois avec grand plaisir que vous preparez toujours d'utiles fondemens pour l'etude de la langue grecque; et l'in struction des jeunes gens.

Les affaires ont mises de grandes entraves a la publication des riches materiaux que j'avais apportés de l'italie, j'ai beau depenser tout ce que je puis, je ne puis pas depenser assez pour une semblable entreprise. je n'ai pu donner que de tres petites dissertations et mes ouvrages importans ne peuvent voir le jour. je joins a cette lettre un prospectus dans lequel j'annonce la belle edition des vases de Canosa ${ }^{4}$ que je me propose de donner j'espere qu'on en fera prendre un exemplaire pour la Bibiotheque de Vilna $<$.> Ces vases sont ce qu'on a vu de plus beau en ce genre.

J'ai donné a l'in $<. . .>^{5}$ la relation de mesl voyages et j'espere que la premiere partie paroitra dans l'automne prochain.

Si je savois quel est le libraire qui est charge d'expedier des livres francois pour Wilna je remetrois chez lui pour vous un exemplaire de la seconde edition de la mineralogie homerique. mais je suis obligé d'ecrire a l'avance, et de profiter d'une occasion et ${ }^{6}$ encore grossir le paquet ce sera pour une autre occasion.

Je n'entend point parler de la suite du voyage de M. Morgenstern. ${ }^{7}$ 
Agreez l'assurance de la haute considerat<ion> avec laquelle j'ai l'honneur d'etre Monsieur et cher Confrere

Votre tres humble et

obeissant Serviteur

A. L. Millin ${ }^{1}$ Darüber von der Hand Groddecks: Reçue le 18, d'Octobre 1816 v<ieux $>$ st<yle $>p<a r>l e>C<0 m>t e$
Einsiedel allant à Petersbourg. $-{ }^{2}$ Vielleicht Franz Horn $(1781-1856)$, Pädagoge. $-{ }^{3}$ Wohl Jacobus
Facciolati $(1682-1769)$ aus Padua. $-{ }^{4}$ Canossa war berühmt für seine Sammlung antiker Vasen. $-{ }^{5}$
Nicht lesbar. $-{ }^{6} \mathrm{Im}$ Text, schwer lesbar: et je. $-{ }^{7}$ Morgensterns Beschreibung seiner italienischen
Reise. 